\title{
Effects of ACE-Inhibitors and Angiotensin Receptor Blockers on Inflammation
}

\author{
D. Di Raimondo*, A. Tuttolomondo*, C. Buttà, S. Miceli, G. Licata* and A. Pinto
}

\author{
U.O.C. di Medicina Vascolare - * U.O.C. di Medicina Interna e Cardioangiologia, Dipartimento Biomedico di Medicina Interna e \\ Specialistica, Università degli Studi di Palermo
}

\begin{abstract}
The role of inflammation in cardiovascular disease and in hypertensive disease above all, is complex. Several studies confirm that activation of renin-angiotensin-aldosteron system (RAAS), through increase in the production of angiotensin II (Ang II), is closely related to local vascular inflammation. Over the BP lowering effects of anti-hypertensive treatments, several ancillary effects for every class may be found, distinguishing the various drugs from one another. Given the pro-inflammatory effects of Ang II and aldosterone, agents that interfere with the components of RAAS, such as ACE inhibitors, Angiotensin Recpetor Blockers (ARBs), and mineralocorticoid receptor antagonists (spironolactone or the more selective eplerenone), represent logical therapeutic tools to reduce vascular inflammation and cardiovascular risk, as suggested in large clinical trials in patients with hypertension and diabetes. Regarding ACE inhibitors, actually there is no convincing evidence indicating that ACEi's reduce plasma levels of major inflammatory markers in hypertension models. Lack of evidence concerns especially these inflammation markers, such as fibrinogen of CRP, which are less closely related to atherosclerotic disease and vascular damage and conversely are affected by several more aspecific factors. Results obtained by trials accomplished using ARBs seem to be more univocal to confirm, although to great extent, these is an anti-inflmmatory effect of drugs bocking AT1 receptor. In order to strictly study the effects of blockage of RAAS on inflammation, future studies may explore different strategies by, for example, simultaneously acting on the ACE and the AT1 angiotensin receptors.
\end{abstract}

Keywords: Renin-angiotensin-aldosteron system (RAAS), ACE inhibitors, angiotensin recpetor blockers, inflammation.

\section{INTRODUCTION}

Atherosclerosis and inflammation are extremely linked to one another [1]. In the last decades, increasing evidence has been accumulated about the relationship between inflammation and the development of essential hypertension.

Chronic Systemic Low-level Inflammation, defined as modest (2-4-fold) elevations in circulating levels of pro-inflammatory and anti-inflammatory cytokines, naturally occurring cytokine antagonists, and acute-phase proteins, as well as minor increases in the counts of neutrophils and natural killer cells [2], represents an emerging condition, that accompanies aging such as several pathologic conditions and atherosclerosis itself [3].

The pathogenesis of essential hypertension has been extensively studied; we know that hypertension is a multi-factorial disease resulting from the effect of the combination of both environmental and genetic factors. It has been demonstrated that several factors may contribute to the development of hypertension including excess dietary salt and/or alcohol intake, cigarette smoking, stress, aging, genetics factors and family history, obesity/insulin resistance, physical inactivity, as well as high saturated fat diet.

In the recent years, the suggestion that hypertension-associated vascular disease could be partly due to an inflammatory process, and that the chronic systemic low-grade inflammation may play a role in the pathophysiology of elevated blood pressure found even more supporting data [4].

Taking into account that essential hypertension is a relevant challenge for the public health because of its high prevalence, which is estimated to increase to $29 \%$ by the year 2025 [5], deeper knowledge of the cause leading to vascular damage and clinical appearance may conduce to significant improvement of the prevention of organ damage and vascular event related to hypertension, leading to death and disability throughout the world [5].

\footnotetext{
*Address correspondence to this author at the U.O.C. Medicina Vascolare, Dipartimento Biomedico di Medicina Interna e Specialistica, Università degli Studi di Palermo, Piazza delle Cliniche n 2, 90127 Palermo; Tel: 00390916552102; Fax: 00390916552285;

E-mail: domenico.diraimondo@unipa.it
}

The analysis of the role of inflammation in the pathogenesis of cardiovascular damage and especially in hypertensive disease, is really complex. The inflammatory process, infact, consists of a complex set of interactions between inflammatory cells, which leads to increased expression of adhesion molecules, cytokines, chemokines, matrix metalloproteinases and growth factors. All these elements variously interact with the vascular wall components, and mainly with endothelial cells, that are widespread recognized as an intricate laboratory in which vascular motion, local platelet aggregation, coagulation, and inflammation are determined.

Among the well-known pathophysiological elements leading to essential hypertension, renin-angiotensin-aldosteron system (RAAS) certainly has a main role. Latest studies confirm that activation of RAAS, through increase in the production of angiotensin II (Ang II), is closely related to local vascular inflammation [6]. Furthermore, aldosterone (ALD) and/or mineralocorticoid receptor (MR) activation cause oxidative stress and vascular inflammation [7]. Embracing these theories appear clear how RAAS is a proinflammatory system. Obviously, not all the supposed pathophysiological burden due to inflammation in leading essential hypertension could be ascribed to RAAS; several molecular mechanisms, such as oxidative stress with production of reactive oxygen species (ROS), and activation of inflammatory transcription factors, e. g. the nuclear transcription factor Nuclear Factor $\kappa \mathrm{B}(\mathrm{NF} \kappa \mathrm{B})$ also play a crucial role [2].

If it is true that RAAS is a pro-inflammatory system, then the drugs that antagonize RAAS may be retained as anti-inflammatory drugs, as consequent of reducing vascular inflammation.

We know that in the treatment of patients with hypertension, as stated by the latest guidelines [8], all the available classes of antihypertensive drugs may be used, with the main objective to reduce possible blood pressure (BP) levels as soon as trying to lower at the same time added cardiovascular risk. But over the BP lowering effects of anti-hypertensive treatments, several ancillary effects for every class may be found, distinguishing the various drugs from one another.

Given this, establishing the anti-inflammatory effects of ACEinhibitors (ACE-i) and Angiotensin Recpetor Blockers (ARBs) may be essential for future therapeutical choice. Furthermore, among 
medications of the same therapeutic class, generally having a similar mechanism of action, may be some differences. So, not necessarily, all the ACE-i and all the ARBs may be identified with similar ancillary and anti-inflammatory properties.

Aim of the present review is, first of all, to overview the state of the art of inflammatory mechanisms proposed to explain the pathogenesis of essential hypertension; second, to analyze the characteristics of the main ACE-i and ARBs and finally to discuss the effects of ACE-i and ARBs on inflammation, the differences among the various drugs of the two classes and the hypothetical implications for future therapeutic approaches.

\section{PART I - IS ESSENTIAL HYPERTENSION AN INFLAM- MATORY DISEASE?}

Several hypotheses have been proposed to explain the main pathogenic mechanisms of essential hypertension [9].

Essential hypertension is commonly believed to be initiated by neural or humoral stimuli, which lead to positive feedback mechanisms, such as changes in pressure-natriuresis in the kidney, initiation of the autoregulatory response, and vasoconstriction, because of vascular hypertrophy. [7,10].

Recently, Johnson et al [9], focusing on the renal mechanisms that underlie the defect in pressure natriuresis in essential hypertension and assuming that the pathogenesis of most forms of hypertension (including primary and secondary) involves an important role of the kidney, proposed a pathway which unites many of the previous hypotheses on the pathophysiology of essential hypertension and consists of 3 phases. A first pathway: glomerular filtration ratedependent (renoprival mechanism), a second pathway: transport mechanisms (stimulation of sodium reabsorption in the collecting duct) and a third pathway: renal ischemia (vasoconstriction, oxidative stress and inflammation). The three pathways and the following theories are widely discussed in [9], summarizing the first phase is initiated by episodes of renal vasoconstriction, induced in most cases by hyperactivation of the sympathetic nervous system and activation of the RAS. Whereas, during the second and the third phases, tubulointerstitial inflammation, which is associated with interstitial $\mathrm{T}$ cell and macrophage recruitment, local Ang II formation and generation of ROS, contributes to preglomerular vascular disease and intrarenal vasoconstriction. These processes contribute to a change in local vasoconstrictor-vasodilator balance favoring sodium retention $[11,12]$.

Even though the aetiology of hypertension has been investigated in depth, the pathophysiology is multifactorial and far from being clear. Immunopathogenic mechanisms, in particular $\mathrm{T}$ cells, have been demonstrated to play an important role in the genesis of hypertension. Experimental models with Ang II-infused mice lacking T- and B cells showed that they had blunted hypertension and did not develop vascular dysfunction [13] $\mathrm{T}$ cells function seems to be regulated by an endogenous RAS, which affects nicotinamide adenine dinucleotide phosphate oxidase (NADPH) activity and production of inflammatory cytokines, such as tumor necrosis factor-alpha (TNF- $\alpha$ ). [14] Additionally, recent reports show increased monocyte adhesion to endothelial cells from spontaneously hypertensive rats and elevated levels of activated circulating monocytes in hypertensive patients. $[15,16]$.

Interest has also been directed toward oxidative stress and reduced bioavailability of nitric oxide (NO), as a result of systemic and localized inflammatory responses, which lead to vasoconstriction and impaired vascular function. The overall association of inflammation and blood pressure has been indicated in many crosssectional studies with never-treated essential hypertensives, who exhibited greater plasma levels of C-reactive protein (CRP). [16,17] However, research during the last decade has shed light on the aspect of the possible causal relationship between CRP and essential hypertension, because of its close relationship with markers of arterial stiffness. [18].

At least four novel mechanisms seem to be closely related to vascular inflammation in hypertension: 1) ROS production and redox-sensitive inflammatory response; 2) NFkB activation; 3) Proinflammatory activities of endothelin-1 (ET-1); 4) Pro-inflammatory activities of RAAS.

In the following part of this review we will be briefly analyze the first three; the action of Ang II, aldosterone and of the other components of RAAS on inflammation and on vascular damage will be deeply analyzed later.

\section{1) Reactive Oxygen Species (ROS) Production, Redox-sensitive Inflammatory Response and Vascular Inflammation}

Increased production of reactive oxygen species (ROS), such as superoxide anion $(\bullet \mathrm{O} 2-)$, hydrogen peroxide $(\mathrm{H} 2 \mathrm{O} 2)$, hydroxyl radical $(\mathrm{OH} \bullet), \mathrm{NO}$, and peroxynitrite (ONOO-) leading to cellular oxidative stress is linked to numerous pathologies including cancer, diabetes, and neurological diseases $[19,20]$.

The common term "oxidative stress", that was first defined as "a disturbance in the pro-oxidant-antioxidant balance in favour of the former" [21]. Although this definition has been widely accepted for over 25 years, this description of oxidative stress is under scrutiny and modifications to this meaning have been proposed by several authors. For example, because of the complexity of cellular redox balance, it has been argued that the term "oxidative stress" defines a simple pro-oxidant versus antioxidant definition and that the description of an "oxidant stress" is helpful only if the molecular details of the redox imbalance are known. For these reasons, definitions of oxidative stress and oxidative imbalance are actually ongoing and commonly describe conditions involving increased ROS levels.

Referring to vascular pathophysiology, (see Fig. 1) in the vascular wall a major source of vascular ROS is NADPH, which is produced in endothelial cells, vascular smooth muscle cells (VSMCs), fibroblasts, adventitial cells, and monocytes/macrophages. Several researches on experimental models of hypertension in which antioxidant treatment reduced blood pressure and Ang IIinduced end-organ damage, have shown an established relationship between oxidative stress and blood pressure [22]. Nevertheless, the distinct properties between $\bullet \mathrm{O}_{2}$ - and $\mathrm{H} 2 \mathrm{O} 2$ and their different sites of distribution mean that different species of ROS can activate different signaling pathways, which lead to divergent, and potentially opposing, functional responses. For example, increased .O2- levels inactivate the vasodilator NO leading to endothelial dysfunction and vasoconstriction, characteristic of many vascular diseases, including hypertension. It is widely accepted that production of $\mathrm{NO}$ by the endothelium maintains the vasculature in a state of vasodilation, whereas lack of the endothelial NO synthase gene entails mild hypertension [23].

Furthermore, Ang II has been reported to increase $\mathrm{O} 2$ production in endothelial cells, VSMCs and adventitial fibroblasts through activation of NADH/NADPH oxidase. Such production impairs the balance between relaxing and contracting factors released from the endothelium and results in increased tone of the smooth muscle [24].

In addition to the activation of NADPH oxidase by various stimuli, polymorphisms in this enzyme's subunits are associated with increased atherosclerosis and hypertension. In particular, recent studies have demonstrated that hypertensive patients carrying the $-930(\mathrm{~A} / \mathrm{G})$ polymorphism are more susceptible to oxidative stress [25].

The C242T CYBA polymorphism, and in the Japanese population, the G(-930)A polymorphism of CYBA, may be novel genetic markers associated with the pathogenesis of hypertension [26]. 


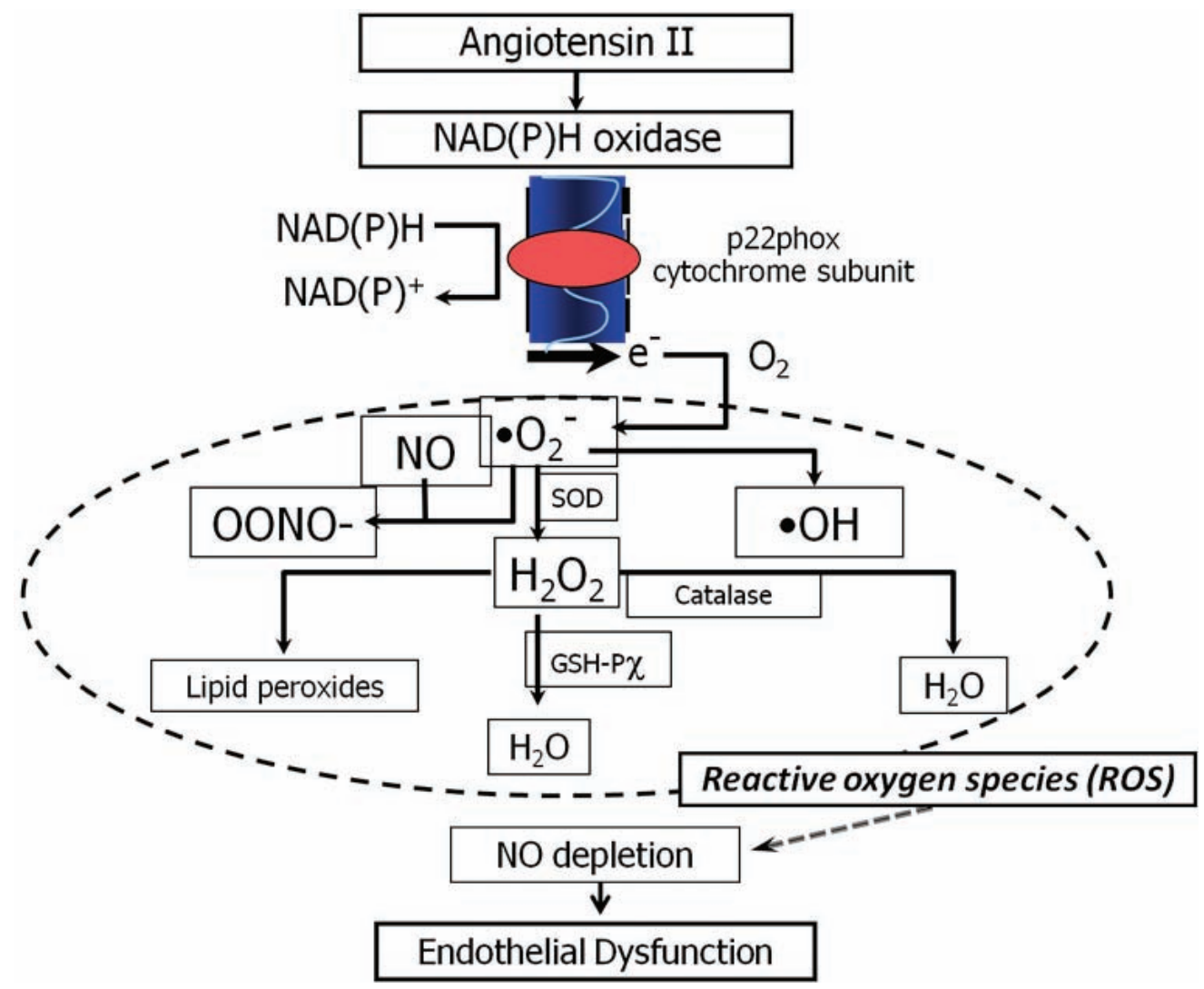

Fig. (1). Reactive oxygen species (ROS) production and vascular inflammation.

ROS potentially influence every stage of inflammation including vascular permeability, leukocyte recruitment, cell growth and fibrosis, modulating vascular tone, and remodelling [27,28]. Physiologically, NAD(P)H oxidase-derived ROS have been implicated in the regulation of vascular tone by modulating vasodilation directly ( $\mathrm{H} 2 \mathrm{O} 2$ may have vasodilator actions) or indirectly by decreasing $\mathrm{NO}$ bioavailability through quenching by .O2- to form ONOO- Because of decreased NO bioavailability, increased $\mathrm{O} 2$ production in the endothelium results in the stimulation of inflammatory process, endothelial dysfunction, and altered vasodilation $[27,28,29]$. These processes are mediated via multiple intracellular proteins, enzymes, and transcription factors, such as NF- $\kappa \mathrm{B}$, activator protein-1 (AP-1) and hypoxia-inducible factor 1 (HIF-1), which can be activated by ROS.

ROS, through the regulation of HIF-1, are also important in $\mathrm{O} 2$ sensing [30], which is essential for maintaining normal $\mathrm{O} 2$ homeostasis. In pathological conditions, ROS are involved in inflammation, endothelial dysfunction, cell proliferation, migration and activation, extracellular matrix deposition, fibrosis, angiogenesis, and cardiovascular remodeling, important processes contributing to cardiovascular and renal remodeling in hypertension, atherosclerosis, diabetes, cardiac failure, and myocardial ischemia/reperfusion injury [31].

The relationship between oxidative stress and increased blood pressure has been demonstrated in many models of experimental hypertension. Animal models show an increased ROS formation preceding development of hypertension. The produced ROS contribute to the activation of signalling molecules, such as mitogenactivated protein kinase, protein tyrosine phosphatases, protein tyrosine kinases, and transcription factors, whereas levels of antioxidant enzymes are reduced in experimental hypertension. These cascades participate in VSMC growth and migration, expression of pro-inflammatory mediators, and modification of extracellular matrix [32].

Ang II is a major mediator of oxidative stress and consequently, of reduced NO (nitric oxide) bioavailability. More specifically, Ang II signalling, via Ang II type 1 (AT1) receptors, is upregulated in VSMC of hypertensive patients, leading to the activation of vascular NADPH oxidase. In VSMC, furthermore, Ang II regulates the expression of redox-sensitive inflammatory genes, such as those encoding monocyte chemoattractant protein-1 (MCP-1) and interleukin-6 (IL-6), inducing an hypertensive response in several experimental models [33].

\section{2) Nuclear Factor $\kappa B$ (NFкB) Activation and Vascular Inflam- mation}

The transcriptional response in innate and adaptive immunity is dependent on the activation of various transcription factors.

A crucial transcription factor is NF- $\kappa \mathrm{B}$, which controls the transcription of many genes with an established role in atherosclerosis, such as cytokines, chemokines, adhesion molecules, acute phase proteins, regulators of apoptosis, and cell proliferation. NF- $\mathrm{KB}$ was discovered in 1986 in the laboratory of David Baltimore [34] and has from that time been the subject of extensive research. NF- $\mathrm{BB}$ is the general name for a family of transcription factors consisting of 5 members: p65 (RelA), c-Rel, RelB, NF- $\mathrm{kB} 1$ (p50 and its precursor p105), and NF-kB 2 (p52 and its precursor p100), all the members of the family share a significant structural homology.

$\mathrm{NF}-\kappa \mathrm{B}$ is involved in all the phases of the atherosclerotic process, from initiation to foam cell formation, cell death and formation of the necrotic core, and finally proliferation of smooth muscle cells and fibrous cap formation [35]. NF- $\kappa \mathrm{B}$ may not only contribute to the different stages in atherosclerosis development it is also likely that its contribution will be cell type- dependent, leading to differ- 
ential regulation of different genes (e.g. in endothelial cells versus macrophages) [35].

$\mathrm{NF}-\kappa \mathrm{B}$ is particularly important in vascular inflammation, as it regulates the transcription levels of several proinflammatory genes.

Ruiz-Ortega et al [36] demonstrated that Ang II activates NF$\kappa \mathrm{B}$ via AT1 and AT2 in VSMCs, although NF- $\mathrm{BB}$-mediated transcription occurs mainly through AT1 [36]. In turn, NF- $\kappa B$ stimulates angiotensinogen and Ang II gene expression, thereby participating in the inflammatory responses related with Ang II. The importance of NF- $\mathrm{KB}$ in inflammation has been suggested by experimental models of atherosclerosis and hypertension, demonstrating that NF- $\kappa \mathrm{B}$ inhibition reduces Ang II-induced expression of IL-6, vascular cell adhesion molecule-1 (VCAM-1) and ameliorated vascular injury [37].

In VSMC from AT1a receptor knockout mice, Ang IV, an angiotensin related peptide, also activated NF- $\kappa$ B pathway via AT4 receptors and increased the expression of proinflammatory factors under NF- $\mathrm{BB}$ control, such as MCP-1, IL-6, TNF- $\alpha$, intercellular adhesion molecule-1 (ICAM-1), and tissue plasminogen activator inhibitor-1 (PAI-1) [38]. Moreover, NF- $\kappa \mathrm{B}$ also plays a key role in other phases of inflammation cascade, such as Ang II-induced migration and proliferation of VSMCs, both of them under normal physiological conditions and following vascular injury [39]. Nevertheless, NF- $\mathrm{KB}$ drives factors that may protect against atherosclerosis, such as IL-6 and IL-10, but also factors that enhance atherosclerosis, such as IL-1, IL-12, and IFN $\gamma$ [35]. These findings may lead to a more complete portrayal of NF- $\mathrm{KB}$ in inflammation showing a role in the onset as well as the resolution of inflammation. The implications for vascular inflammation in atherosclerosis remain to be elucidated.

\section{3) Pro-inflammatory Activities of Endothelin-1 (ET-1)}

Since the first identification in 1985 by Hickey et al [40] of a vasoconstrictor peptide secreted by endothelial cells, today the endothelin system includes several peptides produced by many organs. ET-1 is the most abundant and important ET produced by vascular cells. It is secreted abluminally by endothelial cells toward underlying smooth muscle, and acts in a paracrine or autocrine manner.

ET-1 acts by stimulating ETA and ETB receptors. Both ETA and ETB receptors are localized on vascular smooth muscle cells where they induce their vasoconstrictor, proliferative and hypertrophic action. ETA receptors are the predominant ET vasoconstrictor receptors in arteries.

Vasoconstrictor ETB receptors are present in the veins and pulmonary vessels [41] in larger numbers than in arteries, although ETA still predominate over ETB receptors in these vessels. ETB receptors are also localized on endothelial cells and act through the production of $\mathrm{NO}$ and prostacyclin to exert a vasodilator effect.

The endothelin system has been demonstrated to have a pathophysiological role in several conditions, including hypertension, atherosclerosis, coronary artery disease, heart failure, subarachnoid hemorrhage, diabetes, primary pulmonary hypertension, pulmonary fibrosis, scleroderma, renal failure, prostate cancer and its metastasis, etc. [42]

Regarding the aim of this review, it should be noted that ET-1 not only induces vasoconstriction (being implicated in pathogenesis of essential hypertension), but that it is also a potent growthpromoting agent, and, finally, should be underlined how several studies indicate ET-1 as an important mediator of chronic vascular inflammation.

Experimental data provide evidence that ET-1 induces vascular inflammation by multiple pathways in young animals, such as an increase in blood vessel wall expression of VCAM-1 and MCP-1, macrophage infiltration and increase in the activation of transcription factors AP-1 and NF- $\mathrm{KB}[43]$.

Ang II-induced inflammation mediated by NF- $\mathrm{B}$ might involve ET-1 because when NF- $\kappa$ B was inhibited, there was a parallel suppression of ET-1. Also ROS are potent stimulators of ET-1 synthesis by endothelial cells and VSMCs $[42,43]$. ET-1 activates NADPH oxidase, as well as other sources of ROS, including xanthine oxidase and mitochondria, to produce increased oxidant stress in VSMCs and blood vessels. ET-1-induced oxidative stress elicits inflammatory responses and contributes to the vascular remodelling and endothelial dysfunction found in hypertensive models that exhibit an ET-mediated component. Moreover, Verma et al [44] indicated an interesting relationship between ET-1, CRP, and IL-6, suggesting that the proatherosclerotic and inflammatory effect of CRP could be mediated by the action of ET-1 and IL-1. Interestingly, Hocher et al [45] reported that ET-1 induces chronic inflammation with increased tissue macrophages and lymphocytes infiltration, as well as expression of inducible NO synthase, the effect of which appears to counteract the vascular effects of ET-1. These data increase our knowledge of the connections between ET-1 pathway and NO metabolism and may have great impact on future therapeutic strategies. ETA receptor antagonism decreases oxidative stress, normalizes hypertrophic remodelling, decreases collagen and fibronectin deposition, and reduces ICAM-1 levels in the vasculature of aldosterone-infused rats [44].

\section{PART II - ROLE OF THE RENIN-ANGIOTENSIN- ALDOSTERONE SYSTEM ON SYSTEMIC AND VASCU- LAR INFLAMMATION}

RAAS plays a main role in the preservation of hemodynamic stability through the regulation of extracellular fluid volume, sodium balance and cardiac and vascular trophic effects. In addition, overactivity of the RAAS is associated with the development of atherosclerosis, hypertension, left ventricular hypertrophy, and cardiovascular events, such as myocardial infarction, stroke, congestive heart failure, and nephrosclerosis.

Angiotensin II (Ang II), the major effector peptide in the RAAS, is recognized for its facilitative role in the mechanisms underlying cardiovascular and renal diseases. Most of the known pressor, proliferative, and profibrotic actions of angiotensin II are mediated through its binding to the angiotensin type 1 (AT1) receptor. After the conversion of angiotensinogen to angiotensin I (Ang I) in the circulation and tissues, Ang I, through the interaction with angiotensin-converting enzyme (ACE) forms angiotensin II, whereas additional angiotensin peptides, such as angiotensin-(1-7), are generated from either angiotensin I by the action of several tissue endopeptidases or the metabolism of angiotensin II by ACE2, a newly recognized ACE homologue [46]; the ACE and the ACE2 systems will be better elucidated in the next part of this review.

Activation of RAAS in hypertensive disease leads to a widespread activation of the inflammatory response mediated by the element of the system, mainly by Ang II. Ang II, infact, plays a key role in the regulation of the vascular inflammatory response by activating the recruitment of inflammatory cells to injured arteries. On the other side, inflammatory cells themselves can produce angiotensin II, resulting in a local positive feedback response, thereby perpetuating the inflammatory cycle (see Fig. 2).

One of the main events characterising the early phase of vascular damage Ang-II mediated in hypertensives is VEGF (Vascular Endothelial Growth Factor) over expression. The VEGF family (VEGF-A, VEGF-B, VEGF-C, and VEGF-D) has a key role in physiological vasculogenesis and has been implicated in pathologic angiogenesis, vascular leakage, and inflammation. Angiotensin II up-regulates VEGF mRNA expression in vascular and renal cells (VSMCs, endothelial cells, cardiac myofibroblasts, mesangial cells), primarily through the AT1 receptor. This involvement of 


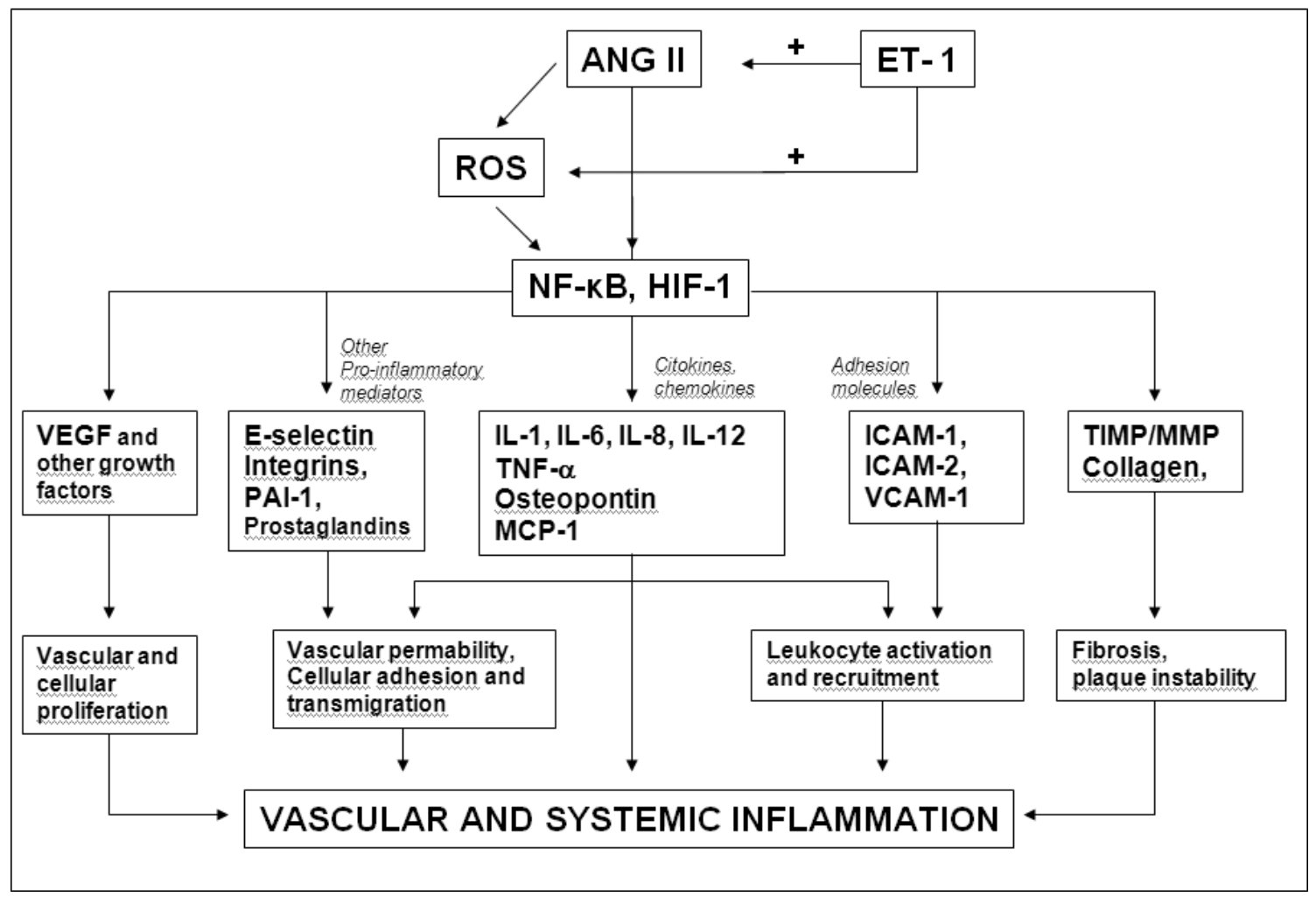

Fig. (2). Angiotensin II-induced vascular and systemic inflammation (see text) - Modified from [4].

Ang II in the early phase of vascular inflammation is mediated independently of hemodynamic changes [47].

Ang II, furthermore, modulates vascular inflammation by regulating the expression of adhesion molecules, chemokines, and cytokines, such as TNF- $\alpha$, IL-6, as well as growth factors and cyclooxygenase- 2 within the arterial wall, that participate at various points in the inflammatory pathway [48]. Ang II also participates in the complex processes of leukocyte margination (rolling and adhesion) and diapedesis (transmigration through the vascular wall), through the upregulation of several mediators such as selectins, integrins, ICAMs, cytokines, and chemokines. Selectins, which are lectin-like molecules, are expressed on leukocytes (L-Selectin), endothelial cells (E-Selectin, P-Selectin) and platelets (P-Selectin) and mediate initial contact between circulating leukocytes and endothelium, manifested as cell rolling [48]. This event promotes the adhesion of lymphocytes and monocytes to the endothelial surface, thus contributing to the initiation and progression of atherosclerotic plaques. Rolling leukocytes encounter activating stimuli which promote leukocyte integrins to bind to adhesion molecules, such as ICAM-1, ICAM-2, and VCAM-1, required for firm adhesion [49]. Recruited cells can produce angiotensin II (intracellular angiotensin system), resulting in a positive feedback response, which can maintain this inflammatory vicious circle.

Ang II also induces vascular injury by increasing the expression of MCP-1, which further facilitates the movement of monocytes and $\mathrm{T}$ cells into the vascular tissue. Ang II infusion in rats upregulates MCP-1 gene expression in renal and vascular cells [50].

Besides its direct effects on the inflammatory pathway, Ang II, through the binding with AT1 receptor, is also capable of promoting inflammation indirectly via the stimulation of several transcription factors, for example, NF- $\mathrm{B}$, that, in turn, regulates production of cytokines in several cell types and expression of adhesion molecule (such as VCAM-1 and ICAM-1). [36-39]. In VSMCs (vascular smooth muscle cells) Ang II stimulates the production of proin- flammatory cytokines and chemokines, such as IL-6, IL-8, osteopontin, and MCP-1, which is an important mediator for the direct migration of monocytes into the intima. [51].

The local effects of Ang II may be mediated in part by the direct pro-inflammatory vascular actions of CRP, because VSMC AT1 receptor expression is increased by CRP [52].

On the other hand, the RAAS can modulate the activation of complement system in both atherosclerosis and renal injury [53].

A recent study developed in cultured rat cerebrovascular smooth muscle cells confirmed that Ang II stimulated gene expression of osteopontin, a soluble cytokine that participates in VSMCs adhesion and migration [54]. Data from experimental studies indicated that Ang II stimulates the expression of TNF- $\alpha$ and IL- 6 in renal cells and in cardiac fibroblasts [55].

In cultured VSMCs, furthermore, Ang II through AT-1 receptor, stimulated hyperplasia and hypertrophy by transactivation of epidermal growth factor receptor, platelet derived growth factor, and insulin-like growth factor receptor [56]. However, Ang II also induced apoptosis of VSMCs mediated by the AT-2 receptor in a mouse model of aortic banding-induced hypertension [57].

Ang II affects also vascular structure, cell growth, and fibrosis which could contribute to vascular remodelling by stimulating hyperplasia, hypertrophy, and apoptosis [6].

Arterial hypertension causes a change in vascular wall structure involving altered extracellular matrix composition. MMPs (matrix metalloproteinases), especially MMP-9, seem to play a key role in vascular remodelling from the early stages of hypertensive damage, influencing also atherosclerotic lesion progression and plaque instability by their observed action against the stability of the plaque and the integrity of fibrous cap: MMPs, infact, can digest the fibrous cap and thereby participate in the triggering of plaque rupture [58]. In Ang II-induced hypertension, there is increased MMP-9 activity in conduit vessels. It has been observed that the absence of 
MMP-9 activity results in vessel stiffness, and MMP-9 activation is associated with a beneficial role early in hypertension [58].

This pro-inflammatory and pro-atherosclerotic effect of Ang II, from the early stage of vascular wall inflammation to the end-stage of atherosclerotic damage with plaque rupture, is further enhanced by the involvement of RAAS in the coagulation cascade. In particular this hormonal axis inhibits fibrinolysis and enhances thrombosis by increasing plasminogen activator-1 production in endothelial and vascular smooth muscle cells and by activating platelets [59], impairing the clot formation/clot degradation local balance. Ang II has been also shown to increase LDL oxidation in macrophages, oxLDL receptor (LOX-1) expression in endothelial cells, superoxide and metalloproteinase production, and lipid peroxidation [59].

De Ciuceis et al [60] recently reported that osteopetrotic mice deficient in mCSF (murine colony-stimulating factor) and accordingly monocytes/macrophages in the vascular wall present less oxidative stress and less induction of inflammatory molecule upregulation in the vasculature by Ang II, and develop less endothelial dysfunction and vascular remodelling, suggesting a central role for macrophages and pro-inflammatory mediators in Ang II induced vascular injury, linking very close Ang II and macrophagic activation. In humans, an analysis of both ruptured and hypercellular plaques demonstrated high levels of ACE in macrophages. Accordingly, little or no ACE was found in areas with only fibrotic plaques [60]. These data suggest that ACE may be associated to atherosclerotic plaque development and vulnerability through the direct regulation of inflammatory cells.

The majority of the direct proinflammatory effects induced by Ang II are mediated by AT1 receptor. These evidences created the plausible belief that AT1 blockers rather than ACEs could exert main anti-inflammatory effects interfering exactly with the key mediator of RAAS pro-inflammatory and pro-atherosclerotic effects. Nevertheless the RAAS is really rather complex and a single intervention may create only a partial inbalance of the system whose consequences are only partly of that expected. AT1 receptor itself exert a wide range of actions and a few of these are only somewhat investigated.

Less is known about AT2 receptors. They are mainly localised in cardiac interstitial fibroblasts and are capable of binding not only Ang II but also other angiotensins, including angiotensin III. AT2 receptors also signal through $\mathrm{NF}-\kappa \mathrm{B}$-mediated pathways but they may counterbalance AT1 receptor-mediated effects through the activation of phosphatases rather than kinases [61]. AT2 receptor pathways increase bradykinin production and NO synthase activity in endothelial cells [61]. AT2 receptor activation also inhibits growth of cultured vascular smooth muscle cells and cardiac myocytes. On the other hand, the selective AT2 receptor blockade has been shown to inhibit in vivo medial smooth muscle hypertrophy and fibrosis in hypertensive rats [61]. These controversial results suggest that also the role of AT2 receptors is still not clear.

We have focused our attention on the effects of Ang II that is certainly the main actor of RAAS-mediated vascular inflammation. Ang II induces aldosterone synthesis through stimulation of AT1 (Ang II type 1) receptors in the adrenal cortex. Aldosterone increases tissue ACE (angiotensin converting enzyme) activity and up-regulates angiotensin receptors [62], which suggests the existence of a vicious cycle that may potentiate the effect of the RAAS.

Several studies have demonstrated that also aldosterone activation induces elevation of oxidative stress and vascular inflammation [63]. Similar role is demonstrated for mineralcorticoid receptor (MR) [63]. Specifically, treatment with aldosterone and salt caused extensive inflammatory arterial lesions with perivascular macrophages in the rat heart and increased the expression of ICAM, cyclooxygenase-2, osteopontin, and MCP-1, effects that were decreased by MR blockade [63].
The activation of mineralocorticoid receptors (MRs) may contribute to cardiovascular dysfunction, inflammation, fibrosis and vascular damage. Several animal models have confirmed that aldosterone and other mineralocorticoids can cause injury of the vasculature of the brain, heart and kidneys by inducing ROS formation and endothelial dysfunction [63]. Mineralocorticoid antagonism attenuates this damage by mechanisms that appear to be independent of changes in BP, involving direct pro-inflammatory and pro-fibrotic effects that may involve activation of the ET system [64,65,66,67]. Mineralocorticoid receptor blockade also improved endothelial function and reduced oxidative stress in Ang II-infused rats [68], suggesting that aldosterone induces actions usually attributed to direct effects of Ang II. Moreover, aldosterone may induce endothelial dysfunction and inflammation through activation of COX-2 (cyclo-oxygenase-2) in normotensive and hypertensive rats [69].

MR antagonism also decreases aortic inflammation, fibrosis, and hypertrophy in hypertensive rats, as well as oxidative stress and inflammation in apolipoprotein E-deficient mice, as indicated by TNF- $\alpha$ and MCP-1 expression [70].

Furthermore, genetic expression studies in cultured VSMCs and cardiomyocytes have confirmed that aldosterone plays a critical role in the inflammatory and profibrotic process [71].

Systemic administration of aldosterone increases oxidative stress in the rat heart, vasculature, and kidney, which activates the redox sensitive NF- $\kappa \mathrm{B}$, triggering inflammation [72].

Regarding the in vivo proinflammatory effects of aldosterone, studies have focused on the measurement of circulating inflammatory biomarkers such as TNF- $\alpha$, MCP-1, and CRP [73].

Twelve-hour infusion of aldosterone increased IL-6 and IL-12 concentrations in normal volunteers. Serum levels of IL-6 were measured in response to mineralocorticoid stimulation, but the available data should be interpreted with caution. Although IL-6 levels increased, they were below the manufacturer's recommended level of detection. In addition, the amount of IL- 6 measured in serum in response to the mineralocorticoid $(1.8 \mathrm{pg} / \mathrm{mL})$ probably was not biologically significant, as at least $10 \mathrm{pg} / \mathrm{mL}$ are necessary in most standard bioassay systems. Thus, such data should be considered more as suggestive of the causal relationship between inflammation and hypertension rather than definitive [74].

Moreover, spironolactone decreased MCP-1 concentration and oxidative stress, as measured by urinary F2-isoprostanes, in hypertensive subjects taking hydrochlorothiazide [75].

Although MR antagonists prevent the inflammatory effects of aldosterone in most rodent models, studies in cultured VSMCs suggest the possibility of an MR-independent proinflammatory effect of aldosterone. For example, treatment with spironolactone does not block specific molecular pathways that result in the production cytokines and chemokines. Obviously, these studies imply therapeutic consequences creating new target for drugs and making theoretically possible new associations among different classes of drugs acting against different targets into RAAS.

\section{PART III - CHARACTERISTICS OF RENIN ANGIOTENSIN ALDOSTERONE SYSTEM AND RAAS-SUPPRESSING DRUGS}

\section{RAAS Overview}

History of RAAS begun in 1898, when Tigerstedt and Bergman published an account of their research demonstrating the existence of a heat-labile substance in crude extracts of rabbit renal cortex that caused a sustained increase in arterial pressure [76]. They proposed the term "renin" for a presumed humoral pressor agent secreted by the kidney, a concept that was widely disputed or ignored until the classical studies of Goldblatt and colleagues, published in 1934, that showed that renal ischemia induced by clamping of the renal artery could induce hypertension [77]. Shortly thereafter it 
was shown that the ischemic kidney also released a heat-stable, short-lived pressor substance, in addition to renin. This finding eventually led to the recognition that renin's pressor activity was indirect and resulted from its proteolytic action on a plasma substrate (eventually termed "angiotensinogen") to liberate a directacting pressor peptide. This peptide was initially termed "angiotonin" or "hypertensin" by competing investigators in the United States (Page and colleagues) and in Argentina (Braun-Menendez and colleagues), who ultimately compromised on the term "angiotensin" [77].

Later, in the 1950s two different peptides of angiotensin were discovered and a plasma enzyme, termed "angiotensin-converting enzyme," able to generate the active pressor peptide Ang II, was identifitied. Soon after, the work of several scientists led to the acquisition of Ang II activity on adrenal cortex, stimulating the release of a hormone, called aldosterone, having main biological role as a regulator of sodium and potassium balance.

Decades of researches led to the knowledge of RAAS we have today (see Fig. 3), and nevertheless the identification of several components of the system, the role of many of these especially in specific areas such as inflammation are still unclear.

Renin is synthesised as a pre-hormone and stored in granules in the juxtaglomerular cells (JG), close to the afferent (and occasionally efferent) arteriole of the renal glomerulus. Release of renin from JG cells into blood flow is dependent on least at four different stimuli: (1) a renal baroreceptor mechanism in the afferent arteriole that senses changes in renal perfusion pressure, (2) changes in delivery of $\mathrm{NaCl}$ (sensed as changes in $\mathrm{Cl}$ - concentration) to the macula densa cells of the distal tubule (which lie close to the JG cells and, together, form the "JG apparatus"), (3) sympathetic nerve stimulation via beta-1 adrenergic receptors, and (4) negative feedback by a direct action of Ang II on the JG cells [78].

So, main factors conditioning renin secretion are the JG stimulation by a fall in perfusion pressure or in $\mathrm{NaCl}$ delivery and by an increase in sympathetic activity.
Renin is also synthesized in other tissues, including brain, adrenal gland, ovary, and visceral adipose tissue, and perhaps heart and vascular tissue. The factors regulating synthesis and possible actions of renin in these other tissues are poorly understood. Control of renin secretion is a key determinant of the activity of the RAAS.

Renin regulates the initial step of the RAAS by cleaving the $\mathrm{N}$ terminal portion of a large molecular weight globulin, angiotensinogen, to form the biologically inert decapeptide Ang I or Ang-(110), The primary source of systemic circulating angiotensinogen is the liver, but angiotensinogen mRNA expression has also been detected in many other tissues, including kidney, brain, heart, vascular, adrenal gland, ovary, placenta, and adipose tissue [79].

Angiotensinogen is secreted constitutively by the liver, so plasma levels are generally stable and do not change acutely; however, both hepatic and extrahepatic synthesis have been shown to rise in response to glucocorticoids, estrogens and other sex steroids, thyroid hormone, inflammatory cytokines (e.g., interleukin-1 and tumour necrosis factor), and Ang II [79].

The inactive decapeptide Ang I is hydrolysed by angiotensinconverting enzyme (ACE), which removes the C-terminal dipeptide to form the octapeptide Ang II [Ang-(1-8)], a biologically active, potent vasoconstrictor. ACE is a membrane-bound exopeptidase and is localised on the plasma membranes of various cell types, including vascular endothelial cells, microvillar brush border epithelial cells (e.g., renal proximal tubule cells), and neuroepithelial cells. It is this membrane-bound ACE that is thought to be physiologically important. ACE also exists in a soluble form in plasma, but this form may simply reflect turnover and clearance of membrane-bound ACE. ACE (also known as kininase II) metabolizes a number of other peptides, including the vasodilator peptides bradykinin and kallidin, to inactive metabolites [80]. Thus, functionally, the enzymatic actions of ACE potentially result in increased vasoconstriction and decreased vasodilation.

Although Ang II is the primary active product of the RAAS, there is evidence that other metabolites of Ang I and II may have

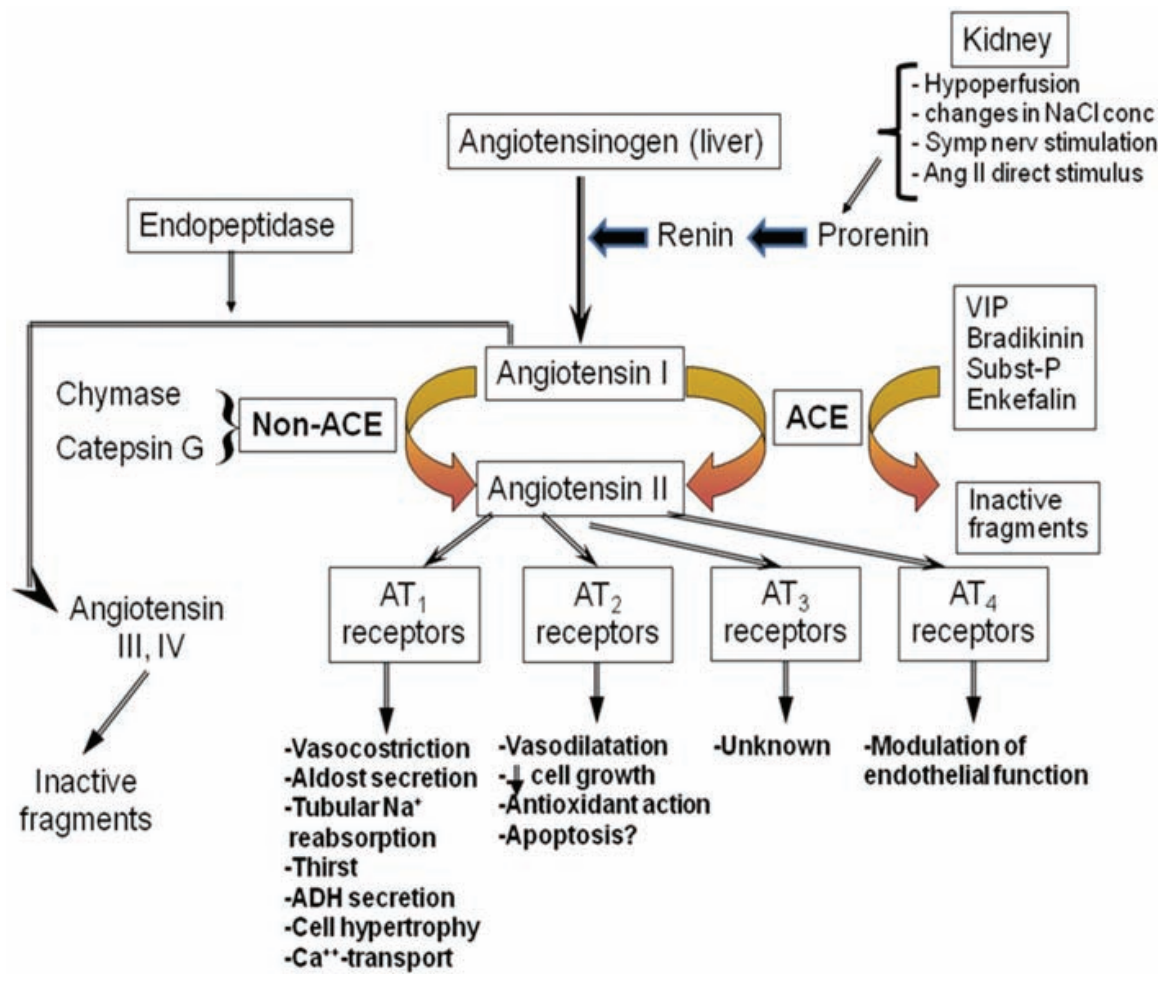

Fig. (3). Scheme of Renin-Angiotensin-Aldosterone System (RAAS). 
significant biological activity, particularly in tissues. Ang III and IV are formed by the sequential removal of amino acids from the $\mathrm{N}$ terminus of Ang II by the action of aminopeptidases.

Ang III [Ang-(2-8)], a heptapeptide formed by removal of the first N-terminal amino acid, is present in the central nervous system (CNS), where it is thought to play an important role in tonic blood pressure maintenance and in hypertension [81]. Ang IV [Ang-(3-8)] is a hexapeptide formed by further enzymatic degradation of Ang III [81]. Preclinical studies have suggested a cooperative effect of Ang IV in Ang II signalling. For instance, it appears that in the brain, Ang IV increases blood pressure by cooperating with Ang II on angiotensin II type 1 (AT1)-receptor signalling, because its hemodynamic effects require the presence of both Ang II and functional AT1 receptors [81].

Peptides truncated at the C-terminus of Ang II may also have biological activity. For example, Ang-(1-7), a heptapeptide fragment of Ang II, can be formed from Ang I or Ang II by the actions of several endopeptidases or from Ang II by the action of carboxypeptidases, including one with significant structural homology to ACE (which has been termed "ACE 2"). Unlike ACE, this enzyme does not convert Ang I to Ang II and its activity and Ang-(17) levels are not affected by ACE inhibitors (ACEIs) and ARBs $[46,80]$.

Ang-(1-7), which seems to act via a unique receptor, was first described to have vasodilatory effects and act as a natural ACEi, acting as a modulator of the RAAS [46,81]. So, ACE2 activity and Ang-(1-7) may counterbalance the activity of the ACE-mediated way, whose blockage is actually a therapeutical target. ACE 2 and Ang-(1-7) appear to be upregulated by ACEis use mainly in myocardium and kidney. Cardioprotective effects have been proposed to result from a direct effect of Ang-(1-7) on heart cells or a generalised systemic effect, $[46,81]$ but evidence for such actions in human studies is lacking. ACE 2 is also highly expressed in hypothalamus and aorta. ACE 2 can also cleave a single amino acid from the Cterminus of Ang I to form Ang-(1-9), a peptide with no known function at this time.

As already noted, Ang II is the primary effector of a variety of RAAS-induced physiological and pathophysiological actions.
These biological effects are mediated by specific receptors: at least 4 angiotensin receptor subtypes have been described [82].

The type 1 (AT1) receptor mediates most of the established physiological effects of Ang II (see Figs. 3 and 4). These include actions on the cardiovascular system (vasoconstriction, increased blood pressure, increased cardiac contractility, vascular and cardiac hypertrophy), kidney (renal tubular sodium reabsorption, inhibition of renin release), sympathetic nervous system, and adrenal cortex (stimulation of aldosterone synthesis), but also mediate the proinflammatory effects, the effects on cell growth and proliferation and, finally ROS production and oxidative stress [80].

This receptor, which is typical of the G protein-coupled receptor superfamily containing 7 membrane-spanning sequences, is widely distributed on many cell types in Ang II target organs.

The type 2 (AT2) receptors are ubiquitously expressed during fetal life in the brain, kidney, and other sites, and its levels decrease markedly in the first few hours after birth. There is some evidence that, despite low levels of expression in the adult, the AT2 receptor might mediate vasodilation and antiproliferative and apoptotic effects in vascular smooth muscle and inhibit growth and remodelling in the heart $[80,82]$. In the kidney, it has been proposed that activation of AT2 receptors may influence proximal tubule sodium reabsorption and stimulate the conversion of renal prostaglandin E2 to prostaglandin F $2 \alpha$ [80]. However, the importance of any of these AT2-mediated actions remains uncertain.

The type 4 (AT4) receptors are thought to mediate the release of plasminogen activator inhibitor 1 by Ang II and by the $\mathrm{N}$ terminal truncated peptides (Ang III and Ang IV), but the function of the type 3 (AT3) receptors is unknown [82]. Lastly, the putative effects attributed to the C-terminal truncated peptide Ang 1-7, including vasodilatation, natriuresis, antiproliferation, and cardiac protection, are presumed to be mediated by a unique receptor that does not bind Ang II, most likely a product of the Mas protooncogene known as the Mas receptor [82]

In addition to receptors for the angiotensin peptides, very recent evidence suggests the existence of high-affinity cell surface receptors that bind both renin and prorenin in several tissues, including heart, brain, placenta, and kidney, with localization to glomerular

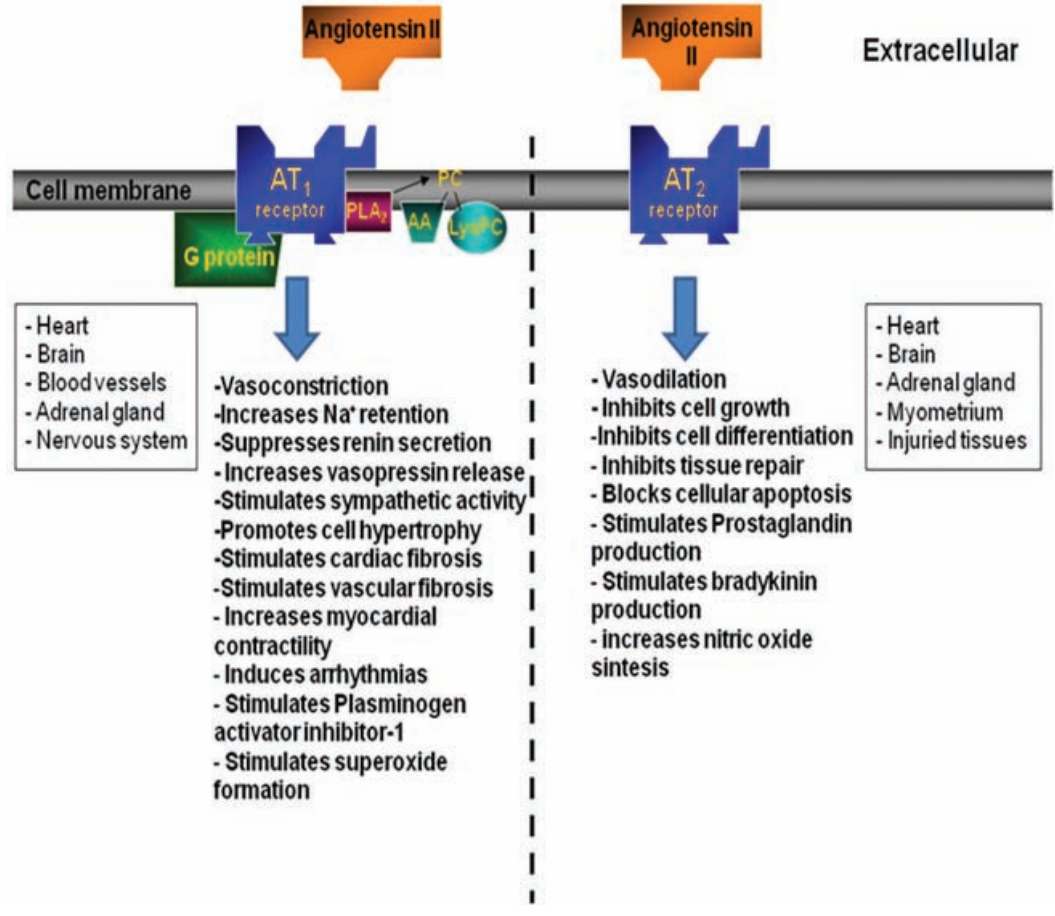

Fig. (4). Differential location and functions of type AT1 and AT2 Angiotensin receptors. 
mesangium and subendothelial vascular smooth muscle [83]. One receptor that has been carefully characterised has been reported to cause reversible activation of bound prorenin and to enhance the catalytic activity of bound renin, thus serving as a template for local Ang I generation. The receptor also has been reported to initiate intracellular signalling, independent of Ang peptide synthesis, leading to activation of mitogen-activated protein kinases ERK1 and ERK2 [83].

As previously described, Ang II, via the AT1 receptor, also stimulates the production of aldosterone by the zona glomerulosa, the outermost zone of the adrenal cortex. Aldosterone is a major regulator of sodium and potassium balance and thus plays a major role in regulating extracellular volume. It enhances the reabsorption of sodium and water in the distal tubules and collecting ducts (as well as in the colon and salivary and sweat glands) and thereby promotes potassium (and hydrogen ion) excretion [84]. Ang II, together with extracellular potassium levels, are the major regulators of aldosterone, but Ang II synthesis may also be stimulated by adrenocorticotrophic hormone (ACTH; corticotropin), norepinephrine, endothelin, and serotonin and inhibited by atrial natriuretic peptide and nitric oxide (NO). It is also important to note that Ang II is a major trophic factor for the zona glomerulosa, which can manifest atrophy (reversibly) in its absence.

Recently, growing evidences are accumulated regarding the concept that the RAAS functions both as a circulating system and as a tissue paracrine/autocrine system [80].

This important new acquisition about RAAS physiology originates from the evidence that angiotensin synthesis, such as receptorial ad signal transduction pathways may be found in several tissues as well as in the circulation.

There is evidence that local or "tissue" Ang II biosynthesis may be initiated by renin and/or angiotensinogen taken up from the circulation. In addition, independent Ang II generating systems have been postulated to exist in the heart, peripheral blood vessels, kidney, brain, adrenal glands, pituitary, adipose tissue, testes, ovaries, and skin [80].

Serine proteases, including several kallikrein-like enzymes (tonins), cathepsin G, and chymase are thought to contribute to Ang II formation in the tissue RAAS [85]. Studies have suggested that non-ACE pathways are, by inference, responsible for about $40 \%$ of Ang II generation in the intact human kidney [86] and that chymase is the dominant Ang II-generating pathway in the human heart, coronary arteries, and atherosclerotic aorta in vitro [85,87,88]. It has thus been proposed that abnormal activation of the tissue RAAS may contribute to the pathogenesis of cardiovascular disease even in the absence of derangements in the circulating system [89]. It must be considered that the greatest part of the evidences regarding the "tissue" RAAS" obtained in vitro, so not necessarily in vivo mechanisms may be similar or have the same pathophysiological and thus clinical relevance. More specific studies are needed to explore this particular subject.

Although these local-synthesized RAAS components are assumed to accomplish similar function of systemic one, different local tissue not necessarily has the same behaviour. For example cardiac RAAS, under physiological conditions, exerts the apparent function to maintain cellular balance of inhibiting and inducing cell growth, and proliferation and mediation of adaptive responses to myocardial stretch [90]. The majority of Ang II in cardiac tissue appears to be produced by local synthesis of Ang I and subsequent local conversion to Ang II, rather than from uptake of peptides from the systemic circulation [80]. Although it has been suggested that locally synthesised renin and/or additional proteolytic enzymes may be involved in this synthetic process, current evidence favours the concept that circulating renin and angiotensinogen, which are able to pass through the endothelial barrier, are taken up by cardiac tissue where they act locally [91]. Ang II exerts an inotropic effect (at least in atrial preparations), mediates myocyte hypertrophy via the AT1 receptor, and is involved in cardiac remodelling [91]. Pathologic activation of cardiac RAAS, perhaps through local upregulation of ACE levels, has been proposed to contribute to the development and maintenance of left ventricular hypertrophy [89].

VSMCs, endothelial, and endocardial cells generate Ang I and Ang II, again apparently via the uptake of circulating renin [80]. It has been suggested that the vascular RAAS contributes to the maintenance of cardiovascular homeostasis through its effects on both AT1 and AT2 receptors and mediates long-term effects on vascular remodeling by stimulating proliferation of vascular smooth muscle cells and fibroblasts [90].

Endothelial dysfunction is associated with upregulation of local tissue ACE, which might contribute to disrupting the balance of vasodilation and vasoconstriction. Vascular local ACE hyperfunction leads also to several Ang II mediated pro-inflammatory effects.

The kidney is one of the districts where RAAS activity exerts more pathophysiological actions, and in which hyperactivity of the system and iperproduction of Ang II and aldosterone cause more changes of glomerular filtration and kidney-mediated idroelectrolitic balance.

The intrarenal RAAS may explain the primary role of Ang II as a paracrine substance in the control of renal function. The direct intrarenal actions of Ang II include renal vasoconstriction, tubular sodium reabsorption, sensitivity of tubuloglomerular feedback, modulation of pressure-natriuresis, and promotion of renal tissue growth [90]. Under normal conditions, Ang II constricts both the afferent and efferent arterioles and stimulates mesangial cell contraction, which results in reduced renal blood flow, glomerular filtration rate (GFR), and filtered sodium load [80].

On the other hand, overactivation of the intrarenal RAAS may thus contribute to the pathophysiology of sodium-retaining states, such as hypertension and congestive heart failure (CHF). On the other hand, in conditions characterized by severe impairment of renal perfusion, such as renal artery stenosis, the afferent circulation, which is dilated as a result of autoregulation, is relatively refractory to the constrictive actions of Ang II, and the predominant constriction of efferent arterioles by Ang II plays a major role in maintaining glomerular perfusion pressure and, thus, GFR.

Due to the presence of the blood-brain barrier, the brain is largely isolated from the circulating RAAS; therefore, local Ang II synthesis by a brain RAAS has been proposed to play a role in central blood pressure regulation [90].

Local brain effects of RAAS overactivation in hypertesive rats have been found through Increasing in brain renin activity, renin and angiotensinogen mRNA, and detectable numbers of AT1- and AT2-receptor subtypes [90].

The existence of a relationship between systemic blood pressure levels and brain RAAS function has been confirmed by data showing that the modulation of brain AT1- and AT2-receptors has been shown to lower blood pressure in hypertensive rats [92] and regarding the hypotensive effects of administration of Ang II into the brain. These effects would be the result of the combined systemic effects of vasopressin release, sympathetic nervous system activation, and inhibition of baroreflexes. [92].

Adrenal glands seems able to produce renin, and consequently Ang II, in a kidney-independent way [93]. All components of the RAAS are present in adrenal cortex and comprise the adrenal RAAS. Renin and angiotensinogen mRNA have been identified in the adrenal gland, and Ang II formation has been demonstrated in zona glomerulosa cells.7 Most $(90 \%)$ adrenal renin activity has been localized to the zona glomerulosa, [93] and more than $90 \%$ of adrenal Ang II originates at local tissue sites. [94] In transgenic animal models it has been shown that sodium restriction can increase adrenal renin and aldosterone independently of plasma or 
kidney renin concentrations. Additionally, bilateral nephrectomy, which decreases cardiac and vascular renin, does not decrease adrenal renin in experimental animals [95]. It is not known if the adrenal RAAS functions as a paracrine or autocrine system or if it has a pathophysiological role, and the relative importance of systemic versus locally synthesized Ang II in the control of adrenal function is uncertain.

\section{Main Characteristics of RAAS-suppressing Drugs}

Angiotensin-Converting Enzyme Inhibitors (ACE-i). Early attempts to block ACE in order to obtain pharmacological advantages date from 1960s [77]. Studies conducted on the peptides derived from the venom of the Brazilian arrowhead viper (Bothrops jararaca) showed inhibition of kinase II, an enzyme that facilitates degradation of bradykinin, and which was later shown to be identical to ACE. Synthetic analogues of the peptide fraction of snake venom, such as the nonapeptide teprotide, were shown to lower blood pressure in patients with hypertension and produce beneficial hemodynamic effects in patients with heart failure [77]. These findings encouraged the search for orally active inhibitors of ACE; the first of these, captopril, was designed based on known inhibitors of another zinc-containing metalloprotease, carboxypeptidase A, and included a sulfhydryl-containing amino acid to serve as ligand for the zinc moiety. Because many of the side effects of captopril, such as proteinuria, skin rashes, and altered taste, were attributed to the sulfhydryl group, subsequent work led to the development of ACEIs that replaced this group with a carboxyl group (e.g., lisinopril, benazepril, quinapril, ramipril, perindopril, cilazapril, trandolapril) or phosphoryl group (fosinopril) [96,97]. The presence of the carboxyl group conferred greater lipophilicity, which actually improved binding to ACE, and improved tissue penetration [97]. ACEIs competitively block the action of ACE and thus the conversion of Ang I to Ang II, thereby reducing circulating and local levels of Ang II. ACEIs also decrease aldosterone and vasopressin secretion and sympathetic nerve activity, but there is controversy regarding their efficacy in blocking other "tissue" actions of the RAAS [98]. Short-term ACEI therapy is associated with a decrease in Ang II and aldosterone and an increase in renin release and Ang I. There is some evidence, however, that over the long term ACE inhibition may be associated with a return of Ang II and aldosterone toward baseline levels ("ACE escape") perhaps through activation of alternate pathways $[98,99]$. The extent of the ACE escape phenomenon has been largely discussed, especially after the introduction of ARBs that theoretically may overcome this problem, certain is that because ACEIs are all competitive inhibitors of the enzyme, it is likely that increased levels of Ang I (provoked by the compensatory increase in PRA due to loss of negative feedback inhibition) can tend to partially overcome the blockade [100]. This event would be especially magnified in high-renin or volume-depleted patients with a particularly robust reactive rise in PRA. ACE-is are generally well-tollerated drugs by most patients. The most frequent side effects are dry cough, which has been attributed to accumulation of substance P (which is normally degraded by kininase II).

In general, short-term pharmacodynamic responses to decreases in Ang II through inhibition of ACE include dose-dependent reductions in cardiac preload and afterload, with lowering of systolic and diastolic blood pressure, although in normotensive and hypertensive patients without cardiac dysfunction, little or no change in cardiac output or capillary wedge pressure are seen.

Of note, unlike direct-acting arterial vasodilators, ACEIinduced reductions in total peripheral vascular resistance occur without a significant change in heart rate [98]. ACEIs also decrease renal vascular resistance, increase renal blood flow, and promote sodium and water excretion. Mainly through cellular effects in the kidney and through alterations in glomerular hemodynamics, ACEIs also may prevent the progression of microalbuminuria to proteinuria, reduce proteinuria in patients with established glomeru- lar disease, and prevent or delay the progression of renal insufficiency to end-stage renal disease. Efficacy in long-term trials has been demonstrated particularly in patients with nondiabetic nephropathies or in patients with insulin-dependent (type 1) diabetes. $[98,101,102]$.

The analysis of the cardiovascular effects of ACE-is administration is not the aim of this review, but several data should be noted. In $40 \%$ to $60 \%$ of patients with mild-to-moderate hypertension, ACEI monotherapy produces a satisfactory reduction in blood pressure; in this population, ACEIs contribute to reversal of cardiac hypertrophy. In patients with CHF, ACEIs relieve pulmonary congestion by a balanced reduction in cardiac preload and afterload, through various vascular mechanisms [103]. ACEIs have also been shown to improve endothelial dysfunction in patients with heart failure, as well as in patients with coronary artery disease and type 2 diabetes $[98,104]$

In early landmark trials in patients with CHF (such as CONSENSUS, SOLVD, and V-HeFT-II), ACEIs were shown not only to markedly improve symptoms and functional status, but also to dramatically reduce mortality. In subsequent studies in patients who have suffered a myocardial infarction (MI), such as SAVE, AIRE, and TRACE, ACEI therapy has been shown to prevent or retard ventricular remodeling and progression to $\mathrm{CHF}$, and thereby to reduce overall mortality and prolong survival [105-112].

Furthermore, results of the HOPE trial and other smaller studies indicate broad cardiovascular benefits of ACEi therapy in "highrisk" patients (including both hypertensive and normotensive individuals), and it is possible that these benefits occur in part independently of their blood pressure-lowering effect [112].

Several large-scale studies of various ACEIs have shown a reduction in incidence of new-onset diabetes in association with ACEI therapy. For example, this has been shown with captopril in patients with hypertension (CAPP), [113] with ramipril in patients at high risk for cardiovascular disease (HOPE), [112] with enalapril in patients with left ventricular dysfunction (SOLVD), [114] and with trandolapril in patients with stable coronary disease (PEACE) [115]. The mechanisms of this benefit has not been determined but open the door to the ancillary effects of RAAS-suppressing drugs, to the achieved health benefits beyond BP levels reduction and hypothesize a further enlargement of ACEi clinical indications. All these issues will find further emphasis after the beginning of ARBs era.

Angiotensin Receptor Blockers (ARBs) development followed the discovery of the different types of Ang II receptors and the knowledge of the AT1 receptors role in cardiovascular pathology. Development of orally active, nonpeptide, selective AT1 receptor blockers began in the 1990s with the synthesis of losartan [77]. Since 1995, when losartan was granted approval as an antihypertensive, a total of seven ARBs have been synthesized and approved, including valsartan, irbesartan, candesartan, eprosartan, telmisartan, and olmesartan. All these ARBs are actually indicated for anti-hypertensive treatment; in some case acquisition of the results of several RCT performed in these years, entailed additional indications (see Table 1).

Because ARBs act by blocking Ang II action at the receptor level, rather than by inhibiting its synthesis, they ought to antagonize AT1-mediated effects of Ang II no matter how it is synthesized. In other words, if there were significant Ang II synthesis in tissues by alternate pathways, such as chymase in the heart, this would limit the efficacy of ACEIs (but not of ARBs) through a mechanism postulated to contribute to the "escape" phenomenon following long-term ACE inhibition. [116] In contrast to the ACEIs, ARB therapy actually results in an increase in Ang II levels [117]. As with ACE inhibition, blockade of the AT1 receptor inhibits the negative feedback loop, leading to increased renin secretion and thus to increased synthesis of Ang I. In the case of ARBs, the 
Table 1. Main Clinical Indications for the Angiotensin Receptor Blockers

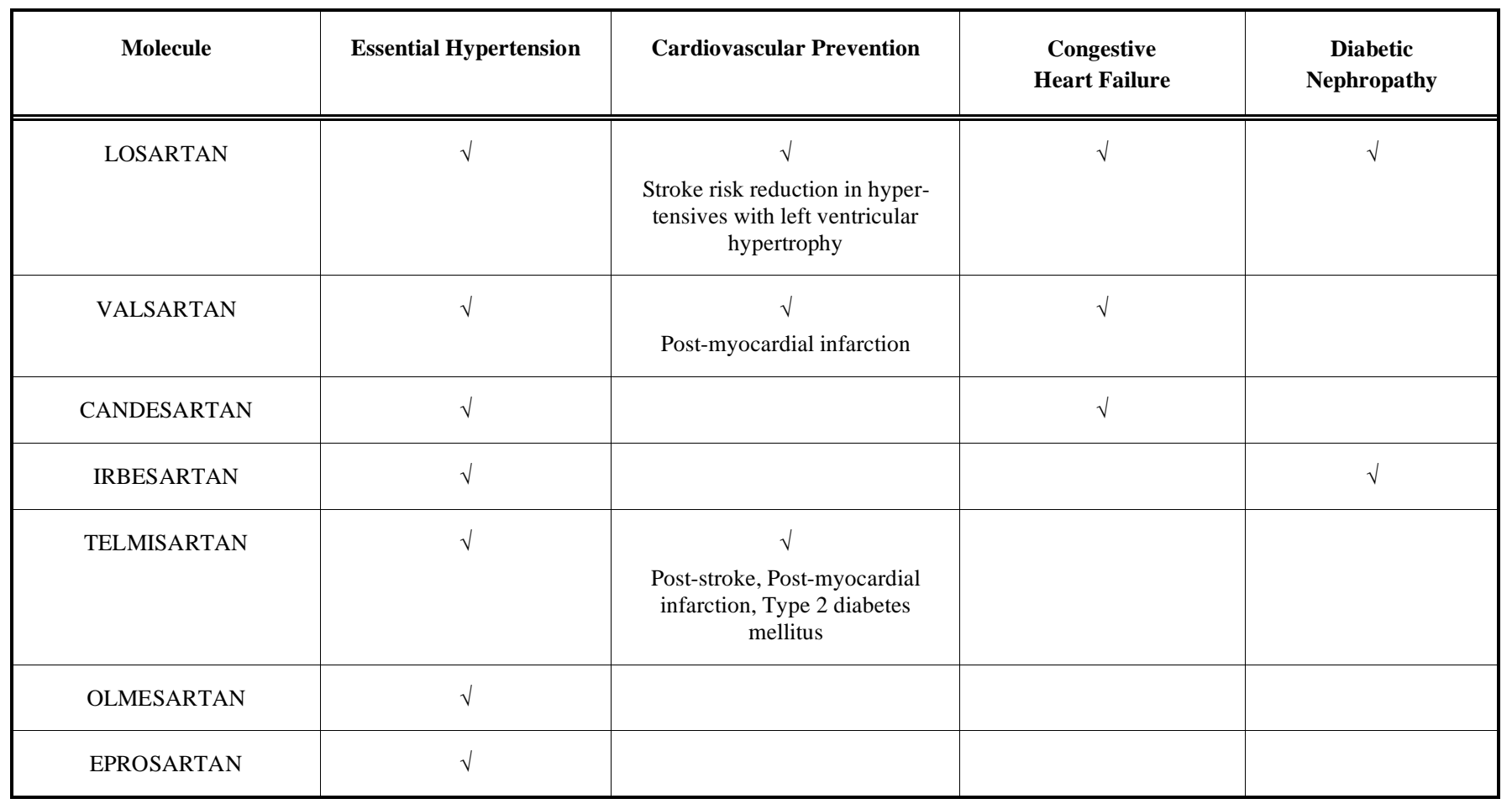

increase in Ang I lead to a commensurate increase in Ang II, which is freely able to bind to AT2 or other receptor subtypes. Earlier preclinical studies have suggested that beyond AT1 receptor blockade, activation of the AT2 receptor might mediate additional beneficial actions on the vasculature, heart, and kidneys, in part via a bradykinin/NO/ cGMP pathway, an effect that would further distinguish ARBs from ACEIs. [80].

Like the ACEIs, ARBs reduce blood pressure by decreasing systemic vascular resistance; they do not affect heart rate and have minimal effect on cardiac output in the nonfailing heart [117]. Reduced systemic vascular resistance results from a combination of inhibition of Ang II-mediated vasoconstriction, reduced sympathetic nervous system activity, and reduced extracellular volume (i.e., by direct inhibition of proximal sodium reabsorption and by inhibition of aldosterone release) [117].

ARB monotherapy produces a satisfactory reduction in blood pressure in $40 \%$ to $60 \%$ of patients with mild-to-moderate hypertension [118,119]. A number of meta-analyses have calculated risk reductions for the ARB class of agents in areas outside of hypertension and, when taken together, suggest favourable effects in terms of preventing stroke and improving renal function and left ventricular (LV) mass, an uncertain risk/benefit profile in LV dysfunction and $\mathrm{HF}$, and a potential increased risk for myocardial infarction (MI) in non-HF patients [120-127].

Although conducting meta-analyses that capture multiple agents within a drug class is a common practice (with a tendency to also group data across ARBs and ACEIs to assess the broader RAAS inhibitor category) and may yield clinically interesting information, the results and conclusions should not be interpreted as implying an overall class effect. In the case of the ARBs, important differences exist across the pharmacologic and pharmacokinetic profiles of the individual agents, including their binding affinity and selectivity for the angiotensin II type 1 receptor (AT1) [128]. When given at their highest recommended doses for the treatment of hypertension, differences in BP lowering have been described [129]. Clinically, the extent to which the AT1 binding affinity/selectivity-related extent to which the AT1 binding affinity/selectivity-related differences within the ARB class influence BP control or long-term cardiorenal morbidity/ mortality is unknown [128].

The vast RCT experiences during which ARB-associated effects on outcomes beyond BP control have been compared with those for non-ARB agents are captured in Table 2 [129-212].

Potential anti-inflammatory effects of ARBs, with respect to the differences emerged among the molecules of the class, have been tested in some of the cited RCT and in other more specific analysis aimed to address this issue obtaining encouraging results, as showed afterwards.

The most recent class of agents that block the RAAS to be introduced is the direct renin inhibitors represented by aliskiren [213], which was recently approved for treatment of hypertension. This compound differs from the ACEIs and ARBs in that, by blocking the catalytic activity of renin at the point of activation of the RAAS, it blocks the synthesis of all angiotensin peptides and prevents the compensatory increase in renin activity. Renin activity and biological effects will not be reviewed here.

\section{PART IV - ANTI-INFLAMMATORY EFFECTS OF ACE-I}

An emerging awareness of the link between RAAS and inflammation has increased the development of theories about the anti-inflammatory activities of ACE inhibitors and ARBs as mediators of cardiovascular benefits. Given the pro-inflammatory effects of Ang II and aldosterone, agents that interfere with the components of RAAS, such as ACE inhibitors, ARBs and mineralocorticoid receptor antagonists (spironolactone or the more selective eplerenone), represent logical therapeutic tools to reduce vascular inflammation and cardiovascular risk, as suggested in large clinical trials in patients with hypertension and diabetes.

However, BP reduction by itself may also influence inflammation, since calcium channel blockers not only decreased BP in patients with hypertension, but also reduced plasma concentrations of ICAM-1, E-selectin and vWF [214]. But nevertheless these reports, 
Table 2. Main randomized controlled trials that have been evaluated angiotensin receptor blockers vs other treatments for other relevant outcomes than blood pressure lowering effect (in boldface are printed the study achieved its primary or secondary endpoint(s); roman type designates that study did not meet its primary or secondary endpoint(s) ).

\begin{tabular}{|c|c|c|c|c|c|c|c|}
\hline & Losartan & Valsartan & Candesartan & Irbesartan & Telmisartan & Eprosartan & Olmesartan \\
\hline Atherosclerosis & $\begin{array}{c}\text { Uchiyama-Tanaka Y et } \\
\text { al, Flammer AJ } \text { et al, } \\
\text { Ichihara A et al, Park } \\
\text { JB et al, Rehman A et } \\
\text { al [130-134]. }\end{array}$ & $\begin{array}{c}\text { MARVAL-2, VIP } \\
{[148,149]}\end{array}$ & $\begin{array}{c}\text { CENTRO, } \\
\text { MITEC } \\
{[167,119]}\end{array}$ & $\begin{array}{c}\text { SILVHIA, } \\
\text { EPAS, ISLAND } \\
{[183-185]}\end{array}$ & $\begin{array}{c}\text { Asmar R et al, Jung AD } \\
\text { et al } \\
{[195,196]}\end{array}$ & $\begin{array}{c}\text { Leu HB et al } \\
{[206]}\end{array}$ & $\begin{array}{c}\text { EUTOPIA } \\
\text { [207] }\end{array}$ \\
\hline $\begin{array}{c}\text { Hypertensive left ventricular } \\
\text { hypertrophy }\end{array}$ & LIFE Study [135-138] & $\begin{array}{c}\text { Anan F et al, } \\
\text { Cuocolo A et al, } \\
\text { Thürmann PA et al, } \\
\text { Yasunari K et al } \\
{[150-153]}\end{array}$ & $\begin{array}{l}\text { CATCH, } \\
\text { CASE-J } \\
{[168,169]}\end{array}$ & $\begin{array}{l}\text { SILVHIA, } \\
\text { CVIP } \\
\text { [186-188] }\end{array}$ & $\begin{array}{c}\text { ONTARGET/ } \\
\text { TRANSCEND } \\
{[197]}\end{array}$ & $\begin{array}{c}\text { Diamond JA et } \\
\text { al } \\
{[208]}\end{array}$ & $\begin{array}{l}\text { Rosendorff C et al } \\
{[209]}\end{array}$ \\
\hline $\begin{array}{l}\text { Secondary prevention post- } \\
\text { myocardial infarction }\end{array}$ & OPTIMAAL [139] & $\begin{array}{c}\text { T-VENTURE, } \\
\text { VALIANT } \\
{[154-156]}\end{array}$ & $\begin{array}{c}\text { E-COST } \\
{[170]}\end{array}$ & & & & \\
\hline Stroke & LIFE Study $[135,140]$ & $\begin{array}{c}\text { JiKei Heart Study, } \\
\text { KYOTO HEART } \\
\text { Study } \\
{[157,158]}\end{array}$ & $\begin{array}{c}\text { SCOPE, } \\
\text { E-COST } * \\
{[170-172]}\end{array}$ & & $\begin{array}{c}\text { TRAN- } \\
\text { SCEND,PROFESS } \\
{[198,199]}\end{array}$ & $\begin{array}{c}\text { MOSES } \\
{[210]}\end{array}$ & \\
\hline Heart Failure & $\begin{array}{c}\text { ELITE/ELITE II [141- } \\
143]\end{array}$ & $\begin{array}{l}\text { Val-HeFT } \\
{[159,160]}\end{array}$ & $\begin{array}{c}\text { RESOLVD, } \\
\text { CHARM } \\
{[173-180]}\end{array}$ & $\begin{array}{c}\text { I-PRESERVE } \\
\text { [189] }\end{array}$ & $\begin{array}{c}\text { REPLACE } \\
\text { [200] }\end{array}$ & $\begin{array}{l}\text { ADEPT } \\
{[211]}\end{array}$ & \\
\hline Atrial Fibrillation & LIFE Study [144] & $\begin{array}{l}\text { GISSI-AF, } \\
\text { Val-HeFT } \\
{[161,162]}\end{array}$ & $\begin{array}{c}\text { CAPRAF } \\
\text { [181] }\end{array}$ & $\begin{array}{c}\text { Guntekin U et al, } \\
\text { Madrid AH et al } \\
{[190,191]}\end{array}$ & $\begin{array}{c}\text { Celik T et al } \\
\text { [201] }\end{array}$ & & \\
\hline $\begin{array}{c}\text { Protection against renal dam- } \\
\text { age }\end{array}$ & $\begin{array}{l}\text { RENAAL, JLIGHT, } \\
\text { ROAD }[145,147]\end{array}$ & $\begin{array}{c}\text { VALERIA, } \\
\text { SMART, } \\
\text { HKVIN, MAR- } \\
\text { VAL, } \\
\text { MARVAL-2 } \\
{[148,163-166]}\end{array}$ & $\begin{array}{l}\text { DIRECT, } \\
\text { CENTRO } \\
{[167,182]}\end{array}$ & $\begin{array}{c}\text { IRMA-2, IDNT, } \\
\text { IMPROVE } \\
{[192-194]}\end{array}$ & $\begin{array}{c}\text { INNOVATION, } \\
\text { TRANSCEND, } \\
\text { ONTARGET, } \\
\text { DETAIL } \\
\text { [202-205] }\end{array}$ & & $\begin{array}{l}\text { ROADMAP } \\
{[212]}\end{array}$ \\
\hline
\end{tabular}

this table is a summary of fully published randomized controlled trial data, with an emphasis on large-scale trials (when available). Additional smaller studies were considered in the absence of data from large-scale clinical trials.

* E-COST Study achieved end-point prevention of stroke only in secondary prevention, not in primary

the comparison between drugs with and without efficacy on RAAS performed in several trials frequently showed clinical benefits of RAAS-suppressing agents beyond those attributable to blood pressure-reducing efficacy alone.

Nevertheless ACE inhibitors and ARBs are drugs acting on different levels of the same metabolic system, differences between the two classes are relevant, both in anti-hypertensive efficacy and in ancillary effects. Referring to the relationship between the two classes of drugs and inflammation, the evidences supporting an anti-inflammatory effect of ACE-i or in the main a significance influence of this class of drugs on systemic inflammatory parameters are rather week. Nevertheless this, several studies investigated the effects of ACE inhibitors on systemic and vascular inflammatory process and tried to analyse the effects of ACE-i administrations on inflammatory markers such as CRP, cytokines, chemokynes, adhesion molecules and more.
Early experimental models indicated that ACEis exert an antiatherosclerotic effect as there was a relative decrease in cellularity and increase in extracellular matrix in aortic atherosclerotic lesions of hyperlipidemic rabbits [215]. The crucial role of the RAAS in inflammatory processes regulating atherosclerosis was also observed in other animal models prone to develop atherosclerosis. One of the most used models was the "stroke-prone" strain (SHRSP) rats. Cardiac tissue of hypertensive stroke-prone rats treated with high doses of ramipril had no evidence of degeneration, loss of structural proteins, or inflammatory infiltrates. Also, ramipril prevented deposition of extracellular matrix proteins and myocyte hypertrophy and, finally, decreased mortality [216]. These results strongly suggested that ACE inhibitors reduce cardiovascular risk and atherosclerosis in animals in different stages of cardiovascular disease. These benefits were confirmed by the majority of the following published studies using similar murin models. 
Very recently, further data about the effects of captopril administration on rat, linked the anti-inflammatory effects of the ACEi with NF- $\kappa B$ inactivation [217]. Left ventricle mRNA expression and plasma levels of pro-inflammatory (interleukin-1beta (IL1beta) and IL-6) and anti-inflammatory (IL-10) cytokines, were measured in spontaneously hypertensive rats (SHR) and their control normotensive, Wistar-Kyoto (WKY) rats, with or without a 12week treatment with captopril $(80 \mathrm{mg} / \mathrm{Kg} / \mathrm{day} ; \mathrm{n}=$ six animals per group) In SHR, the observed increases in blood pressures, heart rate, left ventricle relative weight, plasma levels and cardiac mRNA expression of IL-1beta and IL-6, as well as the reductions in the plasma levels and in the cardiac mRNA expression of IL-10, were reversed after the treatment with captopril. Finally, SHR presented an elevated cardiac mRNA expression and activation of the transcription nuclear factor, NF- $\kappa \mathrm{B}$, accompanied by a reduced expression of its inhibitor, I- $\kappa \mathrm{B}$; captopril administration corrected the observed changes in all these parameters.

An elegant study comparing the effects of the ACEi enalapril and the ARB losartan evaluating in vivo and in vitro data on cell injury and temporal association of leukocyte endothelial interaction in response to ischemia-reperfusion date 2000 [218]. The extent and temporal correlation of cellular damage (propidium-iodide staining), microvascular perfusion failure and leukocyte-endothelial interaction (leukocyte adherence) were investigated by means of intravital microscopy, after the application of hemodynamically ineffective doses of enalapril and losartan $(5 \mathrm{mg} / \mathrm{kg})$. A hamster dorsal skinfold model with a 4-h tourniquet ischemia was used. In vitro, the effect of enalapril and losartan on polymorphonuclear cell (PMN) adherence, as well as adhesion molecule expression (ICAM1, VCAM-1), on hypoxia- or IL-1beta-stimulated endothelial cells (HUVEC) was assessed using a PMN-adhesion assay and flow cytometry, respectively. Enalapril significantly reduced early cellular damage, microvascular perfusion failure, and leukocyte adherence in response to ischemia-reperfusion. Conversely, AT1 receptor inhibition with losartan proved to be ineffective at attenuating postischemic microcirculatory disorders (leukocyte-endothelial interactions, microvascular perfusion failure) and aggravated cellular injury. In vitro, enalapril reduced PMN adherence and ICAM-1 and VCAM-1 expression, while losartan was ineffective in the same respect. Following ischemia-reperfusion injury, ACE- versus AT1-receptor inhibition induces differential effects concerning the extent and temporal association of cell injury and leukocyteendothelial interaction. In this study the use of enalapril seems to combine the beneficial effects of preventing cell and vascular injury immediately after reperfusion, with a delayed inhibition of the inflammatory response. Since the AT1-receptor inhibitor losartan did not mimic effects obtained with ACE inhibition, it is conceivable that the responses in ischemia-reperfusion are mediated by a nonangiotensin II-AT1 receptor-dependent mechanism. So, in this specific topic, blocking of AT1 receptor do not provide benefit, although in vivo studies conducted in assets in which RAAS activation is associated to high cardiovascular risk, searching for more clinical aims provides different results as showed afterwards.

These encouraging results provided by ACEis in animal model clearly suggested to test the hypothesis that also in human models interference with RAAS may block the pathophysiological cascade leading from cardiovascular risk factors to endothelial dysfunction, pre-clinical and clinical atherosclerosis, organ damage and, finally major vascular events (CAD, stroke). The main available data regarding the supposed anti-inflammatory role of ACEis are shown in Table 3 .

Early data about the role of ACEi quinapril in the reversal of the endothelial dysfunction came from TREND Study [219]. This double-blind, randomized, placebo-controlled trial strongly supported the hypothesis that ACE inhibition (obtained here using quinapril), improves endothelial dysfunction of the coronary arteries. Only quinapril induced net change in the acetylcholine- provoked constriction of target segments of the coronaries after 6 months of treatment in a population formed of normotensive patients with coronary artery disease and without confounding variables such as heart failure, cardiomyopathy, or major lipid abnormalities. Similar results of improvement of flow-dependent endothelium-mediated vasodilation are reported in further two studies: the first, even in subjects affected by CAD, reported a similar extent of reduction after 4 weeks of therapy with ramipril $10 \mathrm{mg} / \mathrm{d}$ or losartan $100 \mathrm{mg} / \mathrm{d}$ through increase of bioavailability of NO [220]; the second, evaluated in renal circulation, after once daily treatment with 40/80 mg telmisartan or 5/10 mg ramipril for 9 weeks [221]. No significant differences between the two drugs were observed although the ARB seemed to be a little more efficient.

Given what showed in the TREND trial [219] about the effectiveness of quinapril in improve endothelium function, in BANFF Study [222] were compared the same quinapril $20 \mathrm{mg}$ with enalapril $10 \mathrm{mg}$, losartan $50 \mathrm{mg}$ or amlodipine $5 \mathrm{mg}$ daily. The study enrolled 80 patients with CAD randomly assigned to one of the selected treatments. The change in FMD from baseline was significant only for quinapril $(1.8+/-1 \%, \mathrm{p}<0.02)$. No change was seen with losartan $(0.8+/-1.1 \%, \mathrm{p}=0.57)$, amlodipine $(0.3+/-0.9 \%, \mathrm{p}$ $=0.97)$ or enalapril $(-0.2+/-0.8 \%, \mathrm{p}=0.84)$. This finding appears very interesting because shows that if different ARBs exert their function though an unique mechanism (blocking of AT1 receptor) different ACEis, acting in various extent against plasmatic ACE and tissue ACE might provide different ancillary effects. In BANFF study, for example, the ACEi that resulted not able to affect endothelial function, enalapril, is an ACEi with low activity at the tissue level.

Regarding effect of ACE-i on circulating adhesion molecules levels, in 1998 Ferri et al [223] evaluated circulating soluble Eselectin, ICAM-1, and VCAM-1 concentrations in 93 nonobese essential hypertensive patients hyperilipidemic and/or with impaired glucose tolerance, matching data with those collected in a group of 22 healthy volunteers served as a control group. Soluble adhesion molecules were measured at baseline, during an oral glucose tolerance test, and after 12 weeks of either enalapril or placebo treatments. Authors reported that, compared with placebo, 12 weeks of enalapril treatment significantly $(\mathrm{P}<0.0001)$ reduced soluble $\mathrm{E}$ selectin, ICAM-1, and VCAM-1 (60-70\% decrease in all circulating adhesion molecules tested). Decrements of soluble adhesins were not dependent on enalapril-related blood pressure changes.

Analysing data provided by Gasic et al, [224] the ACEi fosinopril $(10 \mathrm{mg} /$ day $)$ administered over 12 weeks to 11 microalbuminuric patients with non-insulin-dependent diabetes mellitus (NIDDM) provided the following actions: serum levels of cVCAM-1 decreased by $-19 \%$ (CI: $-25 \%$ to $-13 \%$ ) after treatment with fosinopril $(\mathrm{P}=.003)$ and were no longer different from those of the control group. In contrast, plasma levels of E-selectin, ICAM-1, plasminogen activator inhibitor (PAI-1) and tissue plasminogen activator (TPA) were unaffected. In the population enrolled baseline levels of baseline plasma concentrations of E-selectin, ICAM-1, and VCAM1 were markedly higher in patients than in healthy control subjects $(\mathrm{n}=82 ; \mathrm{P}<.001)$, mechanisms behind diabetic endothelial dysfunction and, as a consequence, ancillary effects of ACE-inhibition in diabetic population not necessarily might be similar to healthy subjects. Nevertheless of this fosinopril in this trial did not reach the lowering of both the adhesion molecules and the fibrinolitic markers tested.

The effects of blockade of the RAAS on levels of circulating adhesion molecules in type 1 diabetic patients with diabetic nephropathy were assessed by Andersen et al [225]. The study was designed as a crossover trial with 5 treatment periods, each lasting 2 months; sixteen patients were included. The patients received the AT1 receptor antagonist losartan (50 and $100 \mathrm{mg}$ ), the ACE inhibitor enalapril (10 and $20 \mathrm{mg}$ ), and placebo in random order. Labora 
Table 3. Selected Studies Evaluating Anti-inflammatory Effects of Angiotensin Converting Enzyme inhibitors

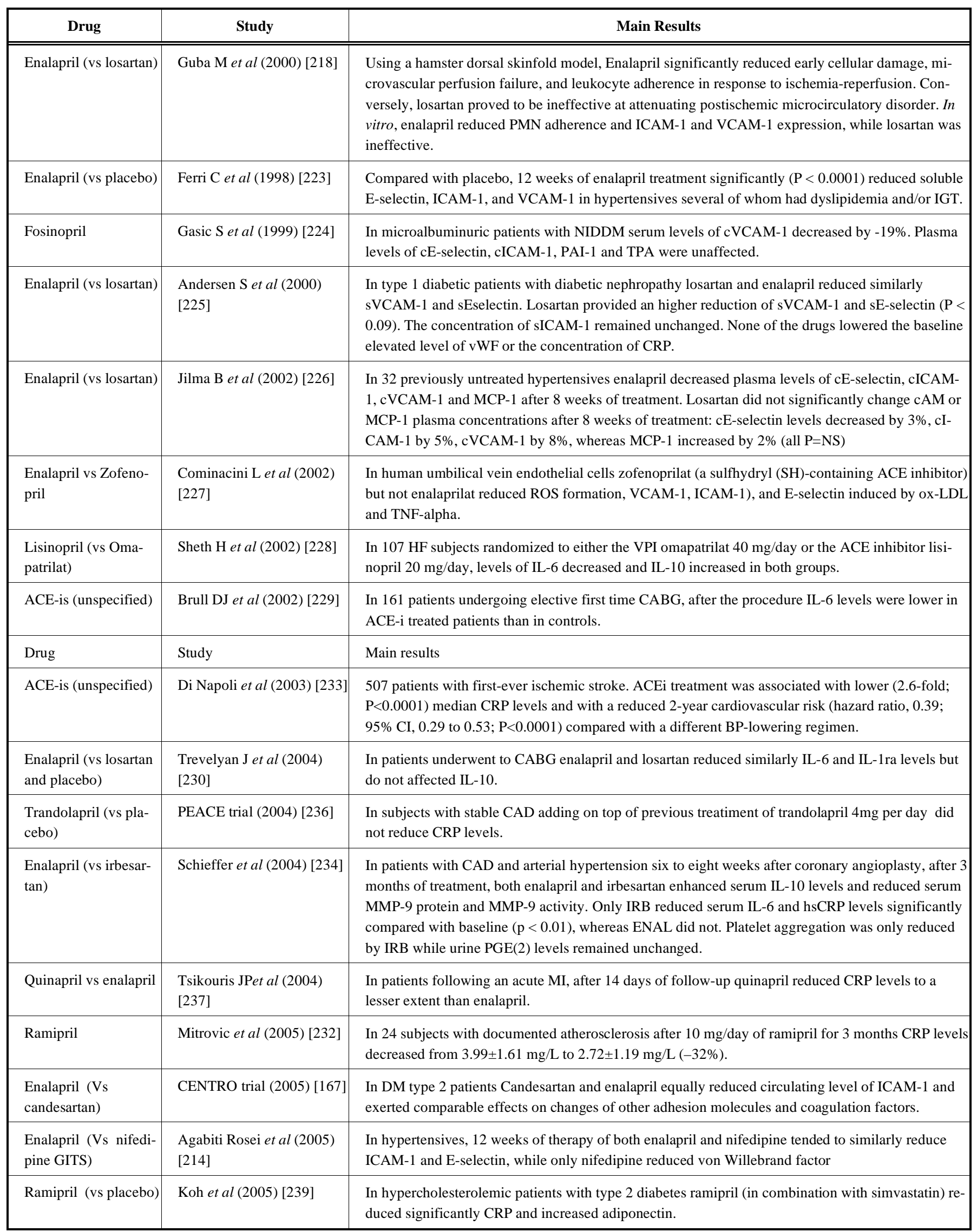


(Table 3) Contd....

\begin{tabular}{|c|c|c|}
\hline Drug & Study & Main results \\
\hline Quinapril (vs placebo) & Tikiz et al (2005) [235] & $\begin{array}{l}\text { In rheumatoid arthritis patients quinapril ( } 10 \mathrm{mg} / \text { day) added to antirheumatic drugs do not modified } \\
\text { CRP, fibrinogen, IL-1 } \beta \text {, IL- } 6 \text { and TNF- } \alpha \text { levels. }\end{array}$ \\
\hline Drug & Study & Main results \\
\hline Quinapril vs enalapril & Kovacs I et al (2006) [231] & $\begin{array}{l}\text { In post-MI patients FMD (marker of endothelial dysfunction), increases after } 8 \text { weeks of treatment } \\
\text { with quinapril but not enalapril. TNF-alpha }(19.0+/-12.21 \mathrm{pg} / \mathrm{ml} \text { ) and CRP (to } 3.91+/-1.82 \mathrm{mg} / \mathrm{L} \text { ) } \\
\text { significantly decreased after } 8 \text { and } 12 \text { weeks of quinapril treatment but not after enalapril treatment. }\end{array}$ \\
\hline Ramipril (vs placebo) & Brili S et al (2008) [240] & $\begin{array}{l}\text { In normotensive subjects with successfully repaired coarctation of the aorta (SCR) ramipril } 5 \\
\text { mg/day for } 4 \text { weeks improved endothelial function }(\mathrm{p}<0.001) \text { and decreased the expression of the } \\
\text { cytokine IL-6 }(\mathrm{p}<0.05) \text {, sCD } 40 \mathrm{~L}(\mathrm{p}<0.01) \text { and sVCAM-1 }(\mathrm{p}<0.01) \text {, but failed to affect serum } \\
\text { levels of C-reactive protein. }\end{array}$ \\
\hline $\begin{array}{l}\text { Perindopril (vs irbe- } \\
\text { sartan and placebo) }\end{array}$ & $\begin{array}{l}\text { Tousoulis D et al (2008) } \\
\text { [241] }\end{array}$ & $\begin{array}{l}\text { In } 60 \text { normotensive patients with CAD, both perindopril and irbesartan similarly reduced fibrinogen } \\
\text { and hsCRP without changing levels of sICAM-1, sVCAM-1, E-selectin and TNF- } \alpha \text {. }\end{array}$ \\
\hline $\begin{array}{l}\text { Fosinopril (vs pla- } \\
\text { cebo) }\end{array}$ & TRAIN Study (2009) [243] & $\begin{array}{l}\text { Subjects } \geq 55 \text { years old with high cardiovascular disease risk profile. Fosinopril did not modify } \\
\text { CRP, IL-6, PAI-1, VCAM-1, endothelin } 1 \text {. }\end{array}$ \\
\hline Ramipril (vs placebo) & 4R Trial (2009) [238] & $\begin{array}{l}264 \text { subjects with CRP levels }>2 \mathrm{mg} / \mathrm{dl} .10 \mathrm{mg} / \text { day of ramipril for } 12 \text { weeks did not lower CRP } \\
\text { levels compared with placebo }\end{array}$ \\
\hline
\end{tabular}

PMN: polymorphonuclear; ICAM-1: intercellular adhesion molecule-1; VCAM-1: vascular adhesion molecule-1; IGT: Impaired Glucose Tolerance; NIDDM: non-insulin-dependent diabetes mellitus; PAI-1: plasminogen activator inhibitor; TPA: tissue plasminogen activator; vWF. Von Willebrand Factor; TNF-alpha: Tumor Necrosis Factor-alpha; CRP: C Reactive Protein; MCP-1: monocyte chemoattractant protein-1; NS: not significant; ROS: Reactive Oxygen Species; CAD: coronary artery disease; HF: Heart Failure; VPI: Vasopeptidase Inhibitor; CABG: coronary artery bypass graft; IL-1 ra: IL-1 receptor antagonist; MMP: Matrix metalloproteinase; DM: diabetes mellitus; FMD: Flow Mediated Dilatation.

tory examinations were performed at the end of each treatment period and included assessment of plasma sVCAM-1; sICAM-1; sE-selectin. Von Willebrand factor (vWF), and CRP. These markers, except sICAM-1, were also examined in a control group of 29 healthy subjects. Plasma levels of sVCAM-1, sE-selectin, and vWF during the placebo period were higher than those in healthy control subjects. The increased concentrations of sVCAM-1 and sEselectin in the patients with diabetic nephropathy were significantly reduced by blockade of RAS, both by losartan and enalapril, except for sEselectin in the losartan-treated patients $(\mathrm{P}=0.08)$. The relative reductions in sVCAM-1 and sE-selectin obtained during treatment with the AT1 receptor antagonist tended to be less pronounced than the reduction obtained with the ACE inhibitor $(\mathrm{P}<0.09)$. The concentration of sICAM-1 remained unchanged in all 5 treatment periods. None of the drugs lowered the elevated level of vWF or the concentration of CRP. This study seems likely to demonstrate that blockade of the activity of angiotensin II in diabetic nephropathy lowers the levels of some, but not all, adhesion molecules (sVCAM-1 and cE-selectin only, reduced levels by approx. 10\%). These results suggest that interfering with the effects of angiotensin II decreases proatherogenic endothelial-leukocyte adhesion in diabetic nephropathy, without acting on all the pro-inflammatory mechanisms. Levels of vWF and CRP did not change, which suggests that a general improvement in endothelial function or a decrease in systemic inflammatory activity did not cause the decreases in SVCAM-1 and sE-selectin.

Jilma et al tested the hypothesis whether enalapril effectively decrease plasma levels of circulating adhesion molecules (cAMs) as showed by the previous reports [226]. To examine whether this effect may be mediated by the decreased action of angiotensin, authors compared the effects of enalapril with the ARB, losartan, on plasma levels of cAMs, and monocyte chemotactic protein-1 (MCP-1). In a randomized trial, they recruited 32 untreated patients
(19 male, aged 59+/-13 years) with hypertension, who received either enalapril (mean dose $17 \mathrm{mg} /$ day) or losartan (mean dose 77 $\mathrm{mg} /$ day) at equipotent doses. Enalapril decreased plasma levels of all cAMs after 8 weeks of treatment: $c E-s e l e c t i n$ levels decreased by $13 \%(\mathrm{P}=0.007)$, cICAM-1 by $15 \%(\mathrm{P}=0.002)$ and cVCAM-1 by $19 \%(\mathrm{P}=0.003)$. Similarly, enalapril decreased plasma levels of MCP-1 by $13 \%(\mathrm{P}<0.001)$. Losartan did not significantly change cAM or MCP-1 plasma concentrations after 8 weeks of treatment: cE-selectin levels decreased by $3 \%$, cICAM- 1 by $5 \%$, cVCAM- 1 by $8 \%$, whereas MCP-1 increased by $2 \%$ (all $\mathrm{P}=\mathrm{NS}$; not significant). The enalapril effect on percentage changes of cVCAM-1 was significantly different from losartan $(\mathrm{P}=0.0429)$. So, eight weeks of antihypertensive treatment with enalapril but not losartan, significantly decreased plasma levels of cAMs and MCP-1 in hypertensive patients. The somewhat surprising difference between treatment with an ACE-i and an ARB in this paper suggests that the cAM lowering effects of ACE-Is might at least in part due to a mechanism other than inhibition of angiotensin generation and action.

Likewise this, but comparing two ACEis: enalapril and zofenopril [227], authors tested the effectiveness of these two molecules on the cellular redox state (monitored by measuring intracellular reactive oxygen species and thiol status), expression of adhesion molecules, and activation of NF-kB in human umbilical vein endothelial cells (HUVECs). Zofenoprilat, the active form of zofenopril, significantly and dose dependently reduced the intracellular ROS and superoxide formation induced by oxidized low-density lipoprotein $(\mathrm{ox}-\mathrm{LDL})(\mathrm{P}<.001)$ and TNF-alpha $(\mathrm{P}<.001)$. Enalaprilat, the active form of enalapril, was ineffective. Zofenoprilat but not enalaprilat also decreased the consumption of the intracellular GSH induced by ox-LDL $(\mathrm{P}<.01)$ and TNF-alpha $(\mathrm{P}<.01)$. Although zofenoprilat significantly and dose dependently reduced the expression of VCAM-1, ICAM-1, and E-selectin induced by ox-LDL (P 
$<.01)$ and TNF-alpha (P <.01) on HUVECs, enalaprilat did not. OxLDL and TNF-alpha increased the activation of NF-kB and the preincubation of HUVECs with zofenoprilat, but not with enalaprilat, dose dependently reduced its activation ( $\mathrm{P}<.001)$. The author's conclusion is that the sulfhydryl ( $\mathrm{SH})$-containing ACE inhibitors may be useful in inhibiting foam cell formation and thus slow the development of atherosclerosis, hypothesizing a differential antiinflammatory effect inside ACE-i class. It should be noticed, once again, how in trials evaluating effects of ACE-i beyond a clinical setting, without testing the drugs in real condition of over-activation of RAAS such as in hypertensive patients, results found are significantly different, likewise is seen for lack of effectiveness of enalapril in this paper.

In the IMPRESS Trial [228], 107 heart failure patients, New York Heart Association functional class II to III, with left ventricular ejection fraction $<40 \%$, were randomized to either the Vasopeptidase inhibitor (VPI) omapatrilat $40 \mathrm{mg} /$ day or the ACEi lisinopril $20 \mathrm{mg} /$ day. After 24 weeks of follow-up C-terminal atrial natriuretic peptide (C-ANP) levels decreased with lisinopril $(\mathrm{p}=0.035)$, but not with omapatrilat. In contrast, N-terminal ANP levels did not change, and brain natriuretic peptide (BNP) levels tended to decrease similarly in both groups. Endothelin-1 levels increased in both groups. Levels of the proinflammatory cytokine IL-6 tended to decrease, and the anti-inflammatory cytokine IL-10 increased in both groups, with statistical significance only for interleukin-10 with omapatrilat therapy.

Evaluation of anti-inflammatory effect of ACE-i after coronary artery bypass graft surgery (CABG) was the aim of a study designed by Brull et al [229]. Authors recruited 161 patients undergoing elective first time CABG, of whom $41(25 \%)$ were receiving ACE inhibitor treatment. Baseline IL-6 concentrations (geometric mean (SEM)) were non-significantly lower among the patients receiving ACE inhibitors (3.7 (0.1) v $4.3(0.1) \mathrm{pg} / \mathrm{ml}, \mathrm{p}=0.12)$. Overall, post-CABG IL-6 concentrations increased significantly (mean rise 177 (12) pg/ml, p < 0.0005). This response was blunted among ACE inhibitor treated patients. Median increases in IL-6 concentrations were $117 \mathrm{v} 193 \mathrm{pg} / \mathrm{ml}$, for treated $\mathrm{v}$ non-treated patients, respectively (Kruskal-Wallis, $\mathrm{p}=0.02$ ), with peak postoperative IL-6 concentrations lower among the subjects receiving ACE inhibitors than in untreated subjects (142 (19) v 196 (13) pg/ml, p = $0.02)$. The effect of ACE inhibitors remained significant after multivariate analysis $(p=0.018)$. In these data early ACE inhibition after CABG treatment was associated with a reduction of IL- 6 concentration.

In another set of data in patients underwent to CABG was collected by Trevelyan et al [230] comparing effects of enalapril, losartan, or placebo on systemic IL-6, IL-8, IL-10, and IL-1ra levels. Enalapril and losartan significantly decreased release of the IL1ra after CABG. Enalapril produced a highly significant decrease of $51 \%$ in the release of IL-6 in patients identified as high producers of IL- 6 by the $-174 \mathrm{G} / \mathrm{C}$ polymorphism, whereas losartan has a similar but less marked effect. Release of IL-10 was nonsignificantly decreased ( $26 \%$ by enalapril and $21 \%$ by losartan), whereas IL-8 was not detected.

Effects of ACEIs, on inflammatory systemic biomarkers such as CRP were investigated in a small study by Kovacs et al [231]. The authors hypothesized that the magnitude of flow mediated dilatation (FMD) of the brachial artery of post myocardial infarction patients will correlate with serum levels of TNF-alpha, CRP, and that treatment with ACEi will increase FMD by reducing TNFalpha and CRP. Patients were treated with low dose $(10 \mathrm{mg} /$ day $)$ quinapril or enalapril and their effects on FMD and inflammatory markers were evaluated after 8 and 12 weeks. In the Quinapril group, but not in the Enalapril group FMD increased significantly, (to $5.96+1.10 \%$ ), whereas TNF-alpha $(19.0+/-12.21 \mathrm{pg} / \mathrm{ml})$ and CRP (to $3.91+/-1.82 \mathrm{mg} / \mathrm{L}$ ) significantly decreased after 8 and 12 weeks of quinapril treatment. Moreover, the magnitude of FMD showed a strong inverse correlation with serum levels of TNF-alpha and CRP after treatment with quinapril. Thus, in post myocardial infarction the endothelial dysfunction assessed by FMD correlates with elevated levels of plasma inflammatory markers, and low dose quinapril improves endothelial function, likely by reducing vascular inflammation.

Mitrovic et al [232] reported results of an uncontrolled, openlabel study of $10 \mathrm{mg} /$ day of ramipril in 24 subjects with documented atherosclerosis. CRP levels decreased from $3.99 \pm 1.61 \mathrm{mg} / \mathrm{L}$ to $2.72 \pm 1.19 \mathrm{mg} / \mathrm{L}(-32 \%)$ after three months, and this effect was greater in patients not treated with statins.

Di Napoli and Papa [233] conducted a prospective observational study of 507 patients with first-ever ischemic stroke to analyze the effect of ACEi treatment at the time of stroke onset on CRP levels within the first $24 \mathrm{~h}$ and the relationship to outcome. The authors reported that ACEi treatment was associated with lower (2.6-fold; $\mathrm{P}<0.0001)$ median CRP levels and with a reduced 2-year cardiovascular risk (hazard ratio, $0.39 ; 95 \% \mathrm{CI}, 0.29$ to 0.53 ; $\mathrm{P}<0.0001)$ compared with a different BP-lowering regimen. The relationship between ACE inhibitor status and log-normalized CRP levels remained significant $(\mathrm{P}<0.0001)$ after control for important confounding variables and concomitant treatments. The reduced risk was also evident in multivariable analysis when ACE inhibitor treatment was controlled for BP, associated risk factors, neuroradiological findings, and concomitant treatments (hazard ratio, 0.43; $95 \% \mathrm{CI}, 0.30$ to $0.62 ; \mathrm{P}<0.0001)$. This risk reduction was greatly attenuated and not more significant when log-normalized CRP levels were included (hazard ratio, $0.67 ; 95 \% \mathrm{CI}, 0.43$ to 1.04 ; $\mathrm{P}=0.0721$ ) in the model. So, in the specific asset of acute stroke, ACE inhibition seems to be associated with lower inflammatory response and better long-term outcomes, apparently apart from the effects on BP.

In a very interesting small randomized study, Schieffer et al [234] assessed, comparing effects of ACEis and ARBs, whether RAS inhibition elicits anti-inflammatory and antiaggregatory effects in patients with CAD and arterial hypertension six to eight weeks after coronary angioplasty. Patients were randomly assigned to either $20 \mathrm{mg}$ enalapril $(\mathrm{n}=27)$ or $300 \mathrm{mg}$ irbesartan $(\mathrm{n}=21)$ for three months. Both treatment regimens enhanced serum IL-10 levels (IRB $\mathrm{p}<0.001$, ENAL $\mathrm{p}<0.03$ ) and reduced serum MMP-9 protein (IRB $p<0.001$, ENAL $p<0.05$ ) and MMP-9 activity (IRB $\mathrm{p}<0.005$, ENAL $\mathrm{p}<0.05)$. Only IRB reduced serum IL-6 and hsCRP levels significantly compared with baseline $(\mathrm{p}<0.01)$, whereas ENAL did not (hsCRP $p<0.02$ IRB vs. ENAL, $p<0.01$ IRB vs. ENAL). Platelet aggregation was only reduced by IRB ( $p<$ 0.001 , ENAL $\mathrm{p}<0.06$, IRB vs. ENAL $\mathrm{p}<0.001)$ while urine PGE (2) levels remained unchanged. ACE inhibition and AT1 blockade reduced serum MMP-9 protein/activity to a similar extent, and only AT1 blockade reduced hsCRP, IL-6, and platelet aggregation in patients with CAD. Thus, AT1-blockade appears to exert stronger systemic anti-inflammatory and anti-aggregatory effects compared with ACE inhibition. This small trial prefigures the concept of the likely greater anti-inflammatory effect of ARBs in comparison to ACEis that will be better addressed in the latter part of this review.

The peculiar asset of rheumatoid arthritis (RA) and the possible activities of the ACEis and of the statins (hydroxy-methyl-glutarylCoA reductase inhibitors) on the inflammatory markers and endothelial functions in these patients were investigated by Tizik et al [235]. A total of 45 patients with longterm RA were randomized into 3 groups to receive 8 weeks of treatment with placebo $(n=15)$, simvastatin ( $20 \mathrm{mg} / \mathrm{day}, \mathrm{n}=15)$, or quinapril $(10 \mathrm{mg} /$ day, $\mathrm{n}=15)$ as an adjunct to existing antirheumatic drug treatment. CRP, fibrinogen, nitric oxide (NO), and serum cytokine concentrations including IL-1beta, IL-6, and TNF-alpha were measured at baseline and in the post treatment period. Quinapril was found to have no significant effects on inflammatory markers and endothelial vasodilator response. Analysing this interesting report we could speculate 
how inflammation per se do not represent the target of ACE inhibition, that only in presence of RAAS hyperactivation exerts an antiinflammatory effect.

In the CENTRO trial [167], a comparative, multicenter, randomized and double blind, with two parallel groups study, in the same way authors compared the effects of an ACEi, enalapril and an highly selective ARB, candesartan cilexetil, on circulating adhesion molecules in a large sample of patients with non-insulindependent diabetes mellitus (NIDDM), enalapril and Candesartan showed similar effects on blood pressure and on circulating adhesion molecules. Candesartan and enalapril equally reduced circulating level of ICAM-1 and exerted comparable effects on changes of other adhesion molecules and coagulation factors. A similar blood pressure-lowering effect was observed with the two drugs (candesartan: from $148 / 90+/-11 / 8$ to $132 / 82+/-12 / 7 \mathrm{mmHg}, \mathrm{P}<0.01$, enalapril: from $148 / 91+/-12 / 8$ to $131 / 85+/-14 / 6 \mathrm{mmHg}, \mathrm{P}<$ 0.01). Candesartan was more effective than enalapril in the reduction of albuminuria $(\mathrm{P}<0.05$ between treatments), although urinary protein excretion can be considered normal in the majority of patients. So, in this trial, enalapril seem to be equivalent to candesartan, being both effective in reducing circulating adhesion molecules levels in diabetic population.

Even this italian group designed a study aimed to compare the effects of nifedipine GITS $20 \mathrm{mg}$ (Nifedipine gastrointestinal therapeutic system (GITS) $20 \mathrm{mg}$ is a new low-dose formulation with an improved tolerability) and enalapril $20 \mathrm{mg}$ on blood pressure and circulating adhesion molecules in a randomized, double-blind, multicentre trial during 12-week in patients with mild-to-moderate hypertension [214]. Nifedipine GITS $20 \mathrm{mg}$ induced a reduction of clinic blood pressure, which was similar to that observed with enalapril $20 \mathrm{mg}$. Nifedipine GITS and enalapril lowered mean sitting diastolic blood pressure by 11.8 and $12.4 \mathrm{mmHg}$, respectively, while systolic blood pressure was reduced by 15.3 and $16.3 \mathrm{mmHg}$, respectively. Ambulatory blood pressure monitoring-derived blood pressure data showed similar results in both groups without any statistically significant differences between treatments. Both enalapril and nifedipine tended to reduce ICAM-1 and E-selectin, while only nifedipine reduced von Willebrand factor. Both treatments were well tolerated. This trial demonstrated how also other antihypertensive drugs might exert anti-inflammatory effects and, probably, as reported previously, BP reduction per se may lead to a reduction of systemic inflammation.

CRP levels after ACEi therapy was also measured in the Prevention of Events with Angiotensin-Converting Enzyme Inhibition (PEACE) trial [236], in subjects with stable CAD. The trial was a double-blind, placebo-controlled study in which 8290 patients were randomly assigned to receive either trandolapril at a target dose of 4 mg per day (4158 patients) or matching placebo (4132 patients). While CRP was predictive of events, treatment with trandolapril $4 \mathrm{mg}$ per day did not reduce CRP levels. Further, in this trial, in patients with stable coronary heart disease and preserved left ventricular function who are receiving "current standard" therapy and in whom the rate of cardiovascular events is lower than in previous trials of ACE inhibitors in patients with vascular disease, no evidence that the addition of an ACE inhibitor provides further benefit in terms of death from cardiovascular causes, myocardial infarction, or coronary revascularization.

Because vascular inflammation contributes to adverse outcomes following acute myocardial infarction (AMI), Tsikouris et al hypothesized that high-tissue penetrating ACE inhibitors (quinapril) would provide more favourable effects on CRP after AMI compared to low-tissue penetrating ACE inhibitors (enalapril) [237]. After 14 days of follow-up quinapril reduced CRP levels to a lesser extent than enalapril.

In 2009, a similar study, the 4R Trial [238], a 12-week randomized, double-blind, placebo-controlled study, enrolled a total of 264 men and women, with CRP levels of $2 \mathrm{mg} / \mathrm{L}$ or greater and no history of cardiovascular disease. Patients were randomly assigned to receive $10 \mathrm{mg} /$ day of ramipril $(n=132)$ or placebo $(n=132)$ for 12 weeks in order to assess CRP differences between the two groups. The percentage change in geometric mean CRP values over 12 weeks was $-13.2 \%$ in the placebo group compared with $-21.1 \%$ in the ramipril group ( $\mathrm{P}$ nonsignificant), indicating no significant reduction in the primary end point of the trial. Ramipril did not lower CRP levels compared with placebo; probably a larger sample and a longer duration of intervention were necessary to evaluate a parameter such as CRP, as concluded by the authors. The data obtained through these two trials show how the reduction of CRP serum levels as a consequence of ACE inhibition appears no to be as immediate as we can expect. CRP, otherwise from other inflammatory markers is linked and regulated by various factor, and a single intervention correcting one of these, as ACE inhibition is, probably do not reach a significant clinical effect. Obviously, other larger trials are needed to clarify this topic.

The link between ACEi and statin concurrent therapy was tested by Koh in 2005 [239], assuming that because the impact of simvastatin and ramipril therapies on NO bioactivity, oxidant stress, inflammation, endothelial function, and insulin resistance may differ, the combined therapy may have additive beneficial effects that are greater than those observed with either simvastatin or ramipril therapy alone in hypercholesterolemic patients with type 2 diabetes. This was a randomized, double-blind, placebo-controlled crossover trial with 3 treatment arms (each 2 months) and 2 washout periods (each 2 months). Fifty patients with type 2 diabetes were given simvastatin $20 \mathrm{mg}$ and placebo, simvastatin $20 \mathrm{mg}$ and ramipril 10 $\mathrm{mg}$, or ramipril $10 \mathrm{mg}$ and placebo daily during each 2-month treatment period. Ramipril alone or combined therapy significantly reduced blood pressure when compared with simvastatin alone. When compared with ramipril alone, simvastatin alone or combined therapy significantly improved the lipoprotein profile. All 3 treatment arms significantly improved flow-mediated dilator response to hyperemia and reduced plasma levels of malondialdehyde relative to baseline measurements. However, these parameters were changed to a greater extent with combined therapy when compared with simvastatin or ramipril alone $(\mathrm{P}<0.001$ by ANOVA). When compared with simvastatin or ramipril alone, combined therapy significantly reduced high-sensitivity CRP levels $(\mathrm{P}=0.004$ by ANOVA). Interestingly, combined therapy or ramipril alone significantly increased plasma adiponectin levels and insulin sensitivity relative to baseline measurements. These changes were significantly greater than in the group treated with simvastatin alone $(\mathrm{P}<0.015$ by ANOVA). Ramipril combined with simvastatin had beneficial vascular and metabolic effects when compared with monotherapy in patients with type 2 diabetes. Interestingly, furthermore of addressing the issue of the greater efficacy of the association ACEi plus statin this work, for the first time demonstrates that ramipril therapy might increase adiponectin levels, improving both insulin sensitivity and endothelial function by multiple mechanisms.

The effect of the ACEi ramipril on endothelial function and inflammatory process was studied in a group of normotensive subjects with successfully repaired coarctation of the aorta (SCR) in a work by Brili et al [240], Twenty young individuals age $27.3+/-$ 2.4 years old with SCR $13.9+/-2.2$ years previously, received ramipril $5 \mathrm{mg} /$ day for 4 weeks in a randomized, cross-over, controlled trial. Endothelial function was evaluated in the right forearm by gauge-strain plethysmography, and serum levels of IL-1 $\beta$, IL-6, soluble CD40 ligand (sCD40L), and soluble VCAM-1 were determined by enzyme-linked immunosorbent assay. Ramipril improved endothelial function $(\mathrm{p}<0.001)$ and decreased the expression of proinflammatory cytokine IL-6 $(\mathrm{p}<0.05)$ and sCD40L $(\mathrm{p}<0.01)$. Furthermore, ramipril decreased serum levels of sVCAM-1 ( $<$ 0.01 ) but, once again, failed to affect serum levels of CRP. These 
effects were independent of blood pressure lowering. These findings would imply that ramipril treatment may have antiatherogenic effects also in a so peculiar class of subjects such as patients with $\mathrm{SCR}$, even in the absence of arterial hypertension.

The same group, in 2008 [241], compared the effect of the ACEi perindopril with the AT1 blocker irbesartan on endothelial function and the expression of inflammatory markers TNF- $\alpha$, soluble VCAM-1, soluble ICAM-1, E-selectin, hsCRP and fibrinogen, in normotensive patients with CAD. Sixty normotensive patients with stable CAD were randomly allocated into 3 groups, to receive irbesartan $(75 \mathrm{mg} /$ day $)$, perindopril $(2 \mathrm{mg} /$ day $)$ or no antihypertensive agent (control group) for 4 weeks. Both irbesartan and perindopril decreased systolic and diastolic blood pressure, having no effect on pulse pressure and improved maximum hyperemic forearm blood flow. Both fibrinogen and hsCRP were decreased in irbesartan and perindopril-treated groups, while there was no change in the control group. There was no significant difference of the change in fibrinogen or hsCRP between irbesartan and perindopril-treated groups. There was no significant change in serum levels of sICAM-1, sVCAM-1, E-selectin and TNF- $\alpha$ in any of the 3 study groups after treatment. The authors conclude that although low dose irbesartan and perindopril have similar effects on acute phase proteins in normotensive patients with CAD, they fail to affect other inflammatory markers with critical role in atherogenesis. This could be a result of the short treatment period or the consequence of the low dose of the two drugs used in this study, although a differential response of normotensive patients with CAD to these drugs cannot be excluded. These results further confirm the fact that the analysis of available evidences shows an heterogeneity of effects of ACEi on inflammatory markers; this definite variability of effects may be probably related to experimental conditions, dosage of drugs, duration of treatment and characteristic and timing of markers dosage.

The ancillary anti-inflammatory properties of perindopril (4 $\mathrm{mg} /$ day) and enalapril (20 mg/day) vs placebo in normotensive patients with stable CAD was the aim of another study [242]. Plasma lipid profile and the levels of oxidized low density lipoproteins (LDLs), MCP-1, IL-10, CRP, fibrinogen and PAI-1 were determined at the beginning of the study and after 30 and 90 days of treatment. Perindopril significantly reduced plasma levels of oxidized LDLs, CRP, MCP-1, fibrinogen and PAI-1, and increased interleukin-10. The effect of enalapril on these markers of systemic inflammation, hemostasis and oxidative functions was much less pronounced.

In one of the latest trial about anti-inflammatory effects of ACE inhibition, has been tested ACE inhibition with fosinopril analyzing data from the Trial of Angiotensin Converting Enzyme Inhibition and Novel Cardiovascular Risk Factors (TRAIN) study, [243] a double-blind, crossover, randomized, placebo-controlled trial enrolling subjects $\geq 55$ years old with high cardiovascular disease risk profile. Biomarkers of hemostasis (ie, PAI 1, D-dimer), inflammation (ie, CRP, IL-6), and endothelial function (ie, endothelin 1, VCAM 1) were measured at the baseline, at the midterm, and at end of follow-up (after 1 year) clinic visits. No significant differences were reported for CRP, IL-6, PAI-1, VCAM-1, and endothelin 1 levels in the comparisons between fosinopril and placebo interventions. D-dimer was the only biomarker showing a significant difference between fosinopril intervention (median $0.32 \mu \mathrm{g} / \mathrm{mL}$, interquartile range $0.22-0.52 \mu \mathrm{g} / \mathrm{mL}$ ) and placebo (median $0.29 \mu \mathrm{g} / \mathrm{mL}$, interquartile range $0.20-0.47 \mu \mathrm{g} / \mathrm{mL}, \mathrm{P}=.007)$. From analysis of their data authors concluded that ACE inhibition does not significantly modify major biomarkers of inflammation, hemostasis, and endothelial function, although further studies should have confirmed the possible effect of ACE inhibitors on the fibrinolysis pathway [234]. These really discouraging findings might be specifically related to the ACE inhibitor molecule adopted in the TRAIN study (ie, fosinopril). It should not be excluded that different results might be found with the use of other ACEis although there is an overall agreement suggesting the efficacy of individual ACE inhibitors to be equivalent.

In conclusion, actually there is no convincing evidence indicating that ACE inhibitors reduce plasma levels of major inflammatory markers in hypertension models. Lack of evidence concerns especially those inflammation markers, such as fibrinogen of CRP, which are less closely related to atherosclerotic disease and vascular damage and conversely are more aspecific .

Results of the trials showed previously are often heterogeneous and not univocal. Reasons for these discrepancies are unclear but may be related to type and/or dose of medication used, characteristics of population enrolled (different in almost any trial), comorbility, severity of hypertension or diabetes or CAD, entity of cardiovascular risk, baseline inflammatory state, and presence of other confounding pro-inflammatory conditions.

Trying to understand this lack of certain effectiveness of ACEinhibition on inflammation mechanisms, the main element suggested is the target of the effects of these drugs: against ACE and not directly affecting the Ang II activity, which is more strictly implicated in the increased inflammatory status in hypertensives and in all the conditions associated to increased Ang II levels. Further investigations are required to evaluate whether ACE inhibition exerts significant anti-inflammatory effects both in hypertensive patients and in other clinical model of cardiovascular and metabolic diseases.

\section{PART V - ANTI-INFLAMMATORY EFFECTS OF ARBS}

Similarly to what happened for ACEis, animal studies using ARBs showed a significant reduction of BP levels and of the progression of atherosclerotic damage. In studies in hypercholesterolemic monkeys, losartan and olmesartan reduced fatty streak formation in the aorta, with a corresponding decrease in the levels of the inflammatory biomarkers. [244,245]. It is important to note that no differences of blood pressure values were noted between controls and drug-treated animals in either of these studies, suggesting that the anti-inflammatory and antiatherogenic actions of these two ARBs were independent of their effects on blood pressure. Differently from ACE inhibitors, the protective effect of ARBs was observed at both high and low doses suggesting a possible dosedependent effect not confirmed afterwards.

Support for the anti-inflammatory effects of ARBs is provided by in vitro data showing that the exposure of human monocytes to irbesartan or losartan dose dependently inhibited the production of MCP-1, as well as low-density lipoprotein cholesterol and plasma activating factor-stimulated MCP-1 expression. [246].

Anti-inflammatory effects exerted by the ARB valsartan in mononuclear cells of normal subjects are reported by Dandona et al in 2003 [247]. In view of the pro-oxidant and proinflammatory effects of ang II, authors have tested the hypothesis that the ARB valsartan, may exert a suppressive action on ROS generation, NF$\kappa \mathrm{B}$ in mononuclear cells. Four groups of eight normal subjects were given 1) $160 \mathrm{mg}$ daily of valsartan, 2) $80 \mathrm{mg}$ daily of simvastatin, 3) $40 \mathrm{mg}$ quinapril, or 4) no treatment. Fasting blood samples were obtained before treatment and at $\mathrm{d} 1,8$, and 14 ( $7 \mathrm{~d}$ after the cessation of the drug). After valsartan, ROS generation by polymorphonuclear cells and mononuclear cells fell significantly by more than $40 \%(\mathrm{P}<0.01)$. NF- $\mathrm{kB}$ binding activity and the expression of total cellular p65, a protein component of NF- $\mathrm{kB}$, fell significantly $(\mathrm{P}<0.01)$. The expression of inhibitor $\kappa \mathrm{B}(\mathrm{I}-\kappa \mathrm{B})$ increased significantly $(\mathrm{P}<0.05)$. Plasma $\mathrm{CRP}$ concentration fell significantly $(\mathrm{P}<$ 0.01 ). All indices, except I $\kappa B$, reverted toward baseline, $7 \mathrm{~d}$ after the cessation of the drug. I- $\kappa$ B persisted in an elevated state. Neither quinapril nor simvastatin given for seven days produced a suppression of ROS generation, intranuclear NF-kB, p65, or CRP, and these two agents did not alter cellular I- $\kappa \mathrm{B}$ either. The untreated controls also did not demonstrate a change in their ROS generation 
or NF- $\kappa \mathrm{B}$ binding activity or plasma CRP concentration. The conclusions were that valsartan at a modest dose exerts a profound and rapid ROS and inflammation-suppressive effect that may be relevant to its potential beneficial effects in atherosclerosis, diabetes, and congestive cardiac failure. In contrast, quinapril and simvastatin produced no similar effect over the period of one week. These observations may also extend the effects of valsartan to all the clinical situations in which a rapid ant-inflammatory effect is required.

The relationship about the taking of different class of antihypertensive drugs and serum CRP levels was investigated by Palmas et al among participants with treated hypertension in the MultiEthnic Study of Atherosclerosis [248] (see Table 4). The study was a cross-sectional study of hypertensive participants free of clinical cardiovascular disease who were taking one or more of the following medication classes: beta-blockers, calcium channel blockers, diuretics, and ACEi or ARBs. Among 2340 participants taking one or more antihypertensive medications, the mean serum CRP level was lower among participants taking a beta-blocker than among those not taking a beta-blocker $(2.13 \mathrm{v} 2.54 \mathrm{mg} / \mathrm{L}, \mathrm{P}=.002)$. This difference persisted after multivariate adjustment $(\mathrm{P}=.021)$. Among 1314 participants receiving monotherapy, the multivariate adjusted mean CRP level among participants taking a beta-blocker was lower $(1.97 \mathrm{mg} / \mathrm{L})$ than those taking a diuretic $(2.72 \mathrm{mg} / \mathrm{L}, \mathrm{P}<$ .001). In this monotherapy group, participants taking an ACE inhibitor or ARB also had a lower adjusted mean CRP $(2.25 \mathrm{mg} / \mathrm{L})$ than those taking a diuretic $(\mathrm{P}=.046)$. African-American race/ethnicity did not modify any of those relationships. In conclusion the use of beta-blocker was associated with lower CRP levels overall and among participants on monotherapy, whereas ACE inhibitor and ARB use was associated with lower CRP levels among participants on monotherapy.

In a small group of hypertensive patients resistance arteries obtained from subcutaneous biopsies were studied before and after one year of treatment with either the ARB losartan and the $\beta$ blocker atenolol and compared to those of normotensive controls [249]. Despite similar reduction in BP, losartan normalized endothelium-dependent relaxation (acetylcholine-induced) and reduced media/lumen ratio whereas atenolol had no effect.

Effectiveness of losartan in reducing circulating levels of adhesion molecules and ameliorating endothelial dysfunction in eighteen healthy older subjects was tested in a study published in 2002 [250]. Patients were prospectively randomized in a double-blind, crossover fashion to receive either losartan $50 \mathrm{mg} /$ day or placebo for 6 weeks. Subjects were switched to the opposite arm after a 2week washout period. Flow-mediated dilation (FMD) in the brachial artery and plasma levels of VCAM-1 and ICAM-1, MCP-1, and E-selectin were measured in both arms at the beginning and end of the 6-week period. Losartan resulted in a 6-mm $\mathrm{Hg}$ decrease in systolic blood pressure (from $130+/-12$ to $124+/-13 \mathrm{~mm} \mathrm{Hg}$ ), which was no different from placebo $(132+/-12$ to $127+/-13 \mathrm{~mm}$ $\mathrm{Hg}$ ). FMD increased from $3.1+/-0.6 \%$ to $3.9+/-0.6 \%$ after losartan, and decreased from $3.3+/-0.3 \%$ to $2.4+/-0.6 \%$ after placebo ( $\mathrm{p}=\mathrm{NS}$ for both). In contrast, losartan reduced circulating concentrations of VCAM-1 $(750+/-73$ to $572+/-39)$, ICAM-1 $(405+/-$ 26 to $196+/-10)$, and MCP-1 (560 +/- 56 to $423+/-35)$ (p <0.01 for all by analysis of variance), but not E-selectin. Thus, vascular benefit of administration of losartan for a duration of 6 weeks was not univocal in healthy older subjects, infact the ARB has favourable effects on inflammatory markers, but does not alter peripheral conduit endothelial function.

Another similar study regarding the ARB losartan has been developed by Sardo et al, in 2004 [251]. The study was designed to determine whether the levels of sICAM-1 and TNF-alpha were elevated in subjects with uncomplicated hypertension without other risk factors or evidence of athero-sclerosis. Twenty hypertensive subjects without other risk factors or cardiovascular disease re- ceived placebo for 4 weeks, then were treated with losartan (50 $\mathrm{mg}$ /day) for 24 weeks. After 4, 12, and 24 weeks of losartan treatment, sICAM-1 and TNF-alpha levels were measured. The same parameters were measured in 20 normotensive control subjects (C), matched for sex and age. HT had sICAM-1 and TNF-alpha basal values higher than $\mathrm{C}$ (respectively $351.7+/-97.4$ vs $201.6+/-32.3$ $\mathrm{ng} / \mathrm{mL}, \mathrm{p}<0.001$ and $31.8+/-2.4$ vs $15.3+/-2.2 \mathrm{pg} / \mathrm{mL}, \mathrm{p}<0.001)$. Losartan treatment caused a significant decrease of sICAM-1 levels at the end of the first month of treatment $(300.2+/-64.4 \mathrm{ng} / \mathrm{mL}$, $\mathrm{p}<0.05$ ), but the values reverted to the basal levels at the following time points. No variation of TNF-alpha levels during losartan treatment was observed. These results show that patients with uncomplicated mild essential hypertension presented with high plasma ICAM-1 and TNF-alpha concentrations. Although all the patients were responsive to the antihypertensive treatment with losartan, their plasma concentrations of TNF-alpha were not modified and sICAM-1 concentrations decreased only for a short period of time. This suggests that in uncomplicated hypertension other factors besides the blood pressure modulate the endothelial inflammation.

Another interesting report regarding the ARB losartan regarding the relationship between CRP and AT1 receptors and the pharmacological modulation of this was published in 2003 [252]. In this paper were examinated the effects of losartan on vascular smooth muscle (VSM) migration, proliferation, and ROS production CRPmediated. From analysis of data collected the authors concluded that CRP, at concentrations known to predict cardiovascular events, upregulates AT1-R-mediated atherosclerotic events in vascular smooth muscle in vitro and in vivo. CRP, furthermore, promoted VSM migration and proliferation in vitro and increased ROS production. So, CRP would act potentiate the effects of Ang II on these processes. In the rat carotid artery angioplasty model, exposure to CRP resulted in an increase in cell migration and proliferation, collagen and elastin content, and AT1-R expression, as well as an increase in neointimal formation; all these effects were attenuated by losartan, that would have a marked anti-inflammatory behaviour in this area.

Trying to address the issue if the ARB irbesartan was able to interfere in the atherosclerotic progression trough a supposed antiinflammatory effect, Navalkar et al [118] designed a study aimed to test effects of irbesartan on specific inflammatory markers included solubilized tumor necrosis factor-alpha receptor II (sTNF-aRII), VCAM-1 and superoxide in atherosclerotic subjects. With a crosssectional study design, 33 normotensive patients with stable CAD were treated with irbesartan for a 24 -week period. These patients were compared against a control population with no known coronary atherosclerosis. serum levels of soluble VCAM-1 were significantly increased at interval 0 weeks compared to corresponding levels in control patients $(466.6 \pm 69.7 \mathrm{ng} / \mathrm{dl} \mathrm{vs} .331 .6 \pm 39.5 \mathrm{ng} / \mathrm{dl}$ at 0 weeks). The graph also indicates serum VCAM-1 levels decreased significantly in patients with CAD treated with irbesartan as compared against control patients over the 24-week study interval $(325.3 \pm 42.3 \mathrm{ng} / \mathrm{dl}$ vs. $466.6 \pm 69.7 \mathrm{ng} / \mathrm{dl}$ at 24 weeks). Patients with CAD had an elevated level of TNF-a RII at the zero time interval as compared with their control counterparts $(319.15 \pm 30.2$ $\mathrm{ng} / \mathrm{dl}$ vs. $221 \pm 63.5 \mathrm{ng} / \mathrm{dl}$ ). Treatment with irbesartan in the population of patients with CAD significantly reduced TNF-aRII levels to those of the control population $(227 \pm 27.9 \mathrm{ng} / \mathrm{dl}$ vs. $221 \pm 63.5$ $\mathrm{ng} / \mathrm{dl}$ at 24 weeks). In brief, treatment with irbesartan in these patients significantly reduced levels of inflammatory molecules measured. Soluble VCAM-1 levels were reduced by $36 \%$; soluble TNFalpha levels were reduced by $54 \%$ and superoxide level decreased by $52 \%$. Maximal suppression of inflammatory markers by irbesartan therapy in patients with CAD was seen at 12 weeks.

Telmisartan, regarding its characteristics, appear to be the most peculiar member of the ARB family, infact its ability to partially activate the nuclear hormone receptor peroxisome proliferatoractivated receptor gamma (PPAR $\gamma)$ at concentrations typically 
Table 4. Selected Studies Evaluating Anti-inflammatory Effects of Angiotensin Receptor Blockers

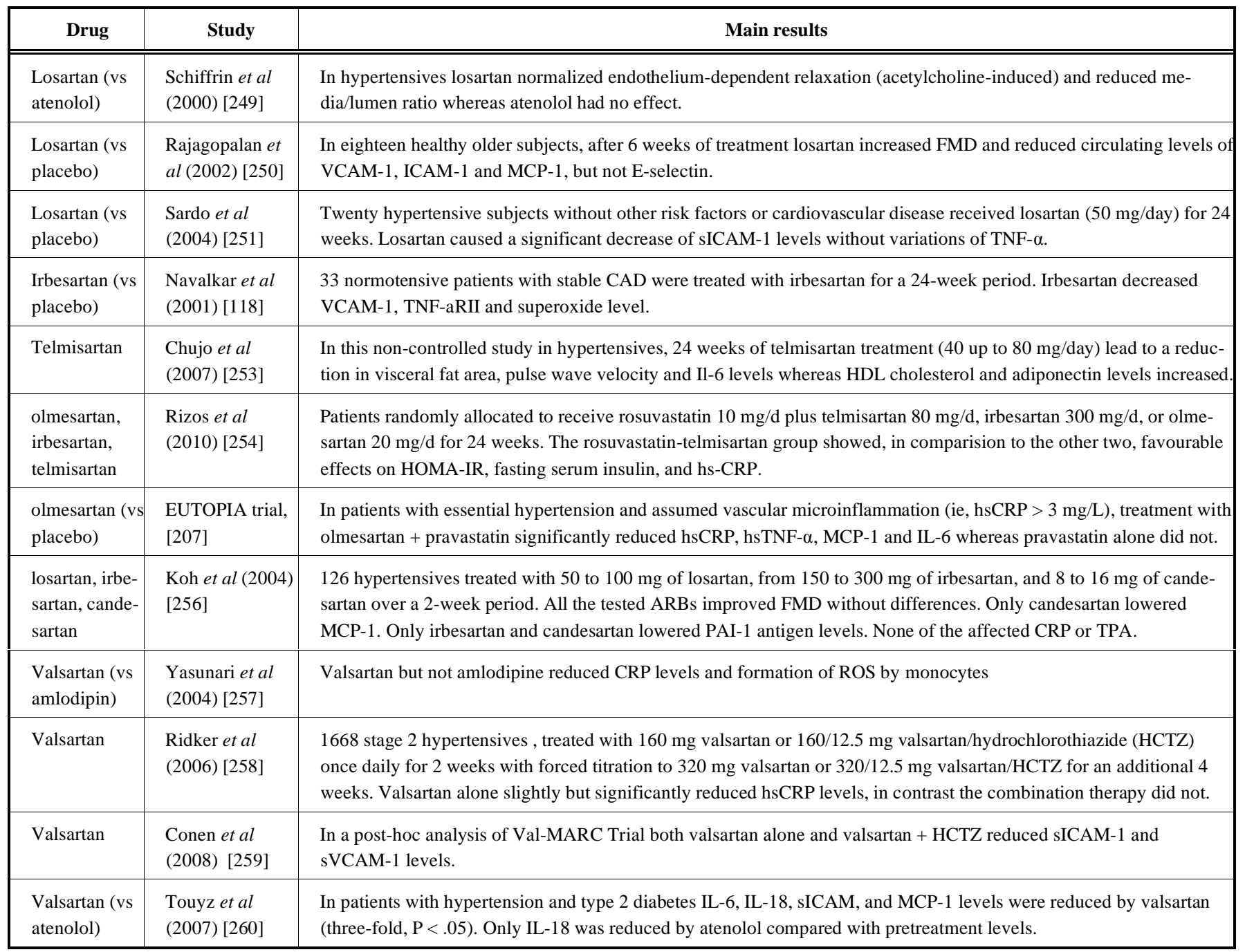

FMD: Flow Mediated Dilatation; ICAM-1: intercellular adhesion molecule-1; VCAM-1: vascular adhesion molecule-1; MCP-1: monocyte chemoattractant protein-1; TNF- $\alpha$ : Tumo Necrosis Factor- $\alpha$; CAD: coronary artery disease; TNF-aRII; tumor necrosis factor- $\alpha$ receptor II; HDL: High Density Lipoprotein; HOMA-IR: homeostasis model assessment of insulin resistance; hs-CRP: high-sensitivity C-reactive protein; PAI-1: plasminogen activator inhibitor; TPA: tissue plasminogen activator;

achieved in plasma with conventional oral dosing, would mediate several additional metabolic effects beyond BP reduction, such as improvement of insulin sensitivity. Chujo et al [253] studied the effects of telmisartan treatment on visceral fat, serum adiponectin and vascular inflammation markers in Japanese hypertensive patients. This was an open-label, non-controlled study with a total duration of 24 weeks. Twenty-eight essential hypertensive patients (22 men and 6 women; age $60.6+/-1.9$ years; body mass index [BMI] $25.5+/-0.6 \mathrm{~kg} / \mathrm{m}^{2}$ ) participated. Fat area was assessed with computerized tomography. All the subjects were started on telmisartan $40 \mathrm{mg} / \mathrm{day}$, which was increased to $80 \mathrm{mg} /$ day to achieve the blood pressure target of less than 130/80 $\mathrm{mmHg}$. There were significant reductions in visceral fat area (from $103.1+/-7.9$ to $93.3+/-8.4 \mathrm{~cm}^{2}, \mathrm{p}<0.01$ ) and pulse wave velocity (from $1,706+/-52$ to $1,587+/-51 \mathrm{~cm} / \mathrm{s}, \mathrm{p}<0.01)$ at 24 weeks. In contrast, significant increases in serum high-density lipoprotein cholesterol (from $5.06+/-0.15$ to $5.32+/-0.13 \mathrm{mmol} / \mathrm{L}, \mathrm{p}<0.05)$ and adiponectin levels (from $8.27+/-0.76$ to $9.13+/-0.81 \mathrm{microg} / \mathrm{mL}, \mathrm{p}<0.05$ ) were observed. Also, there were reductions in the interleukin-6 level (from $2.26+/-0.27$ to $1.60+/-0.14 \mathrm{pg} / \mathrm{mL}, \mathrm{p}<0.01)$. Authors concluded that treatment with telmisartan was associated with an improvement of vascular inflammation, a reduction of visceral fat and an increase in serum adiponectin.

An interesting work evaluating ancillary effects of ARBs in addiction to rosuvastatin on inflammation and glucose metabolism was published recently [254]. In this paper are assumed different degrees of efficacy of the three ARBs added to rosuvastatin (olmesartan, irbesartan, or telmisartan) on PPAR $\gamma$ activity. Infact if telmisartan is a partial activator of PPAR $\gamma$, irbesartan is a weak partial activator, and olmesartan has no effect on PPAR $\gamma$ activation. This was a 24-week, randomized, open-label study. After 12 weeks of dietary intervention, patients were randomly allocated to receive rosuvastatin $10 \mathrm{mg} / \mathrm{d}$ plus telmisartan $80 \mathrm{mg} / \mathrm{d}$ (RT group), irbesar$\tan 300 \mathrm{mg} / \mathrm{d}$ (RI group), or olmesartan $20 \mathrm{mg} / \mathrm{d}$ (RO group) for 24 weeks. The primary end point was change in the following indices of glucose metabolism after 6 months of treatment: FPG, homeostasis model assessment of insulin resistance (HOMA-IR), HOMA of beta-cell function (HOMA-B), and glycosylated hemoglobin $(\mathrm{HbA} 1 \mathrm{c})$. Secondary end points included changes in anthropometric variables, blood pressure, serum lipids, and hs-CRP. Tolerability was monitored throughout the study. The rosuvastatin-telmisartan group showed, in comparison to the other two, favourable effects on HOMA-IR, fasting serum insulin, and hs-CRP. 
In the EUTOPIA trial, involving the ARB olmesartan medoxomil, [207], authors evaluated anti-inflammatory effects of this ARB alone and in cotherapy with the HMG-CoA reductase inhibitor pravastatin in patients with essential hypertension and assumed vascular microinflammation (ie, hsCRP $>3 \mathrm{mg} / \mathrm{L}$ ). It was a prospective, double-blind, placebo-controlled, multicenter study, in which has been measured a panel of inflammation biomarkers, hsCRP, high-sensitivity TNF- $\alpha$, IL- 6 , ICAM-1, band MCP-1. The primary study objective was to evaluate the anti-inflammatory effect of olmesartan alone and in combination with pravastatin. Blood pressure control was achieved with addition of hydrochlorothiazide. Olmesartan treatment had already significantly reduced serum levels of hsCRP $(-15.1 \%$; P<0.05), hsTNF-alpha $(-8.9 \%$; P<0.02), IL-6 $(-14.0 \% ; \mathrm{P}<0.05)$, and MCP-1 $(-6.5 \%$; $\mathrm{P}<0.01)$ after 6 weeks of therapy, whereas placebo treatment (ie, blood pressure reduction) had no major effect on inflammation markers. After 12 weeks of therapy, hsCRP $(-21.1 \% ; \mathrm{P}<0.02)$, hsTNF-alpha $(-13.6 \% ; \mathrm{P}<0.01)$, and IL-6 $(-18.0 \% ; \mathrm{P}<0.01)$ decreased further with olmesartan and pravastatin cotherapy, but treatment with pravastatin alone (ie, cotherapy with placebo) did not significantly alter inflammation markers. In contrast, addition of pravastatin led to a significant $(\mathrm{P}<0.001)$ reduction in LDL cholesterol serum concentrations in the olmesartan and placebo treatment groups $(-15.1 \%$ and $-12.1 \%$, respectively). In this study, treatment with olmesartan significantly reduced a panel of inflammation markers currently used to characterize vascular inflammation such as hsCRP, hsTNF- $\alpha$, and IL-6, whereas pravastatin monotherapy did not significantly alter levels of inflammation markers. After 12 weeks of therapy with olmesar$\tan$, the hsCRP level was reduced by $>20 \%$, whereas blood pressure reduction in the placebo treatment group had only minor or no effect on inflammation markers. The absence of any effect exerted by the HMG-CoA reductase inhibitor pravastatin on inflammatory markers found in this study do not reflect other brilliant results showed, for example, by rosuvastatin on CRP levels during the JUPITER study [255]. Furthermore, in the same trial [207], confirming the anti-atherogenetic properties of ARB-blocking drugs, olmesartan significantly reduces levels of Osteopontin $(\mathrm{p}<0.001)$. Osteopontin (OPN; or secreted phosphoprotein 1 [Spp1]), a pleiotropic cytokine that is broadly expressed and upregulated during inflammation, that has been implicated as a key factor in the development of atherosclerosis.

The comparison of the effects of three different ARBs (losartan, irbesartan, and candesartan) on endothelium-dependent vasomotor responsiveness, oxidant stress, and on markers of inflammation and fibrinolysis in hypertensive patients was investigated in 2004 by Koh et al [256]. One hundred twenty-six patients with mild to moderate hypertension participated in this study. Study medications were titrated upward from 50 to $100 \mathrm{mg}$ of losartan, from 150 to $300 \mathrm{mg}$ of irbesartan, and 8 to $16 \mathrm{mg}$ of candesartan over a 2-week period if no hypotension (systolic blood pressure $<100 \mathrm{~mm} \mathrm{Hg}$ ) was noted. At the end of this time, participants were receiving either placebo or 1 of the 3 ARBs per day. The patients were seen at >14-day intervals during the study. None was diabetic or a current smoker. Compared with placebo, ARB therapies significantly improved the percent flow-mediated dilator response to hyperemia ( $\mathrm{p}$ $=0.019$ by ANOVA) with no differences among the groups. Compared with placebo or losartan, irbesartan and candesartan therapies significantly lowered plasma levels of plasminogen activator inhibitor type- 1 antigen ( $p=0.001$ by ANOVA) with no differences between the 2. Only candesartan therapy significantly lowered plasma levels of MCP-1 ( $\mathrm{p}=0.004$ by ANOVA) compared with placebo, losartan, and irbesartan. However, ARB therapies did not significantly lower serum levels of CRP ( $p=0.613$ by ANOVA). Compared with placebo, therapy with all of the ARBs did not significantly lower plasma levels of tissue plasminogen activator antigen ( $p=0.297$ by ANOVA). There were no significant correlations between these changes and reduction of systolic blood pressure and between these changes and reduction of diastolic blood pressure.
These data not resolve the controversial data collected in previous trials about this topic.

ARB valsartan reduced CRP levels in a work by Yasunari et al when compared with the CCB amlodipin [257]. In this crosssectional and prospective study, participants were randomly assigned to either the 80-mg valsartan $(\mathrm{n}=52)$ or 5-mg amlodipine ( $\mathrm{n}$ $=52$ ) group and were treated for eight months. The left ventricular mass index (LVMI) was calculated from two-dimensional M-mode echocardiography. Formation of ROS by monocytes was measured by gated flow cytometry. In addition, CRP, plasma renin activity, plasma aldosterone, and traditional risk factors were assessed. Multiple regression analysis showed a significant correlation between LVMI and ROS formation by monocytes and between LVMI and CRP. Treatment reduced BP to a similar extent in both groups. Valsartan significantly reduced LVMI after eight months, but amlodipine had less effect ( $16 \%$ vs. $1.2 \%, \mathrm{n}=50, \mathrm{p}<0.01)$. Formation of ROS by monocytes was reduced to a greater extent with valsartan than with amlodipine ( $28 \%$ vs. $2 \%, \mathrm{n}=50, \mathrm{p}<0.01)$. Valsartan but not amlodipine reduced CRP levels. A significant correlation between changes in ROS formation by monocytes and LVMI or between CRP and LVMI was observed.

In 2006 Ridker published data regarding a CRP reduction through use of ARB valsartan in association or less to HCTZ, addressing the issue of whether BP reduction per se lowers CRP levels, or whether selective antagonism of angiotensin type 1 receptors may have independent effects to reduce CRP levels. [258]. Authors enrolled 1668 stage 2 hypertensives, treated with $160 \mathrm{mg}$ valsartan or $160 / 12.5 \mathrm{mg}$ valsartan/hydrochlorothiazide (HCTZ) once daily for 2 weeks with forced titration to $320 \mathrm{mg}$ valsartan or 320/12.5 $\mathrm{mg}$ valsartan/HCTZ for an additional 4 weeks. After 6 weeks, systolic blood pressure $(-25$ versus $-18 \mathrm{~mm} \mathrm{Hg} ; \mathrm{P}<0.001)$ and diastolic blood pressure $(-14$ versus $-9 \mathrm{~mm} \mathrm{Hg} ; \mathrm{P}<0.001)$ were reduced to a greater degree among those allocated to valsartan/HCTZ than to valsartan monotherapy. The median change in hsCRP was -0.12 $\mathrm{mg} / \mathrm{L}$ among those allocated to valsartan compared with +0.05 $\mathrm{mg} / \mathrm{L}$ among those allocated to valsartan/HCTZ, a $13.3 \%$ difference $(\mathrm{P}<0.001)$; this difference between valsartan and valsartan/HCTZ was present in all subgroups evaluated despite the fact that blood pressure reduction was greater in the combined therapy group. No relationship was observed between hsCRP reduction and blood pressure. In conclusion, valsartan alone slightly but significantly reduced hsCRP levels, in contrast the combination therapy did not reduce CRP levels. Thus, these data support the hypothesis that ARBs may have anti-inflammatory effects independently of the degree of BP reduction. However, the implication of the very small change in CRP found with valsartan vs valsartan plus HCTZ remains unclear, as does the therapeutic importance of this difference, since in the clinic most patients who receive an ARB also receive a thiazide diuretic.

In a subsequent post-hoc analysis, Ridker et al [259], evaluated stage 2 hypertensives in order to assess effectiveness of the ARB valsartan $320 \mathrm{mg}(\mathrm{n}=607)$ or the combination therapy with valsartan/hydrochlorothiazide $320 \mathrm{mg} / 12.5 \mathrm{mg}(\mathrm{n}=581)$ for 6 weeks to evaluate whether valsartan soluble ICAM-1 or soluble VCAM-1. After treatment, median (interquartile range) sICAM-1 levels were reduced by both valsartan alone $(-4(-25$ to 16$) \mathrm{ng} / \mathrm{ml}, \mathrm{p}=0.005)$ and valsartan/hydrochlorothiazide ( $-4(-22$ to 17$) \mathrm{ng} / \mathrm{ml}, \mathrm{p}=0.028)$, such that the between-group difference was not significant $(\mathrm{p}=$ $0.7)$. The median percentage change from baseline was small in both groups $(-1.6 \%$ and $-1.3 \%)$. Median (interquartile range) sVCAM-1 levels were reduced by both valsartan alone (-13 (-70 to 42) $\mathrm{ng} / \mathrm{ml}, \mathrm{p}=0.001)$ and valsartan/hydrochlorothiazide $(-26$ (-88 to 38$), \mathrm{p}<0.001)$; the between-group difference was of borderline significance $(\mathrm{p}=0.051)$. The median percentage change from baseline was small $(-2.1 \%$ and $-4.4 \%)$. The reduction of sICAM-1 and sVCAM-1 was independent of blood pressure reduction $(\mathrm{rs}=0.03$ and $\mathrm{rs}=0.06$ for the relationship of change in systolic blood pres- 
sure with change in sICAM-1 and sVCAM-1, respectively). In contrast to hsCRP, both valsartan and valsartan/hydrochlorothiazide induced reductions of sICAM-1 and sVCAM-1 in the Val-MARC trial. These effects, although statistically significant, were rather small and independent of changes in blood pressure.

Touyz et al, tested the hypothesis that in patients with hypertension and type 2 diabetes, hence with a condition of low-grade systemic inflammation, blood pressure (BP) reduction with the ARB valsartan, or with a beta blocker, atenolol, is associated with a decreased inflammatory response [260]. Normotensive subjects and hypertensive patients with type 2 diabetes (40 to 70 years of age) participated in the study. Patients $(n=28)$ were randomized to double-blind treatment for 1 year with valsartan $(80-160 \mathrm{mg}$ ) or atenolol (50-100 mg) daily, added to previous therapy. Age-matched controls $(\mathrm{n}=12)$ were also studied. Serum levels of cytokines (IL6, IL-18), chemokines (MCP-1), and adhesion molecules (sICAM, sE-selectin) were measured by enzyme-linked immunosorbent assay (ELISA) as indices of systemic and vascular inflammation, before and 1 year after treatment. BP was similarly reduced by valsartan and atenolol. Glycemic control and lipid profiles were comparable in the two groups and did not change significantly with antihypertensive therapy. Serum levels of all inflammatory markers were increased in patients before treatment (by two- to four-fold vs. controls, P < .05). IL-6, IL-18, sICAM, and MCP-1 levels were reduced by valsartan (three-fold, $\mathrm{P}<.05$ ). Only IL-18 was reduced by atenolol compared with pretreatment levels $(\mathrm{P}<.05)$. These data indicate that proinflammatory mediators are significantly increased in hypertensive type 2 diabetic patients and that despite similar BP lowering by valsartan and atenolol and similar glucose levels in both treated groups, global inflammatory status was improved only in the valsartan group. These findings suggest convincingly that antihypertensive treatment, particularly with an ARB, ameliorates inflammatory processes in diabetic hypertensive patients, through effects which are independent of BP and glycemic control. Interestingly these effects appeared to be independent of actions of statin and aspirin, which in their own right have been implicated to have anti-inflammatory properties. This is suggested by the facts that an equal number of patients were taking aspirin in the valsartan and atenolol groups and that more patients in the atenolol group were taking statins than in the valsartan group.

In conclusion, results obtained by trials accomplished using ARBs seem to be more univocal to confirm, although in various extent, an anti-inflammatory effect of drugs blocking AT1 receptor. In order to explore more deeply the modulatory effects on inflammation of a more complete blockage of RAAS, future studies may explore different strategies with a more efficient blockage of the renin-angiotensin-aldosterone system by, for example, simultaneously acting on the ACE and the AT1 angiotensin receptors.

\section{CONCLUSIONS}

Vascular inflammation is widely recognized as a main element of pathophysiology of cardiovascular disease. The hypertensive vascular damage model as well as the atherosclerotic damage, attributes a pathogenetic role to reclutation and activation of inflammation-related cells and to various inflammatory mediators. Thus, although the reduction of BP values is the primary goal necessary for obtain the decrease of cardiovascular events in hypertensive patients, the reduction of low-grade inflammation in hypertension may be an interesting and important target in order to reduce the cardiovascular morbidity and mortality.

Behavioural and pharmacological approaches to control high BP may decrease vascular inflammation independently of BP reduction in patients with hypertension, resulting in reduced cardiovascular events in randomized clinical trials. Many studies have demonstrated that Ang II and other components of the RAA system, such as aldosterone and MR, contribute to the inflammatory response.
Among other antihypertensive agents, RAAS-suppressing drugs have shown more potent anti-inflammatory properties unrelated to BP-lowering effect of this class of drugs, but more probably the result of a direct antagonism of the pro-inflammatory effects induced by angiotensin II.

The different classes of RAAS suppressing agents have different mechanisms of action and different ancillary effects beyond BP reduction. How more we examine the RAA system, so more new questions emerge about its function. ACEis are able to reduce the breakdown of bradykinin, and this molecule can cause the most frequent untoward effects of these drugs (cough, angioedema) but it is believed also as an important contributor to the protective cardiovascular effects exerted by them [261]. How relevant is its contribution to the pleiotropic effects provided by them? Different ACEis exerts different degree of block of the tissue ACE system. How important is this different degree of this difference for the pleiotropic effects? And also: How significant is the role of the AT2 receptor stimulation, as a consequence of the antagonism at the AT1 receptor site [262], in the beneficial therapeutic effects of ARBs?

Nevertheless of these unresolved issues, RCT data clearly demonstrate that the inhibition of the renin-angiotensin system represents a pivotal approach for reducing atherosclerosis and its dramatic complications, such as stroke and myocardial infarction (MI). ACE inhibitors and ARBs are well-established pharmacological tools in both primary and secondary prevention of atherosclerotic cardiovascular disease and part of these results are certainly due to a direct anti-inflammatory activity. The real extent of these effects and the real differences among the different drugs in different pathologic contexts and in various populations need further studies.

Taking into account all the new informations about the drugs controlling the RAAS, although many point may be even clarified, probably the question arose by Chobanian in New England Journal of Medicine not so long ago [263]: "Does it matter how hypertension is controlled?" could now have a more clear answer.

\section{CONFLICT OF INTEREST}

The authors confirm that this article content has no conflicts of interest.

\section{ACKNOWLEDGEMENT}

Declared none.

\section{REFERENCE}

[1] Ross R. Atherosclerosis: an inflammatory disease. N Engl J Med 1999; 340(2): 115-26.

[2] Ridker PM, Hennekens CH, Buring JE, Rifai N. C-reactive protein and other markers of inflammation in the prediction of cardiovascular disease in women. N Engl J Med 2000; 342: 836-43.

[3] Tedgui A, Mallat Z. Cytokines in atherosclerosis: pathogenic and regulatory pathways. Physiol Rew 2006; 86: 515-81

[4] Androulakis ES, Tousoulis D, Papageorgiou N, Tsioufis C, Kallikazaros I, Stefanadis C. Essential hypertension: is there a role for inflammatory mechanisms?. Cardiol Rev 2009; 17(5): 216-21.

[5] Kearney PM, Whelton M, Reynolds K, Muntner P, Whelton PK, He J. Global burden of hypertension: analysis of worldwide data. Lancet $2005 ; 365: 217-23$.

[6] Touyz RM. Molecular and cellular mechanisms in vascular injury in hypertension: role of angiotensin II. Curr Opin Nephrol Hypertens 2005; 14: 125-31

[7] Simon G. Pathogenesis of structural vascular changes in hypertension. J Hypertens 2004; 22: 3-10.

[8] Mancia G, De Backer G, Dominiczak A, et al. Guidelines for the Management of Arterial Hypertension: The Task Force for the Management of Arterial Hypertension of the European Society of Hypertension (ESH) and of the European Society of Cardiology (ESC). J Hypertens 2007; 25(6): 1105-87. 
[9] Johnson RJ, Feig DI, Nakagawa T, Sanchez-Lozada LG, Rodriguez-Iturbe B. Pathogenesis of essential hypertension: historical paradigms and modern insights. J Hypertens 2008; 26: 381-91.

[10] Guyton AC, Coleman TG, Cowley AV Jr, Scheel KW, Manning RD Jr, Norman RA Jr. Arterial pressure regulation. Overriding dominance of the kidneys in long-term regulation and in hypertension. Am J Med 1972; 52: 584-94.

[11] Johnson RJ, Schreiner GF. Hypothesis: the role of acquired tubulointerstitial disease in the pathogenesis of salt-dependent hypertension. Kidney Int 1997; 52: 1169 -79.

[12] Hall JE. The kidney, hypertension, and obesity. Hypertension 2003; 41: 625-33.

[13] Guzik TJ, Hoch NE, Brown KA, et al. Role of the T cell in the genesis of angiotensin II induced hypertension and vascular dysfunction. J Exp Med 2007; 204: 2449-60.

[14] Hoch NE, Guzik TJ, Chen W, et al. Regulation of T cell function by endogenously produced angiotensin II. Am J Physiol Regul Integr Comp Physiol 2009; 296: R208-16.

[15] Dorffel Y, Latsh C, Stuhlmuller B, et al. Preactivation peripheral blood monocytes in patients with essential hypertension. Hypertension 1999; 34: 113-7.

[16] McCarron RM, Wang L, Siren AL, Spatz M, Hallenbeck JM. Monocyte adhesion to cerebromicrovascular endothelial cells derived from hypertensive and normotensive rats. Am J Physiol 1994; 267 : H2491-7.

[17] Schillaci G, Pirro M, Gemelli F, et al. Increased C-reactive protein concentrations in never- treated hypertension: the role of systolic and pulse pressures. J Hypertens. 2003; 21: 1841-6.

[18] Virdis A, Ghiadoni L, Plantinga Y, Taddei S, Salvetti A. C-rective protein and hypertension: is there a causal relationship? Curr Pharm Des. 2007; 13: 1693-8.

[19] Fridovich I. Superoxide anion radical, superoxide dismutases, and related matters. J Biol Chem. 1997; 272: 18515-7.

[20] Powers SK, Nelson WB, Hudson MB. Exercise-induced oxidative stress in humans: Cause and consequences. Free Radic Biol Med. 2010 Dec 16. [Epub ahead of print].

[21] Sies H, Cadenas E. Oxidative stress: damage to intact cells and organs. Philos Trans R Soc Lond B Biol Sci. 1985; 311: 617-31.

[22] Virdis A, Neves MF, Amiri F, Touyz RM, Schiffrin EL. Role of $\mathrm{NAD}(\mathrm{P}) \mathrm{H}$ oxidase on vascular alterations in angiotensin II infused mice. J Hypertens. 2004; 22: 535-42.

[23] Tabet F, Savoia C, Schiffrin EL, Touyz RM. Differential calcium regulation by hydrogen peroxide and superoxide in vascular smooth muscle cells from spontaneously hypertensive rats. J Cardiovasc Pharmacol 2004; 44: 200-8.

[24] Touyz RM. Reactive oxygen species in vascular biology: role in arterial hypertension. Expert Rev Cardiovasc Ther 2003; 1: 99 -106.

[25] San José G, Moreno MU, Oliván S, et al. Functional effect of the p22phox -930A/G polymorphism on p22phox expression and NADPH oxidase activity in hypertension. Hypertension 2004; 44: 163-9.

[26] Moreno MU, San José G, Fortuño A, Beloqui O, Díez J, Zalba G. The C242T CYBA polymorphism of NADPH oxidase is associated with essential hypertension. J Hypertens 2006; 24: 1299-306.

[27] Touyz RM, Tabet F, Schiffrin EL. Redox-dependent signalling by angiotensin II and vascular remodelling in hypertension. Clin Exp Pharmacol Physiol 2003; 30: 860-6.

[28] Cai H. Hydrogen peroxide regulation of endothelial function: origins, mechanisms, and consequences. Cardiovasc Res 2005; 68: 2636.

[29] Kajiya M, Hirota M, Inai Y, et al. Impaired NO-mediated vasodilation with increased superoxide but robust EDHF function in right ventricular arterial microvessels of pulmonary hypertensive rats. Am J Physiol Heart Circ Physiol 2007; 292: H2737-44.

[30] Goyal P, Weissmann N, Grimminger F, et al. Upregulation of $\mathrm{NAD}(\mathrm{P}) \mathrm{H}$ oxidase 1 in hypoxia activates hypoxia-inducible factor 1 via increase in reactive oxygen species. Free Radic Biol Med 2004; 36: $1279-88$

[31] San Martin A, Du P, Dikalova A, et al. Reactive oxygen speciesselective regulation of aortic inflammatory gene expression in type 2 diabetes. Am J Physiol Heart Circ Physiol 2007; 292: H2073-82.

[32] Redon J, Oliva MR, Tormos C, et al. Antioxidant activities and oxidative stress byproducts in human hypertension. Hypertension 2003; 41: 1096-101.
[33] Laude K, Cai H, Fink B, et al. Hemodynamic and biochemical adaptations to vascular smooth muscle overexpression of p22phox in mice. Am J Physiol Heart Circ Physiol 2005; 288: H7-12.

[34] Sen R, Baltimore D. Inducibility of kappa immunoglobulin enhancer binding protein NF-kappa B by a posttranslational mechanism. Cell 1986; 47: 921-8.

[35] de Winther MP, Kanters E, Kraal G, Hofker MH. Nuclear factor kappaB signaling in atherogenesis. Arterioscler Thromb Vasc Biol 2005; 25(5): 904-14.

[36] Ruiz-Ortega M, Lorenzo O, Ruperez M, König S, Wittig B, Egido J. Angiotensin II activates nuclear transcription factor kappaB through AT(1) and AT(2) in vascular smooth muscle cells: molecular mechanisms. Circ Res 2000; 86: 1266-72.

[37] Jiang B, Xu S, Hou X, Pimentel DR, Cohen RA. Angiotensin II differentially regulates interleukin-1 beta inducible NO synthase (iNOS) and vascular cell adhesion molecule-1 (VCAM-1) expression: role of p38 MAPK. J Biol Chem 2004; 279: 20363-8.

[38] Esteban V, Ruperez M, Sanchez-Lopez E, et al. Angiotensin IV activates the nuclear transcription factor-kappaB and related proinflammatory genes in vascular smooth muscle cells. Circ Res 2005 ; 96: 965-73.

[39] Zahradka P, Werner JP, Buhay S, Litchie B, Helwer G, Thomas S. NF-kappaB activation is essential for angiotensin II-dependent proliferation and migration of vascular smooth muscle cells. J Mol Cell Cardiol 2002; 34: 1609-21.

[40] Hickey KA, Rubanyi G, Paul RJ, Highsmith, RF. Characterization of a coronary vasoconstrictor produced by cultured endothelial cells. Am J Physiol 1985; 248: C550-6.

[41] Davie N, Haleen SJ, Upton PD, et al. ET(A) and ET(B)-receptors modulate the proliferation of human pulmonary artery smooth muscle cells. Am J Respir Crit Care Med 2002; 165: 398-405.

[42] Schiffrin EL. Vascular enthothelin in hypertension. Vascul Pharmacol 2005; 43: 19-29.

[43] Amiri F, Paradis P, Reudelhuber TL, Schiffrin EL. Vascular inflammation in absence of blood pressure elevation in transgenic murine model overexpressing endothelin-1 in endothelial cells. J Hypertens 2008; 26: 1102-9.

[44] Verma S, Li SH, Badiwala MV, et al. Endothelin antagonism and interleukin-6 inhibition attenuate the proatherogenic effects of Creactive protein. Circulation 2002; 105: 1890-6.

[45] Hocher B, Schwarz A, Slowinski T, et al. In-vivo interaction of nitric oxide and endothelin. J Hypertens 2004; 22: 111-9.

[46] Ferrario CM, Trask AJ, Jessup JA. Advances in biochemical and functional roles of angiotensin-converting enzyme 2 and angiotensin- (1-7) in regulation of cardiovascular function. Am J Physiol Heart Circ Physiol 2005; 89: H2281-90.

[47] Zhao Q, Ishibashi M, Hiasa K, Tan C, Takeshita A, Egashira K. Essential role of vascular endothelial growth factor in angiotensin II-induced vascular inflammation and remodeling. Hypertension 2004; 44: 264 -70.

[48] Graninger M, Reiter R, Drucker C, Minar E, Jilma B. Angiotensin receptor blockade decreases markers of vascular inflammation. J Cardiovasc Pharmacol 2004; 44(3): 335-9.

[49] Zarbock A, Ley K. Neutrophil adhesion and activation under flow. Microcirculation 2009; 16: 31-42.

[50] Ruiz-Ortega M, Ruperez M, Lorenzo O, et al. Angiotensin II regulates the synthesis of proinflammatory cytokines and chemokines in the kidney. Kidney Int Suppl 2002; 82: S12-22.

[51] Funakoshi Y, Ichiki T, Shimikawa K. Rho-kinase mediates angiotensin-II monocyte chemoattractant protein-1 expression in rat vascular smooth muscle cells. Hypertension 2001; 38: 100-4.

[52] Wang CH, Li SH, Weisel RD, et al. C-reactive protein upregulates angiotensin type 1 receptors in vascular smooth muscle. Circulation 2003; 107: 1783-90.

[53] Shagdarsuren E, Wellner M, Braesen JH, et al. Complement activation in angiotensin II-induced organ damage. Circ Res 2005; 97(7): 716-24.

[54] Rose P, Bond J, Tighe S, et al. Genes overexpressed in cerebral arteries following salt-induced hypertensive disease are regulated by angiotensin II, JunB, and CREB. Am J Physiol Heart Circ Physiol 2008; 294: H1075-85.

[55] Sato H, Watanabe A, Tanaka T. Regulation of tumor necrosis factor-alpha promoter by angiotensin II and lippolysaccharide in cardiac fibroblast: different cis-acting promoter sequence and transcriptional factors. J Moll Cell Cardiol 2003; 35: 1197-205. 
[56] Touyz RM. The role of angiotensin II in regulating vascular structural and functional changes in hypertension. Curr Hypertens Rep 2003; 5: 155-64

[57] Hiyoshi H, Yayama K, Takano M, Okamoto H. Stimulation of GMP production via AT2 and B2 receptors in the pressureoverloaded aorta after banding. Hypertension. 2004; 43: 1258-63.

[58] Flamant M, Placier S, Dubroca C, Esposito B, Lopes I, Chatziantoniou $\mathrm{C}$, et al. Role of matrix metalloproteinases in early hypertensive vascular remodeling. Hypertension 2007; 50: 212-8.

[59] Schmidt-Ott KM, Kagiyama S, Phillips MI. The multiple actions of angiotensin II in atherosclerosis. Regul Pept 2000; 93(1-3): 65-77.

[60] De Ciuceis C, Amiri F, Brassard P, Endemann DH, Touyz R M, Schiffrin EL. Reduced vascular remodeling, endothelial dysfunction, and oxidative stress in resistance arteries of angiotensin IIinfused macrophage colony-stimulating factor-deficient mice: evidence for a role in inflammation in angiotensin induced vascular injury. Arterioscler. Thromb Vasc Biol 2005; 25: 2106-13.

[61] Sadoshima J. Cytokine actions of angiotensin II. Circ Res 2000; 86(12): 1187-9.

[62] Harada E, Yoshimura M, Yasue H, et al. Aldosterone induces angiotensin-converting enzyme gene expression in cultured neonatal rat cardiocytes. Circulation 2001; 104: 137-9.

[63] Joffe HV, Alder KA. Effect of aldosterone and mineralocorticoid receptor blockade on vascular inflammation. Heart Failure Rev 2005; 10: 31-7.

[64] Rocha R, Chander PC, Khanna K, Zuckerman A, Stier Jr CT. Mineralocorticoid blockade reduces vascular injury in stroke-prone hypertensive rats. Hypertension 1998; 31: 451-458.

[65] Fiebeler A, Schmidt F, Muller DN, et al. Mineralocorticoid receptor affects AP-1 and nuclear factor- $\mathrm{KB}$ activation in angiotensin IIinduced cardiac injury. Hypertension 2001; 37: 787-93.

[66] Ammarguellat FZ, Gannon PO, Amiri F, Schiffrin EL. Fibrosis, matrix metalloproteinases, and inflammation in the heart of DOCAsalt hypertensive rats: role of ETA receptors. Hypertension 2002; 39: 679-84

[67] Pu Q, Neves MF, Virdis A, Touyz R, Schiffrin EL. Endothelin antagonism on aldosteroneinduced oxidative stress and vascular remodeling. Hypertension 2003; 42: 49-55

[68] Virdis A, Neves MF, Amiri F, Viel E, Touyz RM, Schiffrin EL. Spironolactone improves angiotensin-induced vascular changes and oxidative stress. Hypertension 2002; 40: 504-10.

[69] Blanco-Rivero J, Cachofeiro V, Lahera V, et al. Participation of prostacyclin in endothelial dysfunction induced by aldosterone in normotensive and hypertensive rats. Hypertension 2005; 46: 10712.

[70] Suzuki J, Iwai M, Mogi M, et al. Eplerenone with valsartan effectively reduces atherosclerotic lesion by attenuation of oxidative stress and inflammation. Arterioscler Thromb Vasc Biol 2006; 26: 917-21.

[71] Neves MF, Amiri F, Virdis A, Diep QN, Schiffrin EL. CIHR Multidisciplinary Research Group on Hypertension. Role of aldosterone in angiotensin II-induced cardiac and aortic inflammation, fibrosis, and hypertrophy. Can J Physiol Pharmacol 2005; 83: 9991006.

[72] Brown NJ. Aldosterone and vascular inflammation. Hypertension 2008; 51: 161-7.

[73] Pickering TG. Stress, inflammation, and hypertension. J Clin Hypertens (Greenwich) 2007; 9: 567-71.

[74] Luther JM, Gainer JV, Murphey LJ, et al. Angiotensin II induces interleukin-6 in humans through a mineralocorticoid receptordependent mechanism. Hypertension 2006; 48: 1050-7.

[75] Takebayashi K, Matsumoto S, Aso Y, Inukai T. Aldosterone blockade attenuates urinary monocyte chemoattractant protein-1 and oxidative stress in patients with type 2 diabetes complicated by diabetic nephropathy. J Clin Endocrinol Metab 2006; 91: 2214-7.

[76] Tigerstedt R, Bergman PG. "Nere und Kreislauf," Skandinavisches Archiv f ur Physiologie, vol. 8, 1898, pp. 223-71.

[77] Piepho RW, Beal J. An overview of antihypertensive therapy in the 20th century. J Clin Pharmacol 2000; 40: 967-77.

[78] Brown MJ. Direct renin inhibition-a new way of targeting the renin system. $J$ Renin Angiotensin Aldosterone Syst 2006; 7(suppl 2): $57-11$.

[79] Morgan L, Broughton PF, Kalsheker N. Angiotensinogen: molecular biology, biochemistry and physiology. Int J Biochem Cell Biol 1996; $28: 1211-22$
[80] Carey RM, Siragy HM. Newly recognized components of the reninangiotensin system: potential roles in cardiovascular and renal regulation. Endocr Rev 2003; 24: 261-71.

[81] Ferraro CM. Angiotensin-converting enzyme 2 and angiotensin-(17): an evolving story in cardiovascular regulation. Hypertension 2006; 47(3): 515-21.

[82] Tamura K, Tanaka Y, Tsurumi Y, et al. The role of angiotensin AT1 receptor-associated protein in renin-angiotensin system regulation and function. Curr Hypertens Rep 2007; 9(2): 121-7.

[83] Nguyen G, Delarue F, Burckle C, Bouzhir L, Giller T, Sraer J-D. Pivotal role of the renin/prorenin receptor in angiotensin II production and cellular responses to renin. J Clin Invest 2002; 109: 141727.

[84] Funder JW. New biology of aldosterone, and experimental studies on the selective aldosterone blocker eplerenone. Am Heart J 2002; 144: S8-11.

[85] Ihara M, Urata $\mathrm{H}$, Kinoshita A, et al. Increased chymase-dependent angiotensin II formation in human atherosclerotic aorta. Hypertension 1999; 33: 1399-405.

[86] Hollenberg NK, Fisher NDL, Price DA. Pathways for angiotensin II generation in intact human tissue: evidence from comparative pharmacological interruption of the renin system. Hypertension 1998; 32: 387-92

[87] Urata H, Healy B, Stewart RW, Bumpus FM, Husain A. Angiotensin II-forming pathways in normal and failing human hearts. Circ Res 1990; 66: 883-90

[88] Wolny A, Clozel JP, Rein J, et al. Functional and biochemical analysis of angiotensin II-forming pathways in the human heart. Circ Res 1997; 80: 219-27.

[89] Pagliaro P, Penna C. Rethinking the renin-angiotensin system and its role in cardiovascular regulation. Cardiovasc Drugs Ther 2005 19: 77-87.

[90] Paul M, Poyan Mehr A, Kreutz R. Physiology of local reninangiotensin systems. Physiol Rev 2006; 86: 747-803.

[91] Danser AH, van Kats JP, Admiraal PJ, et al. Cardiac renin and angiotensins. Uptake from plasma versus in situ synthesis. Hypertension 1994; 24: 37-48.

[92] Westcott KV, Huang BS, Leenen FH. Brain renin-angiotensinaldosterone system and ventricular remodeling after myocardial infarct: a review. Can J Physiol Pharmacol 2009 Dec; 87(12): 979-88.

[93] Nogueira EF, Bollag WB, Rainey WE. Angiotensin II regulation of adrenocortical gene transcription. Mol Cell Endocrinol 2009 Apr 29; 302(2): 230-6

[94] Szekeres M, Turu G, Orient A, et al. Mechanisms of angiotensin IImediated regulation of aldosterone synthase expression in H295R human adrenocortical and rat adrenal glomerulosa cells. Mol Cell Endocrinol 2009; 302(2): 244-53.

[95] van Kats JP, Chai W, Duncker DJ, Schalekamp MADH, Danser AHJ. Adrenal angiotensin: origin and site of generation. Am J Hypertens 2005; 18: 1104-10.

[96] Wong J, Patel RA, Kowey PR. The clinical use of angiotensinconverting enzyme inhibitors. Prog Cardiovasc Dis 2004; 47: 11630.

[97] Brown B, Hall AS. Renin-angiotensin system modulation: the weight of evidence. Am J Hypertens. 2005; 18(9 pt 2): 127S-33S.

[98] Lopez-Sendon J, Swedberg K, McMurray J, et al. for the Task Force on ACE-inhibitors of the European Society of Cardiology. Expert consensus document on angiotensin converting enzyme in hibitors in cardiovascular disease. Eur Heart J 2004; 25: 1454-70.

[99] Pitt B. "Escape" of aldosterone production in patients with left ventricular dysfunction treated with an angiotensin converting enzyme inhibitor: implications for therapy. Cardiovasc Drugs Ther 1995; 9: 145-49.

[100] Atlas SA, Case DB, Yu ZY, Laragh JH. Hormonal and metabolic effects of angiotensin converting enzyme inhibitors: possible differences between enalapril and captopril. Am J Med 1984; 77: 13-7.

[101] Maschio G, Alberti D, Janin G, et al. Effect of the angiotensinconverting- enzyme inhibitor benazepril on the progression of chronic renal insufficiency. N Engl J Med. 1996; 334: 939-45.

[102] Lewis EJ, Hunsicker LG, Bain RP, Rohde RD. for the collaborative study group. The effect of angiotensin-converting-enzyme inhibition on diabetic nephropathy. N Engl J Med 1993; 329: 1456-62.

[103] Frank GJ. The safety of ACE inhibitors for the treatment of hypertension and congestive heart failure. Cardiology 1989; 76 Suppl 2 56-67. 
[104] Goto K, Fujii K, Onaka U, Abe I, Fujishima M. Angiotensinconverting enzyme inhibitor prevents age-related endothelial dysfunction. Hypertension 2000; 36(4): 581-7.

[105] The SOLVD Investigators. Effect of enalapril on mortality and the development of heart failure in asymptomatic patients with reduced left ventricular ejection fractions. N Engl J Med 1992; 327: 685-91.

[106] The SOLVD Investigators Effect of enalapril on survival in patients with reduced left ventricular ejection fractions and congestive heart failure. N Engl J Med 1991; 325: 293-302.

[107] Gruppo Italiano per lo Studio della Sopravvivenza nell'infarto Miocardico. GISSI-3: effects of lisinopril and transdermal glyceryl trinitrate singly and together on 6-week mortality and ventricular function after acute myocardial infarction. Lancet 1994; 343: 111522.

[108] ISIS-4 (Fourth International Study of Infarct Survival) Collaborative Group. ISIS-4: a randomised factorial trial assessing early oral captopril, oral mononitrate, and intravenous magnesium sulphate in 58,050 patients with suspected acute myocardial infarction. Lancet 1995; 345: 669-85.

[109] Pfeffer MA, Braunwald E, Moye LA, et al. Effect of captopril on mortality and morbidity in patients with left ventricular dysfunction after myocardial infarction. Results of the survival and ventricular enlargement trial. The SAVE Investigators. N Engl J Med 1992; 327: 669-77

[110] The Acute Infarction Ramipril Efficacy (AIRE) Study Investigators. Effect of ramipril on mortality and morbidity of survivors of acute myocardial infarction with clinical evidence of heart failure. Lancet 1993; 342: 821-28.

[111] Fox KM; EURopean trial On reduction of cardiac events with Perindopril in stable coronary Artery disease [EUROPA] Investigators. Efficacy of perindopril in reduction of cardiovascular events among patients with stable coronary artery disease: randomised, doubleblind, placebo-controlled, multicentre trial (the EUROPA study). Lancet 2003; 362: 782-88.

[112] Yusuf S, Sleight P, Pogue J, Bosch J, Davies R, Dagenais G. for The Heart Outcomes Prevention Evaluation Study Investigators. Effects of an angiotensin-converting-enzyme inhibitor, ramipril, on cardiovascular events in high-risk patients. N Engl J Med 2000; 342: 145-53.

[113] Hansson L, Lindholm LH, Niskanen L, et al. Effect of angiotensin converting- enzyme inhibition compared with conventional therapy on cardiovascular morbidity and mortality in hypertension: the Captopril Prevention Project (CAPPP) randomised trial. Lancet 1999; 353: 611-16.

[114] Vermes E, Ducharme A, Bourassa MG, Lessard M, White M, Tardif JC. Enalapril reduces the incidence of diabetes in patients with chronic heart failure: insight from the Studies Of Left Ventricular Dysfunction (SOLVD). Circulation 2003; 107: 1291-96.

[115] The PEACE Trial Investigators. Angiotensin-converting-enzyme inhibition in stable coronary artery disease. N Engl J Med 2004; 351: 2058-68.

[116] Ruilope LM, Rosei EA, Bakris GL, et al. Angiotensin receptor blockers: therapeutic targets and cardiovascular protection. Blood Press 2005; 14: 196-209.

[117] Hernandez-Hernandez R, Sosa-Canache B, Velasco M, ArmasHernandez MJ, Armas-Padilla MC, Cammarata R. Angiotensin II receptor antagonists role in arterial hypertension. J Hum Hypertens 2002; 16(suppl 1): S93-9.

[118] Navalkar S, Parthasarathy S, Santanam N, Khan BV. Irbesartan, an angiotensin type 1 receptor inhibitor, regulates markers of inflammation in patients with premature atherosclerosis. J Am Coll Cardiol 2001; 37: 440-44.

[119] Baguet JP, Asmar R, Valensi P, Nisse-Durgeat S, Mallion JM. Effects of candesartan cilexetil on carotid remodeling in hypertensive diabetic patients: the MITEC study. Vasc Health Risk Manag 2009; 5: 175-83.

[120] Al Khalaf MM, Thalib L, Doi SA. Cardiovascular outcomes in high-risk patients without heart failure treated with ARBs: a systematic review and meta-analysis. Am J Cardiovasc Drugs 2009; 9: 29-43.

[121] Wang JG, Li Y, Franklin SS, Safar M. Prevention of stroke and myocardial infarction by amlodipine and angiotensin receptor blockers: a quantitative overview. Hypertension 2007; 50: 181-8.

[122] Kunz R, Friedrich C, Wolbers M, Mann JF. Metaanalysis: effect of monotherapy and combination therapy with inhibitors of the renin angiotensin system on proteinuria in renal disease. Ann Intern Med 2008; 148: 30-48.

[123] Sarafidis PA, Stafylas PC, Kanaki AI, Lasaridis AN. Effects of renin-angiotensin system blockers on renal outcomes and all-cause mortality in patients with diabetic nephropathy: an updated metaanalysis. Am J Hypertens 2008; 21: 922-9.

[124] Jennings DL, Kalus JS, Coleman CI, Manierski C, Yee J. Combination therapy with an ACE inhibitor and an angiotensin receptor blocker for diabetic nephropathy: a meta-analysis. Diabet Med 2007; 24: 486-93.

[125] Lakhdar R, Al-Mallah MH, Lanfear DE. Safety and tolerability of angiotensin-converting enzyme inhibitor versus the combination of angiotensinconverting enzyme inhibitor and angiotensin receptor blocker in patients with left ventricular dysfunction: a systematic review and meta-analysis of randomized controlled trials. J Card Fail 2008; 14: 181-8.

[126] Fagard RH, Celis H, Thijs L, Wouters S. Regression of left ventricular mass by antihypertensive treatment: a meta-analysis of randomized comparative studies. Hypertension 2009; 54: 1084-91.

[127] Dimopoulos K, Salukhe TV, Coats AJ, Mayet J, Piepoli M, Francis DP. Metaanalyses of mortality and morbidity effects of an angiotensin receptor blocker in patients with chronic heart failure already receiving an ACE inhibitor (alone or with a beta-blocker). Int J Cardiol 2004; 93: 105-11.

[128] Siragy HM. Angiotensin receptor blockers: how important is selectivity? Am J Hypertens 2002; 15: 1006-14.

[129] Elmfeldt D, Olofsson B, Meredith P. The relationships between dose and antihypertensive effect of four AT1-receptor blockers. Differences in potency and efficacy. Blood Press 2002; 11: 293301.

[130] Uchiyama-Tanaka Y, Mori Y, Kishimoto N, et al. Comparison of the effects of quinapril and losartan on carotid artery intima-media thickness in patients with mild-to-moderate arterial hypertension. Kidney Blood Press Res 2005; 28: 111-6.

[131] Flammer AJ, Hermann F, Wiesli P, et al. Effect of losartan, compared with atenolol, on endothelial function and oxidative stress in patients with type 2 diabetes and hypertension. J Hypertens 2007; 25: 785-91.

[132] Ichihara A, Hayashi M, Kaneshiro Y, et al. Low doses of losartan and trandolapril improve arterial stiffness in hemodialysis patients. Am J Kidney Dis 2005; 45: 866-74.

[133] Park JB, Intengan HD, Schiffrin EL. Reduction of resistance artery stiffness by treatment with the AT(1)-receptor antagonist losartan in essential hypertension. J Renin Angiotensin Aldosterone Syst 2000; 1: $40-45$.

[134] Rehman A, Ismail SB, Naing L, Roshan TM, Rahman AR. Reduction in arterial stiffness with angiotensin II antagonism and converting enzyme inhibition. A comparative study among Malay hypertensive subjects with a known genetic profile. Am J Hypertens 2007; 20: 184-9.

[135] Dahlöf B, Devereux RB, Kjeldsen SE, et al. Cardiovascular morbidity and mortality in the Losartan Intervention For Endpoint Reduction in Hypertension study (LIFE): a randomised trial against atenolol. Lancet 2002; 359: 995-1003.

[136] Kjeldsen SE, Dahlof B, Devereux RB, et al. Effects of losartan on cardiovascular morbidity and mortality in patients with isolated systolic hypertension and left ventricular hypertrophy: a Losartan Intervention for Endpoint Reduction (LIFE) substudy. JAMA 2002; 288: 1491-8.

[137] Okin PM, Devereux RB, Jern S, et al. Regression of electrocardiographic left ventricular hypertrophy by losartan versus atenolol: The Losartan Intervention for Endpoint reduction in Hypertension (LIFE) study. Circulation 2003; 108: 684-90.

[138] Devereux RB, Dahlöf B, Gerdts E, et al. Regression of hypertensive left ventricular hypertrophy by losartan compared with atenolol: the Losartan Intervention for Endpoint Reduction in Hypertension (LIFE) trial. Circulation 2004; 110: 1456-62.

[139] Dickstein K, Kjekshus J. Effects of losartan and captopril on mortality and morbidity in highrisk patients after acute myocardial infarction: the OPTIMAAL randomised trial. Optimal Trial in Myocardial Infarction with Angiotensin II Antagonist Losartan. Lancet 2002; 360: 752-60.

[140] Kizer JR, Dahlöf B, Kjeldsen SE, et al. Stroke reduction in hypertensive adults with cardiac hypertrophy randomized to losartan versus atenolol: the Losartan Intervention For Endpoint Reduction in Hypertension study. Hypertension 2005; 45: 46-52. 
[141] Pitt B, Segal R, Martinez FA, et al. Randomised trial of losartan versus captopril in patients over 65 with heart failure (Evaluation of Losartan in the Elderly Study, ELITE). Lancet 1997; 349: 747-52.

[142] Konstam MA, Patten RD, Thomas I, et al. Effects of losartan and captopril on left ventricular volumes in elderly patients with heart failure: results of the ELITE ventricular function substudy. Am Heart J 2000; 139: 1081-7.

[143] Pitt B, Poole-Wilson PA, Segal R, et al. Effect of losartan compared with captopril on mortality in patients with symptomatic heart failure: randomised trial - the Losartan Heart Failure Survival Study ELITE II. Lancet 2000; 355: 1582-7.

[144] Wachtell K, Lehto M, Gerdts E, et al. Angiotensin II receptor blockade reduces new-onset atrial fibrillation and subsequent stroke compared to atenolol: the Losartan Intervention For Endpoint Reduction in Hypertension (LIFE) study. J Am Coll Cardiol 2005; 45: 712-9.

[145] Brenner BM, Cooper ME, de Zeeuw D, et al. RENAAL Study Investigators. Effects of losartan on renal and cardiovascular outcomes in patients with type 2 diabetes and nephropathy. $\mathrm{N}$ Engl J Med 2001; 345: 861-9.

[146] Iino Y, Hayashi M, Kawamura T, et al. Japanese Losartan Therapy Intended for the Global Renal Protection in Hypertensive Patients (JLIGHT) Study Investigators. Renoprotective effect of losartan in comparison to amlodipine in patients with chronic kidney disease and hypertension - a report of the Japanese Losartan Therapy Intended for the Global Renal Protection in Hypertensive Patients (JLIGHT) study. Hypertens Res 2004; 27: 21-30.

[147] Hou FF, Xie D, Zhang X, et al. Renoprotection of Optimal Antiproteinuric Doses (ROAD) study: a randomized controlled study of benazepril and losartan in chronic renal insufficiency. J Am Soc Nephrol 2007; 18: 1889-98.

[148] Karalliedde J, Smith A, DeAngelis L, et al. Valsartan improves arterial stiffness in type 2 diabetes independently of blood pressure lowering. Hypertension 2008; 51: 1617-23.

[149] Serebruany VL, Pokov AN, Malinin AI, et al. Valsartan inhibits platelet activity at different doses in mild to moderate hypertensives: Valsartan Inhibits Platelets (VIP) trial. Am Heart J 2006; 151: 92-9.

[150] Anan F, Takahashi N, Ooie T, et al. Effects of valsartan and perindopril combination therapy on left ventricular hypertrophy and aortic arterial stiffness in patients with essential hypertension. Eur $\mathbf{J}$ Clin Pharmacol 2005; 61: 353-9.

[151] Cuocolo A, Storto G, Izzo R, et al. Effects of valsartan on left ventricular diastolic function in patients with mild or moderate essential hypertension: comparison with enalapril. J Hypertens 1999; 17: 1759-66.

[152] Thürmann PA, Kenedi P, Schmidt A, Harder S, Rietbrock N. Influence of the angiotensin II antagonist valsartan on left ventricular hypertrophy in patients with essential hypertension. Circulation 1998; 98: 2037-42.

[153] Yasunari K, Maeda K, Watanabe T, Nakamura M, Yoshikawa J, Asada A. Comparative effects of valsartan versus amlodipine on left ventricular mass and reactive oxygen species formation by monocytes in hypertensive patients with left ventricular hypertrophy. J Am Coll Cardiol 2004; 43: 2116-23.

[154] Pfeffer MA, McMurray JJ, Velazquez EJ, et al. Valsartan in Acute Myocardial Infarction Trial Investigators. Valsartan, captopril, or both in myocardial infarction complicated by heart failure, left ventricular dysfunction, or both. N Engl J Med 2003; 349: 1893-906.

[155] Solomon SD, Skali H, Anavekar NS, et al. Changes in ventricular size and function in patients treated with valsartan, captopril, or both after myocardial infarction. Circulation 2005; 111: 3411-9.

[156] Suzuki H, Geshi E, Nanjyo S, et al. Inhibitory effect of valsartan against progression of left ventricular dysfunction after myocardial infarction: T-VENTURE study. Circ J 2009; 73: 918-24.

[157] Mochizuki S, Dahlof B, Shimizu M, et al. Jikei Heart Study group. Valsartan in a Japanese population with hypertension and other cardiovascular disease (Jikei Heart Study): a randomised, open-label, blinded endpoint morbidity-mortality study. Lancet 2007; 369: 1431-9.

[158] Sawada T, Yamada H, Dahlöf B, Matsubara H. Effects of valsartan on morbidity and mortality in uncontrolled hypertensive patients with high cardiovascular risks: KYOTO HEART Study. Eur Heart J 2009; 30: 2461-9.
[159] Cohn JN, Tognoni G. A randomized trial of the angiotensinreceptor blocker valsartan in chronic heart failure. N Engl J Med 2001; 345: 1667-75.

[160] Wong M, Staszewsky L, Latini R, et al. Val-HeFT Heart Failure Trial Investigators. Valsartan benefits left ventricular structure and function in heart failure: Val-HeFT echocardiographic study. J Am Coll Cardiol 2002; 40: 970-5.

[161] Disertori M, Latini R, Barlera S, et al. GISSI-AF Investigators. Valsartan for prevention of recurrent atrial fibrillation. $\mathrm{N}$ Engl $\mathrm{J}$ Med 2009; 360: 1606-17

[162] Maggioni AP, Latini R, Carson PE, et al. Val-HeFT Investigators Valsartan reduces the incidence of atrial fibrillation in patients with heart failure: results from the Valsartan Heart Failure Trial (ValHeFT). Am Heart J 2005; 149: 548-57.

[163] Viberti G, Wheeldon NM. Microalbuminuria reduction with valsartan in patients with type 2 diabetes mellitus: a blood pressureindependent effect. Circulation 2002; 106: 672-8.

[164] Uzu T, Sawaguchi M, Maegawa H, Kashiwagi A. Reduction of microalbuminuria in patients with type 2 diabetes: the Shiga Microalbuminuria Reduction Trial (SMART). Diabetes Care 2007; 30 1581-3.

[165] Menne J, Farsang C, Deák L, et al. Valsartan in combination with lisinopril versus the respective high dose monotherapies in hypertensive patients with microalbuminuria: the VALERIA trial. J Hypertens 2008; 26: 1860-7.

[166] Li PK, Leung CB, Chow KM, et al. HKVIN Study Group. Hong Kong Study Using Valsartan in IgA Nephropathy (HKVIN): a double-blind, randomized, placebo-controlled study. Am J Kidney Dis 2006; 47: 751-60.

[167] Agabiti Rosei E, Rizzoni D, Muiesan ML, et al for the CENTRO (CandEsartaN on aTherosclerotic Risk factors) study investigators. Effects of candesartan cilexetil and enalapril on inflammatory markers of atherosclerosis in hypertensive patients with noninsulin diabetes mellitus. J Hypertens 2005; 23: 435-44.

[168] Cuspidi C, Muiesan ML, Valagussa L, et al. CATCH investigators. Comparative effects of candesartan and enalapril on left ventricular hypertrophy in patients with essential hypertension: the candesartan assessment in the treatment of cardiac hypertrophy $(\mathrm{CATCH})$ study. J Hypertens 2002; 20: 2293-300.

[169] Ogihara T, Fujimoto A, Nakao K, Saruta T. ARB candesartan and CCB amlodipine in hypertensive patients: the CASE-J trial. Expert Rev Cardiovasc Ther 2008; 6: 1195-201.

[170] Suzuki H, Kanno Y. Effects of candesartan on cardiovascular outcomes in Japanese hypertensive patients. Hypertens Res 2005; 28 : 307-14.

[171] Lithell H, Hansson L, Skoog I, et al. SCOPE Study Group. The Study on Cognition and Prognosis in the Elderly (SCOPE): principal results of a randomized double-blind intervention trial. J Hypertens $2003 ; 21: 875-86$.

[172] Papademetriou V, Farsang C, Elmfeldt D, et al. Study on Cognition and Prognosis in the Elderly study group. Stroke prevention with the angiotensin II type 1-receptor blocker candesartan in elderly patients with isolated systolic hypertension: the Study on Cognition and Prognosis in the Elderly (SCOPE). J Am Coll Cardiol 2004; 44: 1175-80.

[173] McKelvie RS, Yusuf S, Pericak D, et al. Comparison of candesartan, enalapril, and their combination in congestive heart failure: randomized evaluation of strategies for left ventricular dysfunction (RESOLVD) pilot study. The RESOLVD Pilot Study Investigators. Circulation 1999; 100: 1056-64.

[174] Pfeffer MA, Swedberg K, Granger CB, et al. CHARM Investigators and Committees. Effects of candesartan on mortality and morbidity in patients with chronic heart failure: the CHARMOverall programme. Lancet 2003; 362: 759-66.

[175] Solomon SD, Wang D, Finn P, et al. Effect of candesartan on cause-specific mortality in heart failure patients: the Candesartan in Heart Failure Assessment of Reduction in Mortality and Morbidity (CHARM) program. Circulation 2004; 110: 2180-3.

[176] O'Meara E, Solomon S, McMurray J, et al. Effect of candesartan on New York Heart Association functional class. Results of the Candesartan in Heart Failure: Assessment of Reduction in Mortality and Morbidity (CHARM) programme. Eur Heart J 2004; 25: 1920-6.

[177] Young JB, Dunlap ME, Pfeffer MA, et al. Candesartan in Heart failure Assessment of Reduction in Mortality and morbidity (CHARM) Investigators and Committees. Mortality and morbidity reduction with candesartan in patients with chronic heart failure and 
left ventricular systolic dysfunction: results of the CHARM low-left ventricular ejection fraction trials. Circulation 2004; 110: 2618-26.

[178] McMurray JJ, Ostergren J, Swedberg K, et al. CHARM Investigators and Committees. Effects of candesartan in patients with chronic heart failure and reduced left-ventricular systolic function taking angiotensin-converting-enzyme inhibitors: the CHARM-Added trial. Lancet 2003; 362: 767-71.

[179] Granger CB, McMurray JJ, Yusuf S, et al. CHARM Investigators and Committees. Effects of candesartan in patients with chronic heart failure and reduced left-ventricular systolic function intolerant to angiotensin-converting-enzyme inhibitors: the CHARMAlternative trial. Lancet 2003; 362: 772-6.

[180] Yusuf S, Pfeffer MA, Swedberg K, et al. CHARM Investigators and Committees. Effects of candesartan in patients with chronic heart failure and preserved left-ventricular ejection fraction: the CHARM-Preserved trial. Lancet 2003; 362: 777-81.

[181] Tveit A, Grundvold I, Olufsen M, et al. Candesartan in the prevention of relapsing atrial fibrillation. Int J Cardiol 2007; 120: 85-91.

[182] Bilous R, Chaturvedi N, Sjølie AK, et al. Effect of candesartan on microalbuminuria and albumin excretion rate in diabetes: three randomized trials. Ann Intern Med 2009; 151: 11-14.

[183] Mörtsell D, Malmqvist K, Held C, Kahan T. Irbesartan reduces common carotid artery intimamedia thickness in hypertensive patients when compared with atenolol: the Swedish Irbesartan Left Ventricular Hypertrophy Investigation versus Atenolol (SILVHIA) study. J Intern Med 2007; 261: 472-9.

[184] Morawietz H, Erbs S, Holtz J, et al. Endothelial Protection, AT1 Blockade and Cholesterol-Dependent Oxidative Stress: the EPAS trial. Circulation 2006; 114(1 suppl): I296-301.

[185] Sola S, Mir MQ, Cheema FA, et al. Irbesartan and lipoic acid improve endothelial function and reduce markers of inflammation in the metabolic syndrome: results of the Irbesartan and Lipoic Acid in Endothelial Dysfunction (ISLAND) study. Circulation 2005; 111: 343-8.

[186] Malmqvist K, Kahan T, Edner M, et al. Regression of left ventricular hypertrophy in human hypertension with irbesartan. J Hypertens 2001; 19: 1167-76.

[187] Malmqvist K, Öhman KP, Lind L, Nyström F, Kahan T. Long-term effects of irbesartan and atenolol on the renin-angiotensinaldosterone system in human primary hypertension: the Swedish Irbesartan Left Ventricular Hypertrophy Investigation versus Atenolol (SILVHIA). J Cardiovasc Pharmacol 2003; 42: 719-26.

[188] Schneider MP, Klingbeil AU, Delles C, et al. Effect of irbesartan versus atenolol on left ventricular mass and voltage: results of the CardioVascular Irbesartan Project. Hypertension 2004; 44: 61-6.

[189] Massie BM, Carson PE, McMurray JJ, et al. I-PRESERVE Investigators. Irbesartan in patients with heart failure and preserved ejection fraction. N Engl J Med 2008; 359: 2456-67.

[190] Guntekin U, Gunes Y, Tuncer M, Simsek H, Gunes A. Comparison of the effects of quinapril and irbesartan on P-wave dispersion in hypertensive patients. Adv Ther 2008; 25: 775-86.

[191] Madrid AH, Bueno MG, Rebollo JM, et al. Use of irbesartan to maintain sinus rhythm in patients with long-lasting persistent atrial fibrillation: a prospective and randomized study. Circulation 2002; 106: 331-6.

[192] Lewis EJ, Hunsicker LG, Clarke WR, et al. Renoprotective effect of the angiotensin-receptor antagonist irbesartan in patients with nephropathy due to type 2 diabetes. N Engl J Med 2001; 345: 851-60.

[193] Parving HH, Lehnert H, Bröchner-Mortensen J, Gomis R, Andersen S, Arner P. Irbesartan in Patients with Type 2 Diabetes and Microalbuminuria Study Group. The effect of irbesartan on the development of diabetic nephropathy in patients with type 2 diabetes. $\mathrm{N}$ Engl J Med 2001; 345: 870-8

[194] Bakris GL, Ruilope L, Locatelli F, et al. Treatment of microalbuminuria in hypertensive subjects with elevated cardiovascular risk: results of the IMPROVE trial. Kidney Int 2007; 72: 879-85.

[195] Asmar R, Gosse P, Topouchian J, N'tela G, Dudley A, Shepherd GL. Effects of telmisartan on arterial stiffness in type 2 diabetes patients with essential hypertension. J Renin Angiotensin Aldosterone Syst 2002; 3: 176-80.

[196] Jung AD, Kim W, Park SH, et al. The effect of telmisartan on endothelial function and arterial stiffness in patients with essential hypertension. Korean Circ J 2009; 39: 180-4.

[197] Verdecchia P, Sleight P, Mancia G, et al. for the ONTARGET/TRANSCEND Investigators. Effects of telmisartan, ramipril, and their combination on left ventricular hypertrophy in individuals at high vascular risk in the Ongoing Telmisartan Alone and in Combination With Ramipril Global End Point Trial and the Telmisartan Randomized Assessment Study in ACE Intolerant Subjects With Cardiovascular Disease. Circulation 2009; 120: 1380-9.

[198] Yusuf S, Teo K, Anderson C, et al. for the Telmisartan Randomised AssessmeNt Study in ACE iNtolerant subjects with cardiovascular Disease (TRANSCEND) Investigators. Effects of the angiotensinreceptor blocker telmisartan on cardiovascular events in high-risk patients intolerant to angiotensin-converting enzyme inhibitors: a randomised controlled trial. Lancet 2008; 372: 1174-83.

[199] Yusuf S, Diener HC, Sacco RL, et al. PROFESS Study Group. Telmisartan to prevent recurrent stroke and cardiovascular events. N Engl J Med 2008; 359: 1225-37.

[200] Dunselman PH. Effects of the replacement of the angiotensin converting enzyme inhibitor enalapril by the angiotensin II receptor blocker telmisartan in patients with congestive heart failure. The Replacement of Angiotensin Converting Enzyme Inhibition (REPLACE) investigators. Int J Cardiol 2001; 77: 131-8.

[201] Celik T, Iyisoy A, Kursaklioglu H, et al. The comparative effects of telmisartan and ramipril on $\mathrm{P}$-wave dispersion in hypertensive patients: a randomized clinical study. Clin Cardiol 2005; 28: 298-302.

[202] Makino H, Haneda M, Babazono T, et al. for the INNOVATION Study Group. Prevention of transition from incipient to overt nephropathy with telmisartan in patients with type 2 diabetes. Diabetes Care 2007; 30: 1577-8.

[203] Mann JF, Schmieder RE, Dyal L, et al. TRANSCEND (Telmisartan Randomised Assessment Study in ACE Intolerant Subjects with Cardiovascular Disease) Investigators. Effect of telmisartan on renal outcomes: a randomized trial. Ann Intern Med 2009; 151: 1-10, W1-2.

[204] Mann JF, Schmieder RE, McQueen M, et al. for the ONTARGET Investigators. Renal outcomes with telmisartan, ramipril, or both, in people at high vascular risk (the ONTARGET study): a multicentre, randomised, double-blind, controlled trial. Lancet 2008; 372: 547 53.

[205] Barnett A. Preventing renal complications in type 2 diabetes: results of the diabetics exposed to telmisartan and enalapril trial. J Am Soc Nephrol 2006; 17: S132-5.

[206] Leu HB, Charng MJ, Ding PY. A double blind randomized trial to compare the effects of eprosartan and enalapril on blood pressure, platelets, and endothelium function in patients with essential hypertension. Jpn Heart J 2004; 45: 623-35.

[207] Fliser D, Buchholz K, Haller H; for the EUropean Trial on Olmesartan and Pravastatin in Inflammation and Atherosclerosis (EUTOPIA) Investigators. Antiinflammatory effects of angiotensin II subtype 1 receptor blockade in hypertensive patients with microinflammation. Circulation 2004 Aug 31; 110(9): 1103-7.

[208] Diamond JA, Gharavi A, Roychoudhury D, et al. Effect of longterm eprosartan versus enalapril antihypertensive therapy on left ventricular mass and coronary flow reserve in stage I-II hypertension. Eprosartan Study Group. Curr Med Res Opin 1999; 15: 1-8.

[209] Rosendorff C, Dubiel R, Xu J, Chavanu KJ. Comparison of olmesartan medoxomil versus amlodipine besylate on regression of ventricular and vascular hypertrophy. Am J Cardiol 2009; 104: 359-65.

[210] Schrader J, Luders S, Kulschewski A, et al. Morbidity and Mortality After Stroke, Eprosartan Compared with Nitrendipine for Secondary Prevention: principal results of a prospective randomized controlled study (MOSES). Stroke 2005; 36: 1218-26.

[211] Murdoch DR, McDonagh TA, Farmer R, Morton JJ, McMurray JJ, Dargie HJ. ADEPT: addition of the AT1 receptor antagonist eprosartan to ACE inhibitor therapy in chronic heart failure trial: hemodynamic and neurohormonal effects. Am Heart J 2001; 141: 800-7.

[212] Haller H, Ito S, Izzo JL Jr, Januszewicz A, Katayama S, Menne J for the ROADMAP Trial Investigators. Olmesartan for the delay or prevention of microalbuminuria in type 2 diabetes. $\mathrm{N}$ Engl $\mathrm{J}$ Med 2011; 364(10): 907-17.

[213] Pool JL. Direct renin inhibition: focus on aliskiren. J Manag Care Pharm 2007; 13(8)(suppl b): S21-33.

[214] Agabiti Rosei E, Morelli P, Rizzoni D. Effects of nifedipine GITS $20 \mathrm{mg}$ or enalapril $20 \mathrm{mg}$ on blood pressure and inflammatory markers in patients with mild-moderate hypertension. Blood Press 2005; 1: 14-22.

[215] Chobanian AV, Haudenschild CC, Nickerson C, Drago R. Antiatherogenic effect of captopril in the Watanabe heritable hyperlipidemic rabbit. Hypertension 1990; 15: 327-31. 
[216] Zimmermann R, Kastens J, Linz W, Wiemer G, Schölkens BA, Schaper J. Effect of long-term ACE inhibition on myocardial tissue on hypertensive stroke-prone rats. J Mol Cell Cardiol 1999; 31: 1447-1456.

[217] Miguel-Carrasco JL, Zambrano S, Blanca AJ, Mate A, Vázquez CM. Captopril reduces cardiac inflammatory markers in spontaneously hypertensive rats by inactivation of NF-kB. J Inflamm (Lond) 2010 May $12 ; 7: 21$.

[218] Guba M, Steinbauer M, Büchner M, et al. Differential effects of short-term ace- and AT1-receptor inhibition on postischemic injury and leukocyte adherence in vivo and in vitro. Shock 2000; 13(3): 190-6.

[219] Mancini GB, Henry GC, Macaya C, et al. Angiotensin-converting enzyme inhibition with quinapril improves endothelial vasomotor dysfunction in patients with coronary artery disease. The TREND (Trial on Reversing ENdothelial Dysfunction) Study. Circulation 1996; 94(3): 258-65

[220] Hornig B, Landmesser U, Kohler C, et al. Comparative effect of ace inhibition and angiotensin II type 1 receptor antagonism on bioavailability of nitric oxide in patients with coronary artery disease: role of superoxide dismutase. Circulation 2001 Feb 13; 103(6): 799-805

[221] Schmieder RE, Delles C, Mimran A, Fauvel JP, Ruilope LM. Impact of telmisartan versus ramipril on renal endothelial function in patients with hypertension and type 2 diabetes. Diabetes Care 2007; 30(6): 1351-6.

[222] Anderson TJ, Elstein E, Haber H, Charbonneau F. Comparative study of ACE-inhibition, angiotensin II antagonism, and calcium channel blockade on flow-mediated vasodilation in patients with coronary disease (BANFF study). J Am Coll Cardiol 2000; 35(1): 60-6.

[223] Ferri C, Desideri G, Baldoncini R, et al. Early activation of vascular endothelium in nonobese, nondiabetic essential hypertensive patients with multiple metabolic abnormalities. Diabetes 1998; 47(4): 660-7.

[224] Gasic S, Wagner OF, Fasching P, et al. Fosinopril decreases levels of soluble vascular cell adhesion molecule-1 in borderline hypertensive type II diabetic patients with microalbuminuria. Am J Hypertens. $1999 ; 12(2 \mathrm{Pt} \mathrm{1}): 217-22$.

[225] Andersen S, Schalkwijk CG, Stehouwer CD, Parving HH. Angiotensin II blockade is associated with decreased plasma leukocyte adhesion molecule levels in diabetic nephropathy. Diabetes Care 2000; 23(7): 1031-2.

[226] Jilma B, Li-Saw-Hee FL, Wagner OF, Beevers DG, Lip GY. Effects of enalapril and losartan on circulating adhesion molecules and monocytes chemotactic protein-1. Clin Sci (Lond) 2002; 103: 131-6.

[227] Cominacini L, Pasini A, Garbin U, et al. Zofenopril inhibits the expression of adhesion molecules on endothelial cells by reducing reactive oxygen species. Am J Hypertens. 2002 Oct; 15(10 Pt 1): 891-5.

[228] Sheth T, Parker T, Block A, et al. IMPRESS Investigators. Comparison of the effects of omapatrilat and lisinopril on circulating neurohormones and cytokines in patients with chronic heart failure. Am J Cardiol 2002; 90(5): 496-500.

[229] Brull DJ, Sanders J, Rumley A, Lowe GD, Humphries SE, Montgomery HE. Impact of angiotensin converting enzyme inhibition on post-coronary artery bypass interleukin 6 release. Heart. 2002; 87(3): $252-5$

[230] Trevelyan J, Brull DJ, Needham EW, Montgomery HE, Morris A, Mattu RK. Effect of enalapril and losartan on cytokines in patients with stable angina pectoris awaiting coronary artery bypass grafting and their interaction with polymorphisms in the interleukin-6 gene. Am J Cardiol 2004; 94(5): 564-9.

[231] Kovacs I, Toth J, Tarjan J, Koller A. Correlation of flow mediated dilation with inflammatory markers in patients with impaired cardiac function. Beneficial effects of inhibition of ACE. Eur J Heart Fail 2006; 8(5): 451-9.

[232] Mitrovic V, Klein HH, Krekel N, et al. Influence of the angiotensin converting enzyme inhibitor ramipril on high-sensitivity $\mathrm{C}$-reactive protein (hs-CRP) in patients with documented atherosclerosis. Z Kardiol 2005; 94: 336-42.

[233] Di Napoli M, Papa F. Angiotensin-converting enzyme inhibitor use is associated with reduced plasma concentration of C-reactive protein in patients with first-ever ischemic stroke. Stroke 2003; 34: 2922-9.
[234] Schieffer B, Bunte C, Witte J, et al. Comparative effects of AT1antagonism and angiotensin-converting enzyme inhibition on markers of inflammation and platelet aggregation in patients with coronary artery disease. J Am Coll Cardiol 2004; 44: 362-8.

[235] Tikiz C, Utuk O, Pirildar T, et al. Effects of Angiotensin-converting enzyme inhibition and statin treatment on inflammatory markers and endothelial functions in patients with longterm rheumatoid arthritis. J Rheumatol 2005; 32(11): 2095-101.

[236] Braunwald E, Domanski MJ, Fowler SE, et al. PEACE Trial Investigators. Angiotensin-converting-enzyme inhibition in stable coronary artery disease. N Engl J Med 2004; 351: 2058-68.

[237] Tsikouris JP, Suarez JA, Simoni JS, Ziska M, Meyerrose GE. Exploring the effects of ACE inhibitor tissue penetration on vascular inflammation following acute myocardial infarction. Coron Artery Dis $2004 ; 15(4): 211-7$

[238] Verma S, Lonn EM, Nanji A, et al for the ramipril C-reactive pRotein randomized evaluation (4R) trial investigators. Effect of angiotensin-converting enzyme inhibition on $\mathrm{C}$-reactive protein levels: the ramipril C-reactive pRotein randomized evaluation (4R) trial results. Can J Cardiol 2009; 25(7): e236-40.

[239] Koh KK, Quon MJ, Han SH, et al. Vascular and metabolic effects of combined therapy with ramipril and simvastatin in patients with type 2 diabetes. Hypertension 2005; 45(6): 1088-93.

[240] Brili S, Tousoulis D, Antoniades C, et al. Effects of ramipril on endothelial function and the expression of proinflammatory cytokines and adhesion molecules in young normotensive subjects with successfully repaired coarctation of aorta: a randomized cross-over study. J Am Coll Cardiol 2008; 51(7): 742-9.

[241] Tousoulis D, Kourtellaris P, Antoniades C, et al. Effects of irbesartan and perindopril on forearm reactive hyperemia and inflammatory process, in normotensive patients with coronary artery disease. Int J Cardiol 2008 Feb 20; 124(1): 127-9.

[242] Krysiak R, Okopień B. Pleiotropic effects of angiotensin-converting enzyme inhibitors in normotensive patients with coronary artery disease. Pharmacol Rep. 2008; 60(4): 514-23.

[243] Cesari M, Kritchevsky SB, Atkinson HH, et al. Angiotensinconverting enzyme inhibition and novel cardiovascular risk biomarkers: results from the Trial of Angiotensin Converting Enzyme Inhibition and Novel Cardiovascular Risk Factors (TRAIN) study. Am Heart J 2009; 157: 334.e1-8

[244] Miyazaki M, Takai S. Anti-atherosclerotic efficacy of olmesartan. J Hum Hypertens 2002; 16(suppl): S7-S12.

[245] Strawn WB, Chappell MC, Dean RH, Kivlighn S, Ferrario CM. Inhibition of early atherogenesis by losartan in monkeys with dietinduced hypercholesterolemia. Circulation 2000; 101: 1586-93.

[246] Proudfoot JM, Croft KD, Puddey IB, Beilin LJ. Angiotensin II type 1 receptor antagonists inhibit basal as well as low-density lipoprotein and platelet-activating factor-stimulated human monocyte chemoattractant protein-1. J Pharmacol Exp Ther 2003; 305: 84653.

[247] Dandona P, Kumar V, Aljada A, et al. Angiotensin II receptor blocker valsartan suppresses reactive oxygen species generation in leukocytes, nuclear factor-kappa B, in mononuclear cells of normal subjects: evidence of an antiinflammatory action. J Clin Endocrinol Metab 2003 Sep; 88(9): 4496-501.

[248] Palmas W, Ma S, Psaty B, Goff DC Jr, Darwin C, Barr RG. Antihypertensive medications and C-reactive protein in the multi-ethnic study of atherosclerosis. Am J Hypertens 2007; 20(3): 233-41.

[249] Schiffrin EL, Park JB, Intengan HD, Touyz RM. Correction of arterial structure and endothelial dysfunction in human essential hypertension by the angiotensin receptor antagonist losartan. Circulation 2000; 101(14): 1653-9.

[250] Rajagopalan S, Brook R, Mehta RH, Supiano M, Pitt B. Effect of losartan in aging-related endothelial impairment. Am J Cardiol 2002; 89(5): 562-6.

[251] Sardo MA, Castaldo M, Cinquegrani M, et al. Effects of AT1 receptor antagonist losartan on SICAM-1 and TNF-alpha levels in uncomplicated hypertensive patients. Angiology 2004; 55(2): 195203.

[252] Wang CH, Li SH, Weisel RD, Fedak PW, Dumont AS, Szmitko P. $\mathrm{C}$-reactive protein upregulates angiotensin type 1 receptors in vascular smooth muscle. Circulation 2003; 107(13): 1783-90.

[253] Chujo D, Yagi K, Asano A, et al. Telmisartan treatment decreases visceral fat accumulation and improves serum levels of adiponectin and vascular inflammation markers in Japanese hypertensive patients. Hypertens Res 2007; 30(12): 1205-10. 
[254] Rizos CV, Milionis HJ, Kostapanos MS, et al. Effects of rosuvastatin combined with olmesartan, irbesartan, or telmisartan on indices of glucose metabolism in Greek adults with impaired fasting glucose, hypertension, and mixed hyperlipidemia: a 24-week, randomized, open-label, prospective study. Clin Ther 2010; 32(3): 492-505.

[255] Ridker PM; JUPITER Study Group. Rosuvastatin in the primary prevention of cardiovascular disease among patients with low levels of low-density lipoprotein cholesterol and elevated high-sensitivity C-reactive protein: rationale and design of the JUPITER trial. Circulation 2003; 108(19): 2292-7.

[256] Koh KK, Han SH, Chung WJ, et al. Comparison of effects of losartan, irbesartan, and candesartan on flow-mediated brachial artery dilation and on inflammatory and thrombolytic markers in patients with systemic hypertension. Am J Cardiol 2004; 93(11): 1432-5, A10.

[257] Yasunari K, Maeda K, Watanabe T, Nakamura M, Yoshikawa J, Asada A. Comparative effects of valsartan versus amlodipine on left ventricular mass and reactive oxygen species formation by monocytes in hypertensive patients with left ventricular hypertrophy. J Am Coll Cardiol 2004; 43(11): 2116-23.
[258] Ridker PM, Danielson E, Rifai N, Glynn RJ. Val-MARC Investigators. Valsartan, blood pressure reduction, and C-reactive protein: primary report of the Val-MARC trial. Hypertension 2006; 48(1): 73-9.

[259] Conen D, Everett BM, Glynn RJ, Ridker PM. Effect of valsartan compared with valsartan/hydrochlorothiazide on plasma levels of cellular adhesion molecules: the Val-MARC trial. Heart. 2008; 94(3): e13.

[260] Touyz RM, Savoia C, He Y, et al. Increased inflammatory biomarkers in hypertensive type 2 diabetic patients: improvement after angiotensin II type 1 receptor blockade. J Am Soc Hypertens. 2007; 1(3): 189-99.

[261] Watanabe T, Barker TA, Berk BC. Angiotensin II and the endothelium: diverse signals and effects. Hypertension 2005; 45(2): 163-9.

[262] Schulman IH, Raij L. The angiotensin II type 2 receptor: what is its clinical significance? Curr Hypertens Rep 2008; 10(3): 188-93.

[263] Chobanian AV. Does it matter how hypertension is controlled? N Engl J Med 2008; 359 (23): 2485-8. 